\section{U.S. DEPARTMENT OF ENERGY}

\section{Office of}

ENERGY EFFICIENCY \& RENEWABLE ENERGY

\title{
National Plug-In Electric Vehicle Infrastructure Analysis
}


(This page intentionally left blank) 


\section{Authors}

Eric Wood, Clément Rames, Matteo Muratori, Sesha Raghavan, and Marc Melaina National Renewable Energy Laboratory

\section{Acknowledgments}

This study was supported by the U.S. Department of Energy's Vehicle Technologies Office. The authors would specifically like to thank Michael Berube, Sarah Olexsak, Jacob Ward, Rachael Nealer, and David Gohlke for their guidance and support. Additional thanks to Jarett Zuboy for insightful suggestions and contributions during the internal writing and editing process, to Julia Thomas and Stephanie Price for providing timely and thorough reviews, and to Ted Kwasnik for support with geographic information systems.

Special thanks to those who contributed reviews during various phases of the work, including:

- $\quad$ Nick Nigro (Atlas Public Policy)

- Kadir Bedir (California Energy Commission)

- Tyler Svitak (City and County of Denver)

- Marcus Alexander (Electric Power Research Institute)

- Wayne Killen (Electrify America)

- Michael Tamor (Ford Motor Company)

- Britta Gross (General Motors)

- Matthew Goetz (Georgetown Climate Center)

- Michael Nicholas (International Council on Clean Transportation)

- Kathy Kinsey (Northeast States for Coordinated Air Use Management)

- Ralph Troute (Sacramento Municipal Utility District)

- Don MacKenzie (University of Washington)

- Susan Burke, Meredith Cleveland (U.S. Environmental Protection Agency)

- Michael Scarpino, Diane Turchetta, John Davies, Tianjia Tang (U.S. Federal Highway Administration) 


\section{List of Acronyms}

BEV

BEVxxx

$\mathrm{DC}$

DCFC

DOE

DOT

EV

EVI-Pro

eVMT

EVSE

FHWA

HEV

HPMS

INL

L2

LDT

LDV

MUD

NHTS

NREL

PEV

PHEV

PHEVxx

SHRP2 NDS

SUV

TAF

VMT

ZEV battery electric vehicle

battery electric vehicle with an electric range of $\mathrm{xxx}$ miles

direct current

direct current fast charging

U.S. Department of Energy

U.S. Department of Transportation

electric vehicle

Electric Vehicle Infrastructure Projection Tool

electric vehicle miles traveled

electric vehicle supply equipment

U.S. Federal Highway Administration

hybrid electric vehicle

Highway Performance Monitoring System

Idaho National Laboratory

level 2 (charging station)

long-distance trip

light-duty vehicle

multiple-unit dwelling

National Household Travel Survey

National Renewable Energy Laboratory

plug-in electric vehicle (BEV or PHEV)

plug-in hybrid electric vehicle

plug-in hybrid electric vehicle with an electric range of $\mathrm{xx}$ miles

Second Strategic Highway Research Program's Naturalistic Driving Study

sport utility vehicle

Traveler Analysis Framework

vehicle miles traveled

zero-emission vehicle 


\section{Executive Summary}

This report addresses the fundamental question of how much plug-in electric vehicle (PEV) charging infrastructure - also known as electric vehicle supply equipment (EVSE) - is needed in the United States to support both plug-in hybrid electric vehicles (PHEVs) and battery electric vehicles (BEVs). It complements ongoing EVSE initiatives by providing a comprehensive analysis of national PEV charging infrastructure requirements. The result is a quantitative estimate for a U.S. network of non-residential (public and workplace) EVSE that would be needed to support broader PEV adoption. The analysis provides guidance to public and private stakeholders who are seeking to provide nationwide charging coverage, improve the EVSE business case by maximizing station utilization, and promote effective use of private/public infrastructure investments.

The analysis is organized around the non-residential EVSE network required to meet consumer coverage expectations and to satisfy consumer demand in high-PEV-adoption scenarios. Coverage and charging demand estimates needed to serve growing PEV markets are made for the communities where people live and the highway corridors on which they travel (Figure ES-1), including four specific geographic areas:

- Cities (486 Census Urban Areas, population greater than 50,000, 71\% of U.S. population)

- Towns (3,087 Census Urban Clusters, population 2,500 to 50,000, 10\% of U.S. population)

- Rural Areas (regions not covered by Census Urban Areas/Clusters, 19\% of U.S. population)

- Interstate Highway System Corridors (28,530 miles of highway).

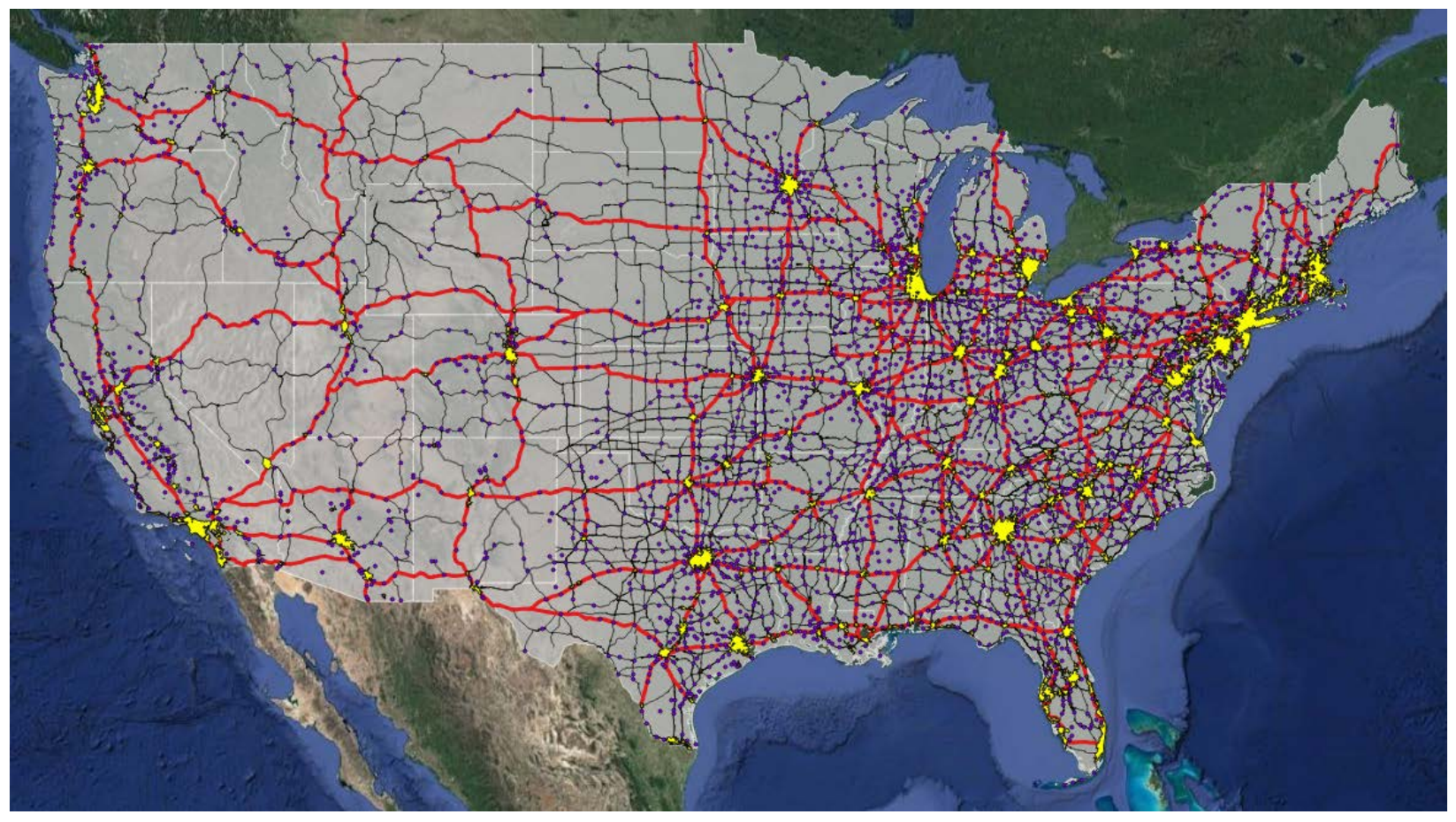

Figure ES-1. Cities (yellow polygons), towns (purple points), and interstates (thick red lines) considered in this analysis.

(Satellite imagery credit: (c) 2017 Google, Map Data (c) 2017 Tele Atlas)

While this work is not intended to forecast future PEV markets, scenarios are developed to exercise the infrastructure estimation methodology and highlight sensitivities. The analysis assigns no probabilities to any PEV market or technology scenarios and considers none of the scenarios as most likely. However, a central scenario is established from which individual elements of the modeling framework are studied using 
parametric sensitivity analysis as shown in Table ES-1. The central scenario and bounds on the accompanying sensitivities have been developed using a combination of existing PEV market/technology data and engineering judgement to represent a set of scenarios that are illustrative of the role that key variables play in dictating PEV infrastructure requirements. The goal of this scenario development is to estimate the magnitude of PEV infrastructure requirements (relative to a growing national fleet of PEVs) and to highlight dependencies with consumer preferences and technology development.

Table ES-1. PEV Market Conditions for the Central Scenario and Sensitivities Explored

\begin{tabular}{|c|c|c|}
\hline Variable & Central Scenario & Sensitivity \\
\hline PEV Total & $\begin{array}{l}\text { 15M (linear growth to } 20 \% \text { of } \\
\text { LDV sales in 2030) }\end{array}$ & $\begin{array}{l}9 \mathrm{M} \text { (growth to } 10 \% \text { of } 2030 \text { sales) } \\
21 \mathrm{M} \text { (growth to } 30 \% \text { of } 2030 \text { sales) }\end{array}$ \\
\hline $\begin{array}{l}\text { PEV Mix } \\
\text { (range preference) }\end{array}$ & $\begin{array}{ll} & \text { Mix } \\
\text { PHEV20 } & 10 \% \\
\text { PHEV50 } & 35 \% \\
\text { BEV100 } & 15 \% \\
\text { BEV250 } & 30 \% \\
\text { PHEV20-SUV } & 5 \% \\
\text { BEV250-SUV } & 5 \%\end{array}$ & $\begin{array}{ll} & \text { Long / Short } \\
\text { PHEV20 } & 0 \% / 40 \% \\
\text { PHEV50 } & 50 \% / 0 \% \\
\text { BEV100 } & 0 \% / 50 \% \\
\text { BEV250 } & 40 \% / 0 \% \\
\text { PHEV20-SUV } & 0 \% / 10 \% \\
\text { BEV250-SUV } & 10 \% / 0 \%\end{array}$ \\
\hline $\begin{array}{l}\text { Share of PEVs in Cities } \\
\text { (w/ pop. }>50 k)\end{array}$ & $\begin{array}{l}83 \% \\
\text { (based on existing HEVs) }\end{array}$ & $\begin{array}{l}\text { 71\% (based on existing LDVs) } \\
91 \% \text { (based on existing PEVs) }\end{array}$ \\
\hline PHEV:BEV Ratio & $1: 1$ & $4: 1$ to $1: 4$ \\
\hline PHEV Support & Half of full support & $\begin{array}{l}\text { No PHEV support to full support } \\
\text { (maximize PHEV eVMT) }\end{array}$ \\
\hline SUV Share & $10 \%$ & $5 \%$ to $50 \%$ \\
\hline \% Home Charging & $88 \%$ & $88 \%, 85 \%$, and $82 \%$ \\
\hline Interstate Coverage & Full Interstate & $\begin{array}{l}\text { Mega-regions, } 80 \% \text { of Long Distance } \\
\text { Trips (Traveler Analysis Framework } \\
{[\text { TAF]), and Full Interstate }}\end{array}$ \\
\hline Corridor DCFC Spacing & 70 miles & 40 to 100 miles \\
\hline DCFC Charge Time & 20 minutes $(150 \mathrm{~kW})$ & $\begin{array}{l}10 \text { to } 30 \text { minutes } \\
(400 \text { to } 100 \mathrm{~kW})\end{array}$ \\
\hline
\end{tabular}

$\mathrm{BEV} x \mathrm{xx}=$ battery electric vehicle with a range of $\mathrm{xxx}$ miles

$\mathrm{DCFC}=$ direct current fast charging

eVMT = electric vehicle miles traveled

$\mathrm{kW}=$ kilowatt

LDV = light-duty vehicle

PHEV = plug-in hybrid electric vehicle

PHEV $x x x=$ plug-in hybrid electric vehicle with a range of $x x x$ miles

SUV $=$ sport utility vehicle

The analysis relies on advanced PEV simulations using millions of miles of real-world daily driving schedules sourced from large public and commercial travel data sets. Technical considerations are made for the spatial 
density of PEVs concentrated in cities and towns, ambient temperature effects on electric driving range, and frequency of long distance driving days requiring non-residential EVSE. Simulations are rooted in a set of foundational assumptions which are applied across all scenarios. For example, consumers are simulated in all scenarios as preferring to perform the majority of charging at their home location. This assumption produces simulation results in the central scenario where $88 \%$ of PEV charging takes place at home locations (due to the large amount of time vehicles are parked at home and relatively short typical daily driving distances), consistent with early market findings in the EV Project. Charging at non-residential stations is simulated on an as-necessary basis such that consumers are able to maximize electric vehicle miles traveled (eVMT).

Additionally, it is assumed that future PEVs will be driven in a manner consistent with present day gasoline vehicles (e.g., $70 \%$ of daily driving under 40 miles and $95 \%$ under 100 miles). While impacts of transportation network companies (e.g., Uber, Lyft) and advances in automated driving technology are not considered in this analysis, interactions between evolving mobility patterns and refueling infrastructure supporting advanced vehicles are currently being investigated by the consortium of national laboratories participating in the U.S. Department of Energy's SMART Mobility Initiative.

Analysis results for the central scenario are summarized in Table ES-2. Results are reported as numbers of direct current fast charging (DCFC) stations required to provide an acceptable level of coverage and the number of plugs required to satisfy PEV charging demand. Figure ES-2 and Figure ES-4 highlight the sensitivities of these values to the many variables explored in the analysis.

Table ES-2. Summary of Station and Plug Count Estimates for the Central Scenario (15M PEVs in 2030)

\begin{tabular}{llrrrr}
\hline & & Cities & Towns & $\begin{array}{c}\text { Rural } \\
\text { Areas }\end{array}$ & $\begin{array}{r}\text { Interstate } \\
\text { Corridors }\end{array}$ \\
\hline PEVs & & & & - & - \\
DCFC & Stations (to provide coverage) & 4,900 & 3,200 & - & 400 \\
& Plugs (to meet demand) & 19,000 & 4,000 & 2,000 & 2,500 \\
& Plugs per station & 3.9 & 1.3 & - & 6.3 \\
& Plugs per 1,000 PEVs & 1.5 & 2.2 & 3.1 & - \\
\multirow{2}{*}{ Non-Res L2 } & Plugs (to meet demand) & 451,000 & 99,000 & 51,000 & - \\
& Plugs per 1,000 PEVs & 36 & 54 & 79 & - \\
\hline
\end{tabular}

Note: Station count estimates for providing a minimum level of coverage have been omitted for community L2 stations under the assumption that non-residential L2 is primarily used for charging within walking distance of a destination (based on the low charge power and long charge time of L2 stations) and coverage for every destination was considered unrealistic for the early PEV market (however, demand estimates for L2 plug counts are included). Similarly, coverage estimates are omitted for DCFC stations in rural areas as coverage provided by stations in cities/towns and along interstate corridors was deemed sufficient. 


\section{Non-Residential Charging for Communities}

The analysis first estimates the minimum DCFC coverage requirements for dispelling range anxiety concerns by providing a safety net of DCFC stations in cities and towns for emergency situations (such as failing to overnight charge at home). To ensure that BEV drivers in cities are never more than 3 miles from a DCFC station, approximately 4,900 DCFC stations are required across the United States. Providing the same level of coverage for towns would require approximately an additional 3,200 DCFC stations.

The analysis also estimates non-residential charging stations (work and public) required to satisfy intracommunity charging demands. Figure ES-2 shows the sensitivity of total national plug requirements to several input variables. In the central scenario, a total of approximately 600,000 non-residential Level 2 (L2) plugs and 25,000 DCFC plugs are necessary to satisfy consumer charging demand (assuming 15 million PEVs are on the road in 2030).
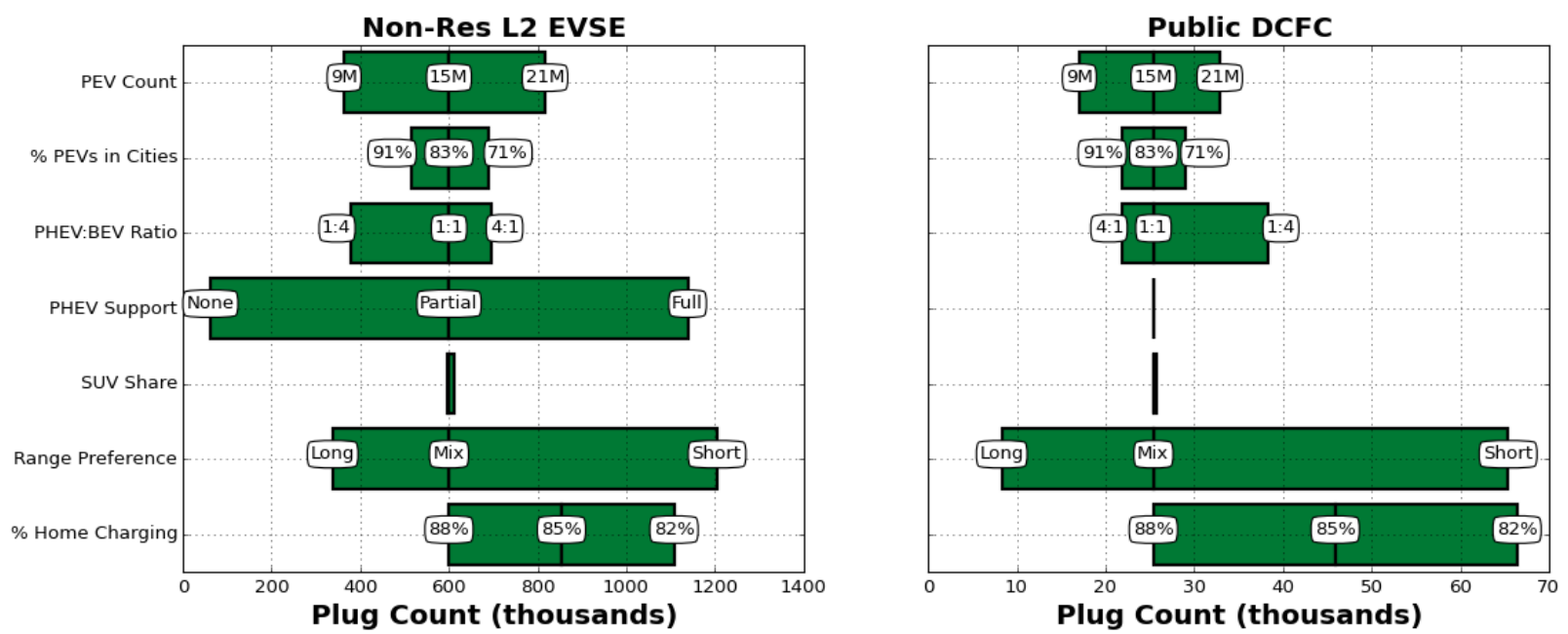

Figure ES-2. Effects of input variables on estimated total national plug requirements in communities.

Perhaps surprisingly, the national PEV total is not the most sensitive input parameter in this analysis; PEV electric range, commitment to maximizing PHEV eVMT, and percent of charging taking place at home have the largest effects. For instance, assuming a PEV market composed entirely of PHEV50s (PHEVs with a range of 50 miles) and BEV250s (BEVs with a range of 250 miles) (the long range preference scenario) drops nonresidential L2 requirements to approximately 338,000 plugs and public DCFC to 8,400 plugs. The sensitivity on PHEV support reveals that non-residential L2 charging is modeled almost exclusively as supporting PHEVs, where providing full support (maximizing eVMT for all PHEV owners) results in over 1,100,000 plugs, and providing no PHEV support drops the non-residential L2 plug requirement to under 63,000. Finally, the sensitivity analysis on home charging demonstrates a strong relationship between home charging utilization and non-residential infrastructure requirements. Specifically, a decrease in the amount of charging happening at residential locations from $88 \%$ in the central scenario to $82 \%$ results in charging requirements increasing to 1,100,000 non-residential L2 EVSE plugs and over 65,000 public DCFC plugs. 


\section{Fast Charging for Long-Distance Travel Corridors}

Long-distance travel has been a barrier to BEV adoption due to real vehicle range limitations, which can be exacerbated by even more restrictive perceived range anxiety. Long-range BEVs have the potential to address this issue if coupled with an extensive and convenient network of DCFC stations that enable reliable intercity travel. The analysis finds that approximately 400 corridor DCFC stations (spaced 70 miles apart on average) are required to provide convenient access to BEV drivers across the U.S. Interstate System. Approximate coverage enabled by DCFC stations in this scenario is visualized in Figure ES-3 with red buffers placed around the Interstate network, each with a radius of 70 miles.

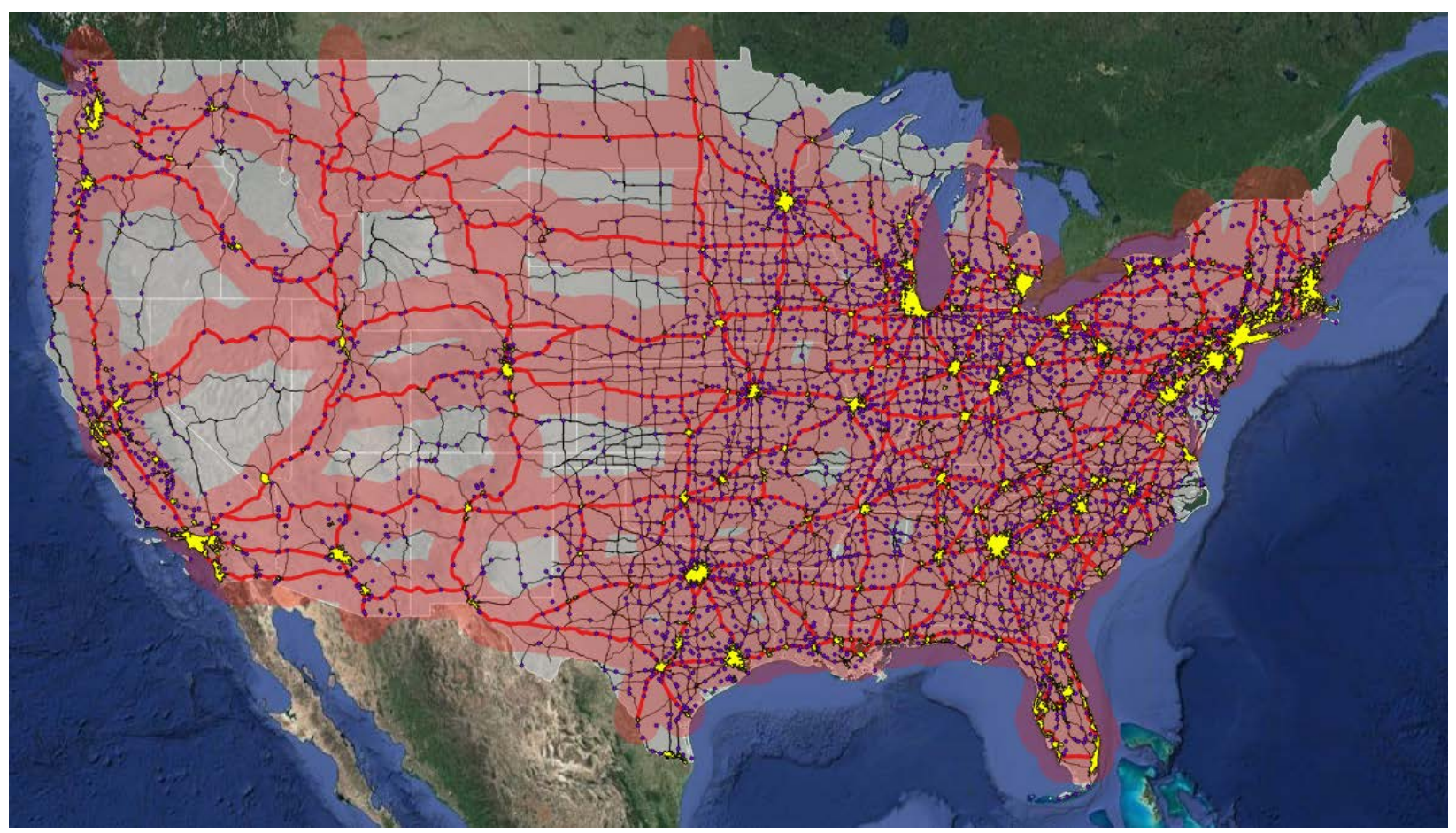

Figure ES-3. Approximate BEV driving coverage enabled by providing DCFC stations along the U.S. Interstate System. (Satellite imagery credit: (c) 2017 Google, Map Data @ 2017 Tele Atlas)

Figure ES-4 shows estimated station and plug counts for corridor fast charging supporting BEV travel along the U.S. Interstate network. Results are presented using parametric sensitivity analysis highlighting the influence of four input variables: 1) network coverage, 2) average station spacing, 3) national BEV count, and 4) average DCFC charge time. For example, 408 corridor DCFC stations are necessary in the central scenario, which assumes full Interstate coverage and 70-mile average station spacing. However, corridor DCFC station counts range from 137 to 713 depending on network and station spacing. Similarly, corridor DCFC plug counts are estimated at 2,472 in the central scenario but vary from 824 to 3,709 in the parametric sensitivity analysis depending on network coverage, size of the BEV fleet, and DCFC charge times. 

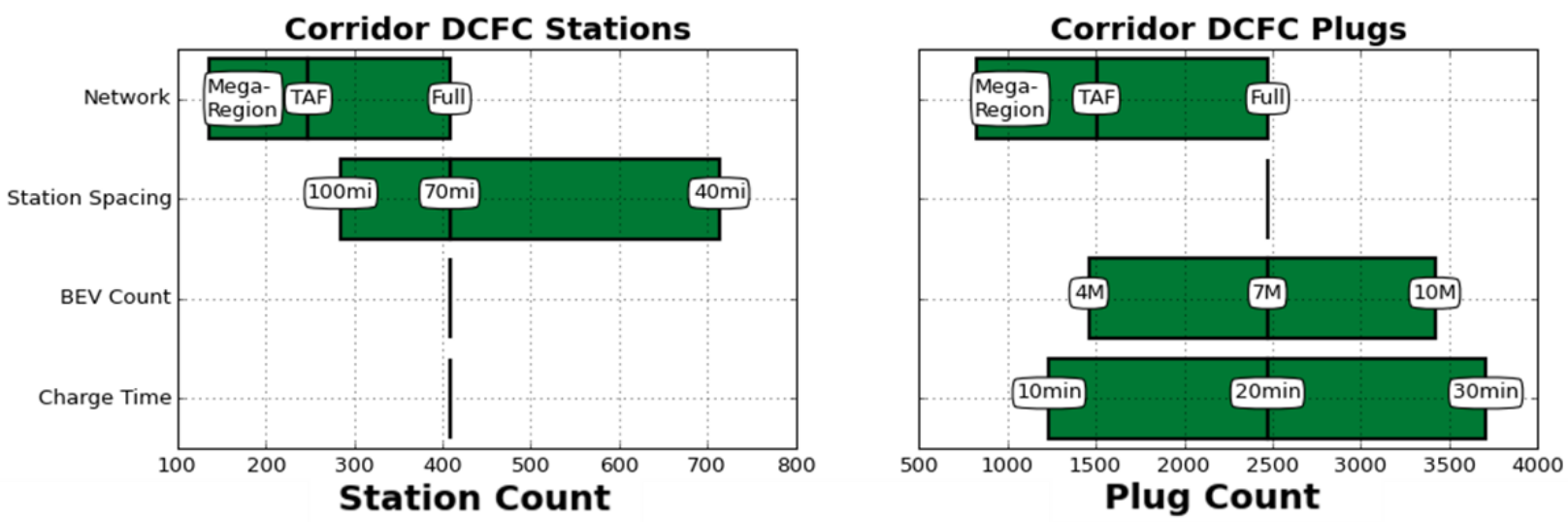

Figure ES-4. Sensitivity of corridor DCFC station (left) and plug (right) counts to selected networks, station spacings, BEV counts, and DCFC charge times.

As described above, the U.S. Interstate System provides a basis for DCFC infrastructure that can efficiently satisfy long-distance driving demands in the near term. The Interstate System is not, however, entirely isolated from community-based DCFC infrastructure. Although full community-based infrastructure may take longer to establish, it could provide travel corridors with charging backup options, route flexibility, and additional coverage along U.S. highways and state routes. Figure ES-5 shows the national DCFC station coverage enabled by providing the community-based charging station coverage previously discussed. Each covered city and town has a 70-mile radius buffer around it, approximating station coverage.

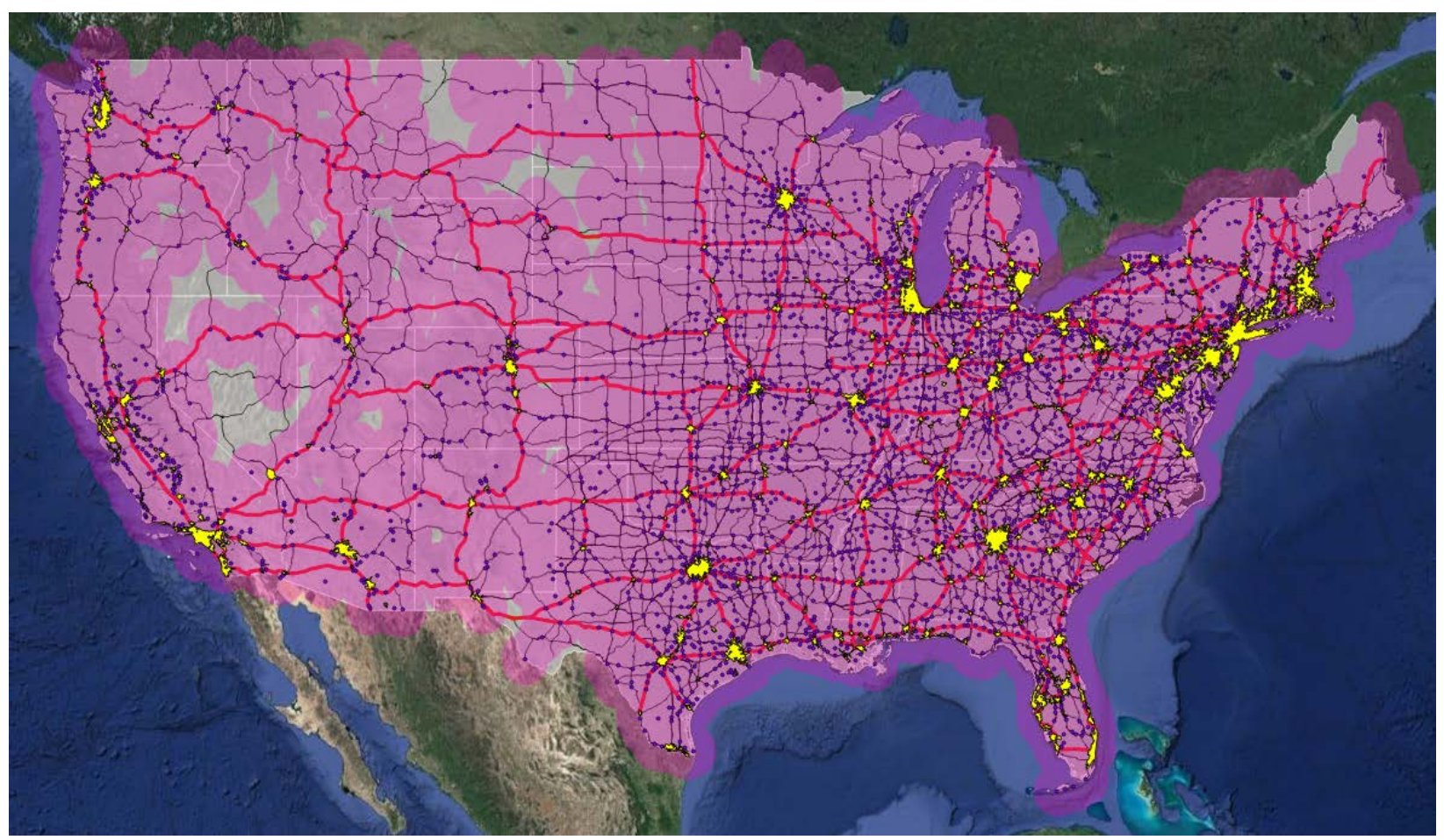

Figure ES-5. Approximate BEV driving coverage enabled by providing DCFC stations in all cities and towns in the United States.

(Satellite imagery credit: (c) 2017 Google, Map Data @ 2017 Tele Atlas) 


\section{Major Conclusions}

This report categorizes PEV charging infrastructure requirements by area served (cities, towns, rural areas, and Interstate corridors) and role during early PEV market growth (providing coverage to early PEVs and satisfying demand due to increased PEV adoption). The analysis makes no assumptions about the likelihood of particular PEV market or technology scenarios. Rather, a range of plausible scenarios explores the relationship between the evolution of the PEV fleet and charging infrastructure.

Communities are expected to have significantly larger charging infrastructure requirements than Interstate corridors under both the coverage and demand assessments. About 4,900 DCFC stations are required across cities with an additional 3,200 DCFC stations required in towns to provide a minimum level of nationwide coverage in the communities where $81 \%$ of people live. Such a network would dampen range anxiety concerns by providing drivers with a safety net for emergency charging situations.

Intracommunity charging demand analysis demonstrates how utilization of the DCFC coverage network would be expected to grow in increased PEV adoption scenarios based on a home-dominant charging assumption. Results for a 15-million PEV market estimate a DCFC plug requirement of 25,000 in communities (approximately 3.1 plugs per average DCFC station and 3.4 plugs required to support 1,000 BEVs). Demand for non-residential L2 EVSE (including work and public charging) is estimated as 600,000 plugs necessary to support 15 million PEVs (approximately 40 plugs per 1,000 PEVs).

Sensitivity analysis of the community results for consumer charging demand indicates a strong relationship between the evolution of the PEV and EVSE markets. As this analysis attempts to arrive at charging infrastructure solutions that fill the eVMT gaps between consumer travel patterns and PEV electric ranges, infrastructure requirements are not only proportional to the total number of PEVs in the system, but also inversely proportional to PEV electric range. Manufacturer and consumer preferences with respect to electric range, charging power, and utilization of residential EVSE have direct and dramatic consequences on the level of charging demand calculated in this analysis.

Results suggest that approximately 400 corridor DCFC stations are needed to enable long-distance BEV travel along Interstate highways between cities (where the majority of BEVs are likely to be concentrated). Understanding driving patterns, vehicle characteristics, and charging behavior and then prioritizing corridors and setting station spacing accordingly — as illustrated in the network scenarios - could help optimize the utility and economics of early-market corridor charging stations.

Regardless of geographic scope, the analysis suggests that organizations planning for charging infrastructure to support consumer adoption of PEVs need to be aware of the importance of consumer preferences with respect to electric range and charging behavior. Furthermore, planners should focus on providing consumers with adequate charging coverage (particularly DCFC supporting adoption of BEVs) while monitoring station utilization over time and increasing charging capacity (both in terms of rated power and number of plugs) as the PEV market continues to grow. 


\section{Table of Contents}

List of Acronyms........................................................................................................................... iv

Executive Summary ..................................................................................................................... V

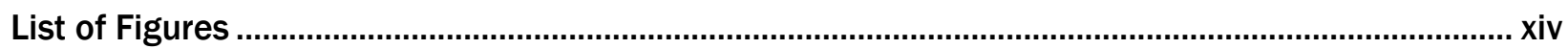

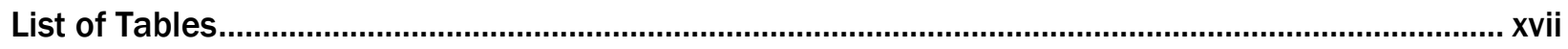

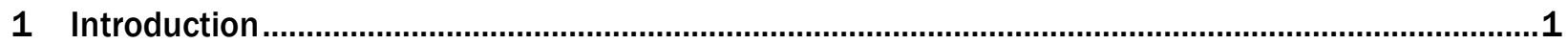

1.1 Recent EVSE Initiatives and Analysis Studies.................................................................. 1

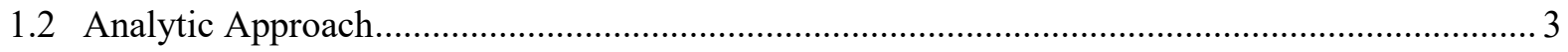

1.2.1 Conceptual Representation of PEV Charging Infrastructure Requirements ........................ 3

1.2.2 Scenario Discussion .................................................................................................. 4

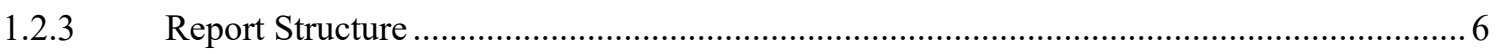

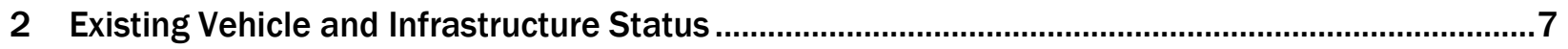

2.1 Plug-in Electric Vehicle Market Analysis ..........................................................................

2.2 Electric Vehicle Supply Equipment Availability.................................................................. 10

3 Non-Residential L2 and DCFC for Community Charging ……………......................................... 11

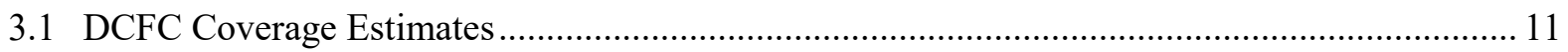

3.2 Non-Residential EVSE Community Demand Estimates ............................................................. 11

3.2.1 Electric Vehicle Infrastructure Projection (EVI-Pro) Tool ................................................. 12

3.2.2 Estimating Non-Residential EVSE/PEV Nominal Ratios................................................. 13

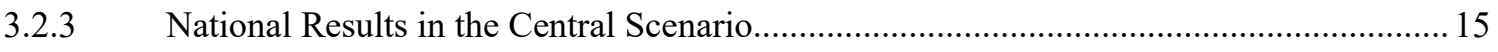

3.2.4 Sensitivities of National Results to Various Assumptions ................................................. 16

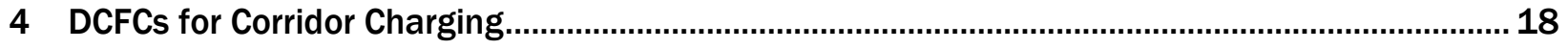

4.1 DCFC Interstate Corridor Coverage Calculations ……………………………………............ 18

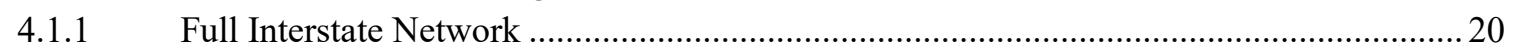

4.1.2 Corridor Prioritization........................................................................................... 21

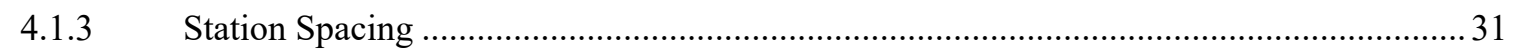

4.2 DCFC Interstate Corridor Demand Calculations.......................................................................... 33

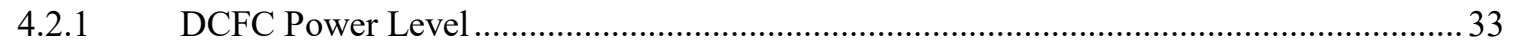

4.2.2 TAF Volumes................................................................................................... 33

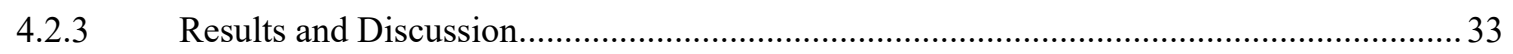

4.3 Challenges to Interstate Corridor Charging Infrastructure …………………………………......... 36

4.3.1 Retail Land Use Availability........................................................................................... 36

4.3.2 Existing Electrical Infrastructure: Proximity between Interstate Exits and Electrical

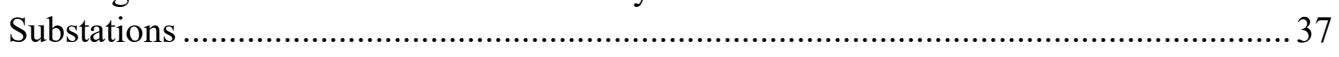

4.4 Corridor Charging Support from Community-Based DCFC..................................................... 38

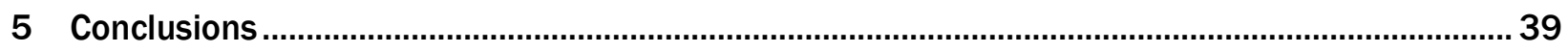

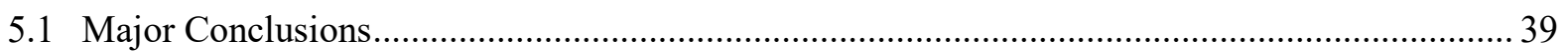

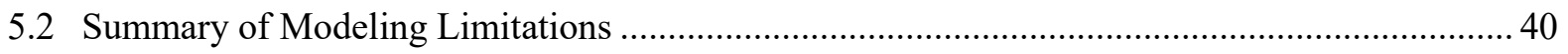

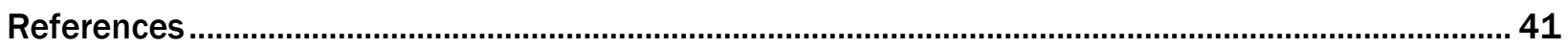




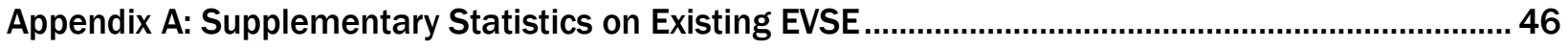

Appendix B: EVSE/PEV Adjustment Factors to Account for Local Conditions.................................... 47

Appendix C: Central Scenario PEV/EVSE Estimates by State ......................................................... 51

Appendix D: Long-Distance Travel Frequency from the SHRP2 NDS ................................................. 53 


\section{List of Figures}

Figure ES-1. Cities (yellow polygons), towns (purple points), and interstates (thick red lines) considered in this analysis.

Figure ES-2. Effects of input variables on estimated total national plug requirements in communities. viii

Figure ES-3. Approximate BEV driving coverage enabled by providing DCFC stations along the U.S. Interstate System. (Satellite imagery credit: @ 2017 Google, Map Data (c) 2017 Tele Atlas) ...... ix

Figure ES-4. Sensitivity of corridor DCFC station (left) and plug (right) counts to selected networks, station spacings, BEV counts, and DCFC charge times.

Figure ES-5. Approximate BEV driving coverage enabled by providing DCFC stations in all cities and towns in the United States.

Figure 1. PEV charging requirements evolution as a function of PEV market share.

Figure 2. Distribution of all 2016 registrations of LDVs, HEVs, and PEVs in the United States by state ZEV status.

Figure 3. Composition of 2016 U.S. PEV stock

Figure 4. Distribution of all 2016 registrations of LDVs, HEVs, and PEVs in the United States by area8

Figure 5. Schematic for estimating community charging requirements. 12

Figure 6. Nominal non-residential EVSE/PEV ratios (home dominant charging behavior).

Figure 7. Nominal charging load profile from EVI-Pro simulations (home dominant charging behavior).

Figure 8. Effects of input variables on estimated total national plug requirements.

Figure 9. Effects of input variables on normalized national plug requirements (EVSE/PEV ratios).. 17

Figure 10. Methodology and sensitivity schematic for corridor DCFC analysis.

Figure 11. Nationwide DCFC station counts to cover corridors as a function of station spacing for different scenarios.

Figure 12. Interstate corridor network (thick red lines) considered in this analysis (70-mile radius red buffer approximates areas that would be served by the proposed DCFC network). Included for reference: yellow polygons represent cities, purple points represent towns, and thin black lines represent the national highway system.

Figure 13. DCFC corridors providing coverage to intra-mega-region travel (70-mile radius yellow buffer approximates areas that would be served by the proposed DCFC network).

Figure 14. PEV Alternative Fuel Corridors as designated by DOT Alternative Fuel Corridor Map ...... 23

Figure 15. DCFC corridors providing coverage as designated by the DOT Alternative Fuel Corridor Map (DOT 2017a) (70-mile radius yellow buffer approximates areas that would be served by the proposed DCFC network). 
Figure 16. U.S. Interstate Highway corridors. Line thickness is proportional to HPMS average daily traffic.

Figure 17. DCFC corridors providing coverage to the top $80 \%$ of HPMS annual average daily traffic (70-mile radius yellow buffer approximates areas that would be served by the proposed DCFC network).

Figure 18. TAF summary statistics. 25

Figure 19. TAF long-distance travel origin-destination pairs by mode; only top $10 \%$ visualized here for clarity. 26

Figure 20. Map of U.S. Census divisions 27

Figure 21. TAF long-distance auto passenger trip origin-destination pairs; only top $10 \%$ visualized here for clarity.

Figure 22. Chord diagram generated using TAF long-distance auto passenger travel volume 28

Figure 23. U.S. Interstate Highway corridors. Line thickness proportional to TAF Iong-distance auto traffic.

Figure 24. DCFC corridors providing coverage to the top $80 \%$ of the TAF long-distance auto traffic (FHWA 2013) (70-mile radius yellow buffer approximates areas that would be served by the proposed DCFC network).

Figure 25. Comparison of TAF and HPMS volumes (color scale proportional to TAF:HPMS ratio).... 30

Figure 26. Station spacing methodology proposed in this study.

Figure 27. Nationwide corridor DCFC station count versus station spacing, annual average volume.34

Figure 28. Plug requirement variance between stations.

Figure 29. Sensitivity of corridor DCFC station and plug counts to network, station spacing, BEV count, and charge time.

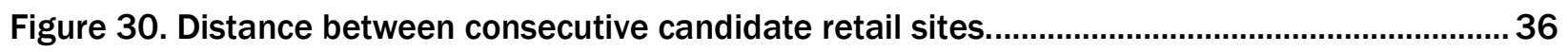

Figure 31. Highway exits color-coded by distance to the nearest electrical substation.

Figure 32. National charging station coverage enabled by providing minimum DCFC station coverage (70-mile buffers placed around all cities and towns).

Figure B-1. Daily VMT cumulative distribution functions by population density, from the 2009 NHTS.47

Figure B-2. Mimicking NHTS daily VMT cumulative distribution functions by population density by resampling INRIX travel data.

Figure B-3. Adjustment factor: non-residential EVSE/PEV ratio as a function of population density.48

Figure B-4. Adjustment factor: non-residential EVSE/PEV ratio as a function of PEV concentration.49

Figure B-5. EVI-Pro DCFC effective charge rate model: percentage of EVSE rated power delivered as a function of charge duration and battery temperature. 50

Figure B-6. Adjustment factor: non-residential EVSE/PEV ratio as a function of ambient temperature. 
Figure D-1. Cumulative distribution of daily VMT in 2009 NHTS and SHRP2 NDS.

Figure D-2. Annual VMT distribution in 2009 NHTS and SHRP2 NDS.

Figure D-3. Impact of annualized VMT (AVMT) on average long-distance travel frequency from SHRP2 NDS.

Figure D-4. Impact of annualized VMT (AVMT) on long-distance travel frequency from SHRP2 NDS (percentile bins, frequency of $200+$ mile days) 


\section{List of Tables}

Table ES-1. PEV Market Conditions for the Central Scenario and Sensitivities Explored..................... vi

Table ES-2. Summary of Station and Plug Count Estimates for the Central Scenario (15M PEVs in 2030)

Table 1. PEV Market Conditions for the Central Scenario and Sensitivities Explored ..........................5

Table 2. Top 10 U.S. Urban Areas by PEV Stock, 2016 (IHS Markit 2017)..........................................

Table 3. EVSE Characteristic of the Top 10 U.S. Urban PEV Markets, 2017 (DOE 2017b) ................. 10

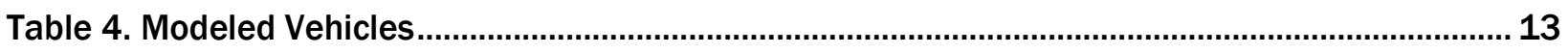

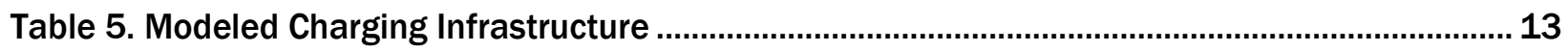

Table 6. Central Scenario PEV and Non-Residential EVSE Estimates in 2030, Top 10 Urban Areas 16

Table 7. Central Scenario PEV and Non-Residential EVSE Estimates in 2030, by Community Type

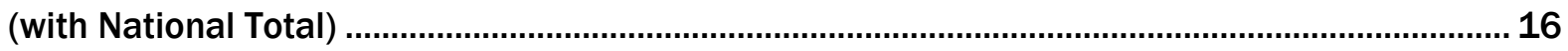

Table 8. National DCFC Coverage Scenarios along U.S. Interstate Corridors....................................... 18

Table 9. Estimated National DCFC Station Counts to Cover Corridors under Different Scenarios .... 19

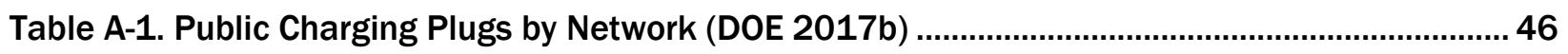

Table A-2. Public DCFC Plugs and Stations by Network (DOE 2017b) .................................................46

Table B-1. EVI-Pro Driving Discharge Model: Relative Battery Discharge Rates as a Function of Ambient Temperature and Average Trip Speed 
NATIONAL PLUG-IN ELECTRIC VEHICLE INFRASTRUCTURE ANALYSIS

(This page intentionally left blank) 


\section{Introduction}

Plug-in hybrid electric vehicles (PHEVs) and battery electric vehicles (BEVs)—collectively known as plug-in electric vehicles (PEVs) - provide various benefits to the United States. They reduce reliance on petroleum, which accounts for over $90 \%$ of total U.S. transportation energy consumption (U.S. Energy Information Administration [EIA] 2017) and is characterized by an extremely volatile market. Substituting electricity for gasoline and diesel could significantly improve U.S. energy security, providing greater fuel diversity in a market currently dominated by a single energy source. PEVs also produce zero tailpipe emissions and potentially low or zero greenhouse gas emissions, depending on the electricity generation mix (Orsi et al. 2016).

PEV sales in the United States increased by $40 \%$ in 2016, reaching a total stock of over 500,000 vehicles (IHS Markit 2017). This rapid market growth is the result of significant advances in PEV technologies, most notably the rapidly falling cost of lithium-ion batteries used in automotive applications (U. S. Department of Energy [DOE] 2017a, Nykvist and Nilsson 2015), as well as policy support. Policy support includes government research and development support (which also enabled battery technology advancements); technical and cost targets, mandates, and regulations (e.g., corporate average fuel economy [CAFE] standards and zero emission vehicle [ZEV] mandates); financial incentives for PEV purchase and charging station installations; and other measures increasing the value proposition of alternative fuel vehicles (e.g., preferential parking or access to high-occupancy vehicle lanes) (International Energy Agency [IEA] 2017). Still, widespread market adoption of PEVs remains hindered by many factors, including limited availability of models and styles, higher cost compared with conventional vehicles, and the lack of a convenient and ubiquitous network of charging stations.

Understanding the barriers to and benefits of deploying a widespread and effective network of PEV charging stations, also known as electric vehicle supply equipment (EVSE), is particularly important. Such a network would promote PEV consumer acceptance and market growth, enable long-distance travel for BEVs (alleviating the range anxiety concerns of many consumers), and potentially increase the share of electric miles driven by PHEVs. Infrastructure planning must anticipate PEV adoption while remaining cost-effective so low station utilization does not severely undermine the business case for building and operating stations (Melaina et al. 2017). Sufficient revenue is required to build and continue operating the EVSE network as the PEV market grows over time.

This report presents an approach for developing a U.S. network of non-residential EVSE that enables broader PEV adoption and maximizes PEV use. This analysis can help inform various public and private stakeholders who are seeking to provide nationwide charging coverage and improve the business case for building stations by maximizing station utilization.

\subsection{Recent EVSE Initiatives and Analysis Studies}

Several recent public and private initiatives and pilot projects are promoting EVSE growth across the United States as a way to increase PEV adoption by enhancing consumer familiarity and acceptance of this technology as well as providing a more convenient network of charging stations. In particular, direct current fast charging (DCFC) is receiving significant attention as the fastest PEV charging system currently available. Tesla's Supercharger, CHAdeMO, and SAE's combined charging system (CCS) are the currently available standards for DCFC. The landscape of DCFC in the United States is expected to change significantly with the penetration of longer-range BEVs (with over 200 miles of driving range), which likely will rely on DCFC to make long-distance trips (LDTs). While fast charging currently ranges between 50 and 120 kilowatts (kW), power levels up to $400 \mathrm{~kW}$ are currently being explored to reduce charging time and provide a more convenient consumer experience. 
Over the past five years, Tesla has established a network of 357 fast-charging stations, supporting 2,478 individual fast chargers rated at up to $120 \mathrm{~kW}$ (DOE 2017b). Each supercharger station has between one and $12120-\mathrm{kW}$ plugs, with an average of seven plugs per station. As the only automaker selling long-range BEVs in the United States during this period, Tesla started addressing the circular dilemma between alternative fuel vehicle adoption and refueling infrastructure availability by deploying a national network of proprietary charging stations to enable long-distance travel for Tesla vehicles. Tesla recently announced the goal of doubling the number of superchargers both nationally and globally. As of June 2017, the average distance between Tesla supercharger stations is approximately 67 miles (based on data from DOE [2017b]).

Electrify America - a project funded in December 2016 by Volkswagen Group of America as required by Appendix C to the 2.0-Liter Partial Consent Decree- has committed to investing \$2 billion over the next 10 years in ZEV infrastructure and education programs, including $\$ 800$ million in California alone (Electrify America 2017, Green Car Reports 2017). In its first national ZEV investment cycle (30 months, through mid2019), Electrify America plans to develop a large network of community-based PEV charging stations as well as approximately 300 fast-charging stations along high-traffic corridors between metropolitan areas in 39 states. Each corridor DCFC station will include four to ten plugs with an average of five plugs per station. Individual plugs will be rated at $150 \mathrm{~kW}$ with the ability to be upgraded to up to $350 \mathrm{~kW}$ for future vehicles that can accept higher power charging. Corridor DCFC stations will be spaced on average 70 miles apart with a maximum distance of 120 miles between consecutive stations. The Electrify America network will be nonproprietary by providing both CHAdeMO and SAE CCS plug types, allowing any BEV to charge.

Nissan and BMW are partnering to double the EVgo network of fast charging stations across the United States. As of January 2017, an additional 174 EVgo 50-kW fast charging stations across 33 states have been installed, with an additional 50 stations planned for 2017 (Nissan 2017).

The U.S. Department of Transportation (DOT) recently designated several highways as alternative fuel corridors (including $48 \mathrm{PEV}$ charging corridors) with the intent of establishing a comprehensive national network of refueling stations to promote the continued adoption of alternative fuel vehicles (DOT 2017a). This network will include nationally consistent signage and is intended to encourage multi-state collaborations of public/private stakeholders.

Launched in 2009, the EV Project partnered with city, regional, and state governments; utilities; and other organizations in 18 cities to deploy about 14,000 Level 2 PEV chargers and 300 direct current (DC) fast chargers (DOE 2014). The EV Project was the first large-scale data-collection effort for PEVs and related infrastructure in the United States (Idaho National Laboratory [INL] 2013).

In parallel to these initiatives, several analytical studies have explored the opportunities and implications related to EVSE development. In this early market phase for PEV adoption, vehicle configurations, styles, and all-electric ranges are changing rapidly in response to evolving consumer preferences and technology improvements (particularly battery cost). Future vehicle attributes and requirements remain uncertain, and the most effective EVSE strategy to support PEV adoption will depend on how these trends evolve over time. Still, various stakeholders must anticipate a range of possible future trends to develop cost- and marketeffective EVSE plans. In this context, scenario analysis and market simulation studies can inform different stakeholders during the EVSE planning process, including federal and local governments, private investors, vehicle manufacturers, and infrastructure developers.

In the $18^{\text {th }}$ edition of the Automotive Executive Survey, an annual international assessment of the current state and future prospects of the worldwide automotive industry, KPMG focused on the role of vehicle electrification and its connection with infrastructure (KPMG 2017). Although 50\% of the 953 executives who participated in the KPMG survey identified BEVs as the industry's key near-term (2017 to 2025) trend, most respondents ( $62 \%$ of executives) also absolutely or partly agreed that BEVs "will fail" owing to infrastructure challenges. This pessimistic long-term view of the industry's ability to overcome infrastructure challenges was more pronounced from respondents in Organisation for Economic Co-operation and Development countries, 
whereas respondents in China were more optimistic. KPMG concluded that significant investments in a ubiquitous and user-friendly PEV charging infrastructure are crucial for supporting long-term PEV adoption and that overcoming the range anxiety issue for BEV users is critical for the long-term survival of BEVs.

INL recently leveraged information from previous data collection activities to assess criteria for designing and upgrading DCFC complexes that provide fast-charging opportunities for BEV drivers in urban communities and on corridors (Francfort et al. 2017). Findings and lessons learned suggest that "DCFCs are most useful when they are sited within a half-mile of major transportation corridors, where they can support both intra and inter-urban travel" and that "there is a greater likelihood that a DCFC will be highly utilized if it is located at or near a workplace where employees are likely to own PEVs" (Francfort et al. 2017).

Navigant Research has published several studies about opportunities for global PEV and related infrastructure markets. Its DC Charging Map for the United States explores fast-charging opportunities that enable intercity, interstate, and cross-country travel in response to market trends that are promoting long-range BEV adoption (such as battery capacities of $\sim 60$ kilowatt-hours) (Navigant Research 2016). The report maps the progression of fast-charging stations needed to meet the demands of light-duty BEVs through a phased rollout, focusing on the needs of long-range BEVs. The analysis shows that 95 fast charging stations would provide basic longdistance coverage for BEV travel. It also shows that sufficient coverage for BEVs in the top 100 metropolitan areas could be achieved with 408 stations.

The California Energy Commission's Statewide PEV Infrastructure Assessment is an example of scenario analysis developed at the state level (Melaina and Eichman 2015, Melaina and Helwig 2014). In this study, PEV sales are estimated based on compliance with the ZEV mandate, and PEV travel simulations are performed to assess the role of public infrastructure in future PEV market growth, focusing on the degree to which increased public charging may increase e-miles. Results show that 225 to 775 fast-charging stations will be required to support 1 million PEVs in California, depending on charging preference. One conclusion of the report is that insights from analytical studies are required to guide the development of effective near-term fastcharger installation strategies.

A 2013 National Academy of Sciences report explored alternative scenarios that would radically transform the U.S. passenger vehicle sector, including enabling technologies and adoption barriers (National Research Council 2013). The report identifies charging infrastructure availability as a major barrier to consumer adoption of PEVs.

\subsection{Analytic Approach}

This PEV charging study complements the existing literature by providing updated and comprehensive analysis of the national PEV charging infrastructure requirements within cities, towns, and rural areas and along corridors connecting them. It provides guidance to regional and national stakeholders on non-residential EVSE strategies and plans, both to reduce range anxiety as a barrier to increased PEV sales and to promote effective use of private/public infrastructure investments.

\subsubsection{Conceptual Representation of PEV Charging Infrastructure Requirements}

PEV charging infrastructure requirements - the number of stations and plugs required to provide a convenient and ubiquitous network of PEV charging opportunities - will evolve as PEV adoption increases. In particular, two driving forces characterize the charging infrastructure required to support a growing fleet of PEVs:

1. A basic level of geographic coverage is required to guarantee nationwide charging opportunities and enable long-distance travel for BEVs.

2. Over time, a larger network of stations will be required to satisfy growing charging demand. The requirement increases non-linearly with PEV market share. At low market shares, the requirement increases quickly because PEVs are clustered in particular areas and charging is concentrated during 
specific times such as after commuting periods and on weekends (for long-distance travel). As PEV market share increases, the infrastructure requirements increase less aggressively owing to the natural stochastic features of driving behavior - not all drivers will require charging in the same location and at the same time. In a fully developed market, each additional PEV leads to lower incremental requirements for PEV charging infrastructure.

Figure 1 illustrates coverage (blue line) and demand (black line) infrastructure requirements for different PEV market shares. The coverage requirement is independent of PEV adoption: even if few PEVs are deployed, a ubiquitous network of stations is required to enable long-distance travel, prevent range anxiety, and promote PEV adoption. Therefore, a "utilization gap" exists at low PEV market shares, which is characterized by a market demand for charging infrastructure that is lower than the required coverage infrastructure; the infrastructure is underutilized, which negatively impacts station financial performance and makes it difficult to justify investment in new stations (Melaina et al. 2017). As PEV adoption increases, the demand for charging infrastructure exceeds the coverage infrastructure, creating "market pull" for the installation of additional charging stations or the addition of plugs to existing stations.

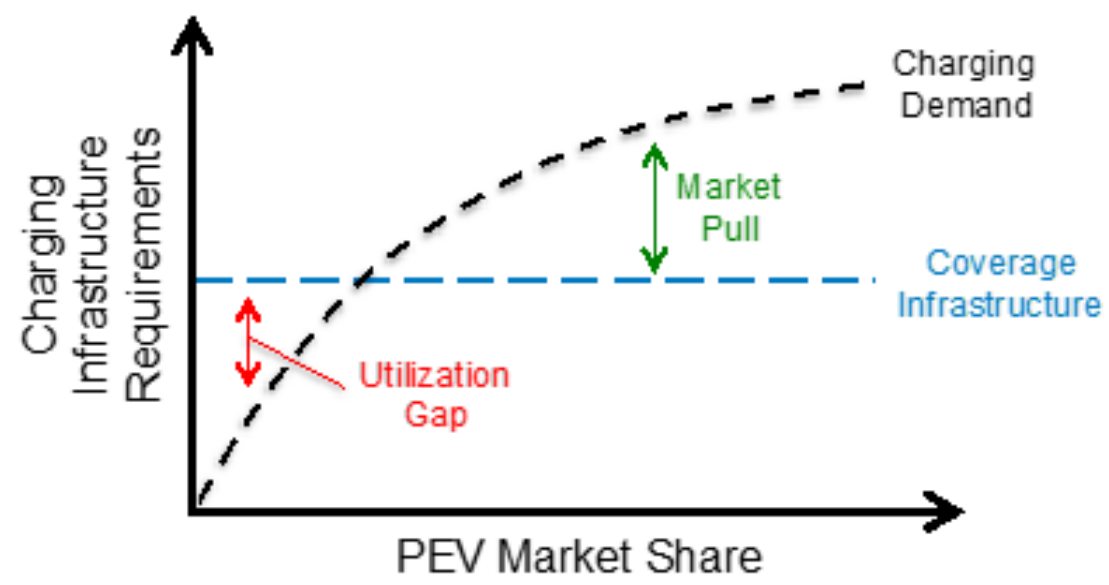

Figure 1. PEV charging requirements evolution as a function of PEV market share.

This report quantifies non-residential EVSE requirements necessary to meet consumer coverage expectations independent of PEV adoption level and to meet consumer demand in high PEV adoption scenarios. Coverage and demand estimates are made for:

- Cities (486 Census Urban Areas, population greater than 50,000, 71\% of U.S. population)

- Towns (3,087 Census Urban Clusters, population 2,500 to 50,000, 10\% of U.S. population)

- Rural Areas (regions not covered by Census Urban Areas/Clusters, 19\% of U.S. population)

- Interstate Highway System Corridors (28,530 miles of highway).

\subsubsection{Scenario Discussion}

The majority of this report describes an analytic process for estimating PEV non-residential charging requirements within communities (cities, towns, and rural areas) and along Interstate corridors, assuming home charging is the dominant behavior. While it is not the intention of this work to forecast the future PEV market, PEV market scenarios are developed to exercise the infrastructure estimation methodology and highlight sensitivities. The analysis assigns no probabilities to any PEV market scenarios and considers none of the scenarios as most likely. However, a central scenario is established from which individual elements of the modeling framework are studied using parametric sensitivity analysis. PEV market conditions for the central scenario and sensitivities explored are shown in Table 1. 
Table 1. PEV Market Conditions for the Central Scenario and Sensitivities Explored

\begin{tabular}{|c|c|c|}
\hline Variable & Central Scenario & Sensitivity \\
\hline PEV Total & $\begin{array}{l}15 \mathrm{M} \text { (linear growth to } 20 \% \text { of } \\
\text { LDV sales in 2030) }\end{array}$ & $\begin{array}{l}9 \mathrm{M} \text { (growth to } 10 \% \text { of } 2030 \text { sales) } \\
21 \mathrm{M} \text { (growth to } 30 \% \text { of } 2030 \text { sales) }\end{array}$ \\
\hline $\begin{array}{l}\text { PEV Mix } \\
\text { (range preference) }\end{array}$ & $\begin{array}{ll} & \text { Mix } \\
\text { PHEV20 } & 10 \% \\
\text { PHEV50 } & 35 \% \\
\text { BEV100 } & 15 \% \\
\text { BEV250 } & 30 \% \\
\text { PHEV20-SUV } & 5 \% \\
\text { BEV250-SUV } & 5 \%\end{array}$ & $\begin{array}{ll} & \text { Long / Short } \\
\text { PHEV20 } & 0 \% / 40 \% \\
\text { PHEV50 } & 50 \% / 0 \% \\
\text { BEV100 } & 0 \% / 50 \% \\
\text { BEV250 } & 40 \% / 0 \% \\
\text { PHEV20-SUV } & 0 \% / 10 \% \\
\text { BEV250-SUV } & 10 \% / 0 \%\end{array}$ \\
\hline $\begin{array}{l}\text { Share of PEVs in Cities } \\
\text { (w/ pop. }>50 \mathrm{k})\end{array}$ & $\begin{array}{l}83 \% \\
\text { (based on existing HEVs) }\end{array}$ & $\begin{array}{l}\text { 71\% (based on existing LDVs) } \\
91 \% \text { (based on existing PEVs) }\end{array}$ \\
\hline PHEV:BEV Ratio & $1: 1$ & $4: 1$ to $1: 4$ \\
\hline PHEV Support & Half of full support & $\begin{array}{l}\text { No PHEV support to full support } \\
\text { (maximize PHEV eVMT) }\end{array}$ \\
\hline SUV Share & $10 \%$ & $5 \%$ to $50 \%$ \\
\hline \% Home Charging & $88 \%$ & $88 \%, 85 \%$, and $82 \%$ \\
\hline Interstate Coverage & Full Interstate & $\begin{array}{l}\text { Mega-regions, } 80 \% \text { of Long Distance } \\
\text { Trips (Traveler Analysis Framework } \\
\text { [TAF]), and Full Interstate }\end{array}$ \\
\hline Corridor DCFC Spacing & 70 miles & 40 to 100 miles \\
\hline DCFC Charge Time & 20 minutes $(150 \mathrm{~kW})$ & $\begin{array}{l}10 \text { to } 30 \text { minutes } \\
(400 \text { to } 100 \mathrm{~kW})\end{array}$ \\
\hline
\end{tabular}

eVMT = miles achieved on electric power

SUV = sport utility vehicle

The central scenario arbitrarily assumes a linear growth in the sale of new PEVs, climbing to $20 \%$ of all lightduty vehicle (LDV) sales in 2030. This sales rate would result in a total of 15 million PEVs on U.S. roads in 2030 (approximately 5\% of the total U.S. LDV stock in 2030). Sensitivities around PEV sales are explored between 9 and 21 million PEVs (10\% to $30 \%$ of U.S. LDV sales in 2030).

The range preference variable is meant to reflect relative adoption of the short- and long-range PHEVs and BEVs. For example, the central scenario features a preference for PHEVs with longer electric driving ranges, resulting in greater shares for PHEV50s and BEV250s (relative to PHEV20s and BEV100s, respectively). During the sensitivity analysis, a short-range preference is explored in which PEVs are exclusively comprised of PHEV20 and BEV100 vehicles (the long-range sensitivity shifts all PEVs to PHEV50 and BEV250 vehicles).

PEVs clustered in cities versus widespread adoption across the United States directly affects the degree to which infrastructure can be regionally concentrated. Three PEV dispersion scenarios are evaluated, each 
informed by the spatial dispersion of existing LDVs across the United States. The central scenario assumes 15 million PEVs are dispersed among cities, towns, and rural areas proportional to existing registrations of hybrid electric vehicles (HEVs). HEVs are considered a useful proxy for the spatial dispersion of an evolving PEV market based on their status as an advanced technology powertrain that predates the introduction of modern PEVs by approximately a decade. Allocating future PEVs using existing HEV registrations results in $83 \%$ of PEVs being located in cities (population greater than 50,000). Sensitivities on the spatial dispersion of future PEVs are developed based on the existing dispersion of all LDVs ( $71 \%$ in cities) and existing PEVs (91\% in cities). Registration data used to develop these estimates are discussed in Section 2.1.

The central scenario assumes a 1:1 ratio between future PHEVs and BEVs (similar to existing PEV registrations, see Section 2.1). Arbitrary sensitivities around this parameter are explored, from 4:1 (80\% PHEV) to 1:4 (80\% BEV).

PHEVs feature internal combustion engines for backup power and consequently have no hard requirements for non-residential charging infrastructure. PHEVs can however utilize work and public Level 2 (L2) EVSE to improve the percent of miles achieved on electric power (eVMT); however, PHEVs are restricted from using DCFC in this analysis. Providing full PHEV support in this model implies enough charging plugs to enable consumers to maximize eVMT (but not necessarily reach 100\% eVMT as individual trips may exceed the PHEV single charge range and L2 EVSE is restricted to destination charging in this project). Conversely, providing no PHEV support implies that no L2 EVSE is allocated on behalf of PHEVs in the model. Partial PHEV support is implemented in the central scenario reflecting $50 \%$ of full support.

The central scenario arbitrarily assumes a $10 \%$ sport utility vehicle (SUV) share within the PEV segment. While relatively modest given the increasing popularity of SUVs in the context of all LDVs (including conventional vehicles), existing PEV registrations reflect a mere 5\% market share for electric SUVs (see Section 3.2.2). SUV market shares within the PEV segment are explored between 5\% and 50\% during sensitivity analysis.

All scenarios assume the majority of consumers prefer to do most of their charging at their home location. In the central scenario, $100 \%$ of PEVs are simulated as having a home-dominant charging preference (resulting in $88 \%$ of charging taking place at home locations). Sensitivity analysis explores scenarios where $90 \%$ and $80 \%$ of PEVs are simulated with home-dominant charging behavior, with the remainder having work- and publicdominant charging behavior. This sensitivity results in PEVs performing $85 \%$ and $82 \%$ of charging at home locations.

Central scenario analysis of the interstate corridor network considers full coverage with average DCFC station spacing of 70 miles and a typical DCFC charge time of 20 minutes. DCFC coverage along the interstate network, station spacing, and average charge time are explored using the sensitivity analysis shown in Table 1.

\subsubsection{Report Structure}

The remainder of this report is structured as follows. Section 2 reviews the current status of the PEV market and EVSE infrastructure. Section 3 presents methods and results for non-residential community charging requirements, including L2 charging and fast-charging stations. Section 4 presents methods and results for fastcharging stations along interstate corridors. Finally, Section 5 summarizes the report's findings and offers insights to decision makers who are working to deploy an effective charging infrastructure network in the United States. 


\section{Existing Vehicle and Infrastructure Status}

This section reviews the current status of the U.S. PEV market and EVSE infrastructure.

\subsection{Plug-in Electric Vehicle Market Analysis}

The PEV market has experienced significant growth over the last few years, with more than 2 million PEVs on the road globally and more than 500,000 in the United States alone (IEA 2017). IHS Markit (formerly R.L. Polk \& Co.) LDV registration data are used in this report to inform geographical disaggregation of PEV adoption in the United States (IHS Markit 2017). This rich data set yields numerous insights into the composition of the PEV stock, its geographical distribution, and its temporal evolution. Out of the approximate 266 million light-duty vehicles registered in the United States in 2016, 239,000 were BEVs and 261,000 were PHEVs (IHS Markit 2017).

Policy support has been a strong driver for PEV adoption in the United States, as shown in Figure 2 by the significantly higher share of PEVs in the "ZEV states" (California, Connecticut, Maine, Maryland, Massachusetts, New Jersey, New York, Oregon, Rhode Island, and Vermont), which require automakers to sell a certain proportion of ZEVs (PEVs and fuel-cell electric vehicles) (California Air Resources Board 2017).

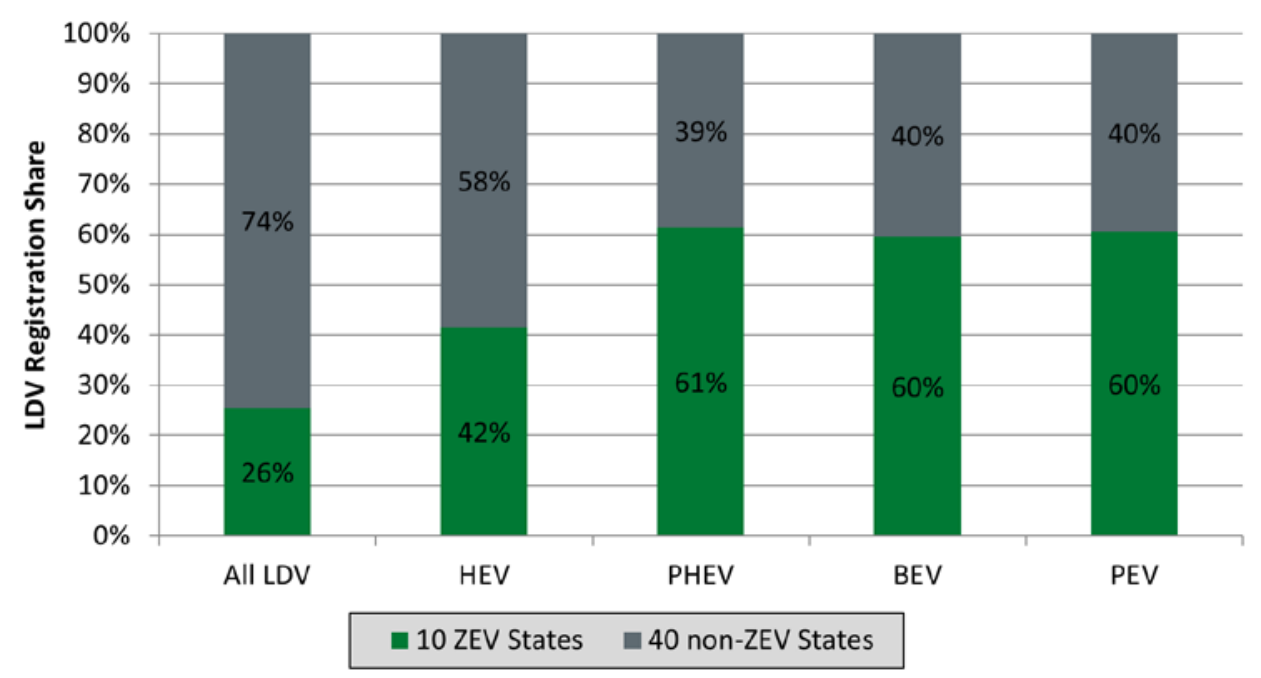

Figure 2. Distribution of all 2016 registrations of LDVs, HEVs, and PEVs in the United States by state ZEV status

(IHS Markit 2017)

While PEV model availability is still limited compared to conventional gasoline vehicles, 30 PEV models were available in the U.S. market at the end of 2016, covering a range of body styles and sizes. Although early PEVs were mainly small hatchbacks and sedans, such as the Nissan Leaf and the Chevrolet Volt, SUVs such as the Tesla Model X and BMW X5 - and even vans such as the Chrysler Pacifica - are now available. This trend will help make PEVs more attractive to customers across several segments. Likewise, longer-range BEVs such as the Chevrolet Bolt (with 238 miles of battery-only range) will appeal to consumers who were previously deterred by the limited range of BEVs. Figure 3 shows the composition of the existing U.S. PEV stock. The Chevrolet Volt and Nissan Leaf are the most popular models in the PHEV and BEV segments, respectively, but several other models account for significant market shares. 


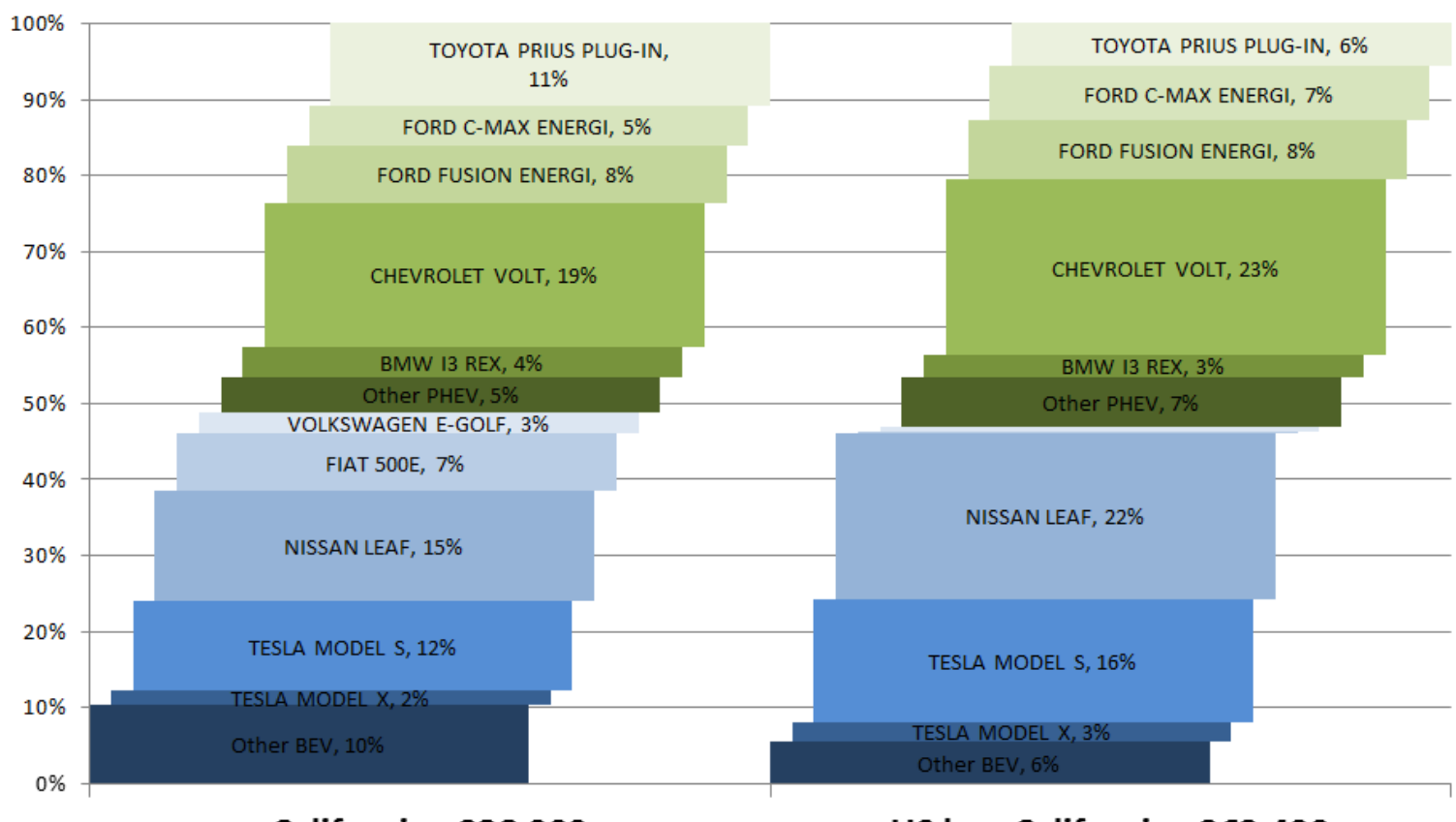

California - 238,000

US less California - 262,400

Figure 3. Composition of 2016 U.S. PEV stock

(IHS Markit 2017)

PEV registrations, shown in Figure 4, appear to be concentrated in cities (91\% of existing PEV registrations are located in cities) with the remainder distributed in towns and rural areas. This disparity is partially driven by a larger population in urban areas ( $71 \%$ of Americans live in cities with populations of 50,000 people or more), but lower PEV adoption in towns and rural areas is also the result of a lack of charging infrastructure combined with lower consumer awareness, lower availability of PEV models, and higher requirements for longer-distance trips.

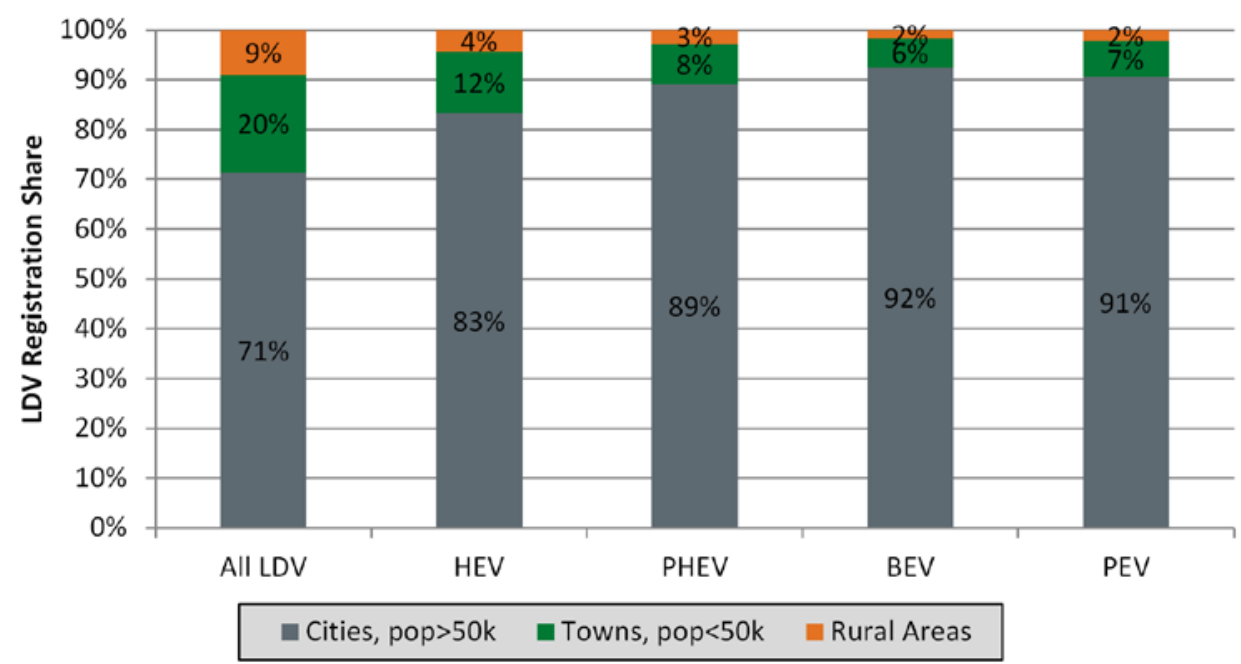

Figure 4. Distribution of all 2016 registrations of LDVs, HEVs, and PEVs in the United States by area (IHS Markit 2017).

Table 2 reports the number of LDV registrations aggregated by urban area for the top 10 U.S. PEV markets. California leads the nation, with six of the top 10 PEV urban area markets. Yet, the overall PEV penetration 
remains modest, with only four major urban areas exceeding 1\% LDV market share. Two of the top 10 urban areas, Concord, California, and Mission Viejo - Lake Forest - San Clemente, California, have populations under 1 million, but have a higher number of PEVs registered than Chicago, which is 10 times larger in terms of population. This may be explained by the demographics of these areas (including high average income) and significant policy support in California, including the ZEV mandate and financial incentives offered by the state- $\$ 2,500$ for BEVs and $\$ 1,500$ for PHEVs - on top of the $\$ 7,500$ federal tax rebate (Clean Vehicle Rebate Project 2017). These numbers also highlight the clustering effect, or neighbor effect, in PEV adoption, where a high existing concentration of PEVs and EVSE increases the awareness and attractiveness of PEVs in the surrounding area (Kahn and Vaughn 2009). Atlanta stands out as the most BEV-leaning market in the country, which can be traced back to a generous state incentive of $\$ 5,000$, which ended in the summer of 2015. Elimination of this incentive (and introduction of a \$200 road tax) may help explain the 8\% year-on-year drop in PEV stock in Atlanta.

Table 2. Top 10 U.S. Urban Areas by PEV Stock, 2016 (IHS Markit 2017)

\begin{tabular}{|c|c|c|c|c|c|c|}
\hline Urban Area & $\begin{array}{l}\text { All LDV } \\
\text { Registrations }\end{array}$ & PHEV & BEV & $\begin{array}{l}\text { PEV } \\
\text { Share }\end{array}$ & $\begin{array}{l}\text { BEV/PEV } \\
\text { Ratio }\end{array}$ & $\begin{array}{l}2015 \text { to } 2016 \\
\text { PEV Stock } \\
\text { Change }\end{array}$ \\
\hline $\begin{array}{l}\text { Los Angeles- } \\
\text { Long Beach- } \\
\text { Anaheim, CA }\end{array}$ & $9,851,000$ & 48,800 & 36,700 & $0.9 \%$ & $43 \%$ & $32 \%$ \\
\hline $\begin{array}{l}\text { San Francisco- } \\
\text { Oakland, CA }\end{array}$ & $2,500,000$ & 15,800 & 23,600 & $1.6 \%$ & $60 \%$ & $27 \%$ \\
\hline San Jose, CA & $1,504,000$ & 14,700 & 22,100 & $2.4 \%$ & $60 \%$ & $22 \%$ \\
\hline $\begin{array}{l}\text { New York- } \\
\text { Newark, } \\
\text { NY-NJ-CT }\end{array}$ & $10,652,000$ & 11,800 & 7,300 & $0.2 \%$ & $38 \%$ & $30 \%$ \\
\hline Atlanta, GA & $4,459,000$ & 3,100 & 15,700 & $0.4 \%$ & $83 \%$ & $-8 \%$ \\
\hline San Diego, CA & $2,548,000$ & 7,900 & 9,000 & $0.7 \%$ & $53 \%$ & $28 \%$ \\
\hline Seattle, WA & $2,874,000$ & 4,800 & 10,100 & $0.5 \%$ & $68 \%$ & $25 \%$ \\
\hline Concord, CA & 636,000 & 5,400 & 5,800 & $1.8 \%$ & $52 \%$ & $25 \%$ \\
\hline $\begin{array}{l}\text { Mission Viejo- } \\
\text { Lake Forest-San } \\
\text { Clemente, CA }\end{array}$ & 572,000 & 5,400 & 3,900 & $1.6 \%$ & $42 \%$ & $28 \%$ \\
\hline Chicago, IL-IN & $6,769,000$ & 4,700 & 4,400 & $0.1 \%$ & $48 \%$ & $30 \%$ \\
\hline
\end{tabular}




\subsection{Electric Vehicle Supply Equipment Availability}

According to the DOE's Alternative Fuels Data Center Station Locator, as of June 2017 there were approximately 16,000 PEV charging stations with 43,000 charging plugs nationwide (DOE 2017b), where a station is defined as a location with one or more individual plugs for PEV charging. L2 chargers are the most commonly installed type, accounting for approximately $80 \%$ of the installed plugs (DOE 2017b). Table 3 summarizes the public EVSE characteristics of the top 10 urban PEV markets including the number of plugs per 1,000 PEVs (existing public charging capacity) and stations per 1,000 square miles (existing public charging coverage). Although these top 10 urban areas typically feature public charging capacity and coverage above the national average, significant variability exists. For example, the Mission Viejo-Lake Forest-San Clemente urban area in California currently supports the nation's ninth largest PEV market with relatively low public charging capacity and coverage. Additional summaries of public EVSE networks are included in Appendix A.

Table 3. EVSE Characteristic of the Top 10 U.S. Urban PEV Markets, 2017 (DOE 2017b)

\begin{tabular}{|c|c|c|c|c|c|c|c|}
\hline Urban Area & $\begin{array}{l}\text { L2 } \\
\text { Plugs }\end{array}$ & $\begin{array}{l}\text { DCFC } \\
\text { Plugs }\end{array}$ & $\begin{array}{l}\text { L2 } \\
\text { Stations }\end{array}$ & $\begin{array}{l}\text { DCFC } \\
\text { Stations }\end{array}$ & $\begin{array}{l}\text { L2 Plugs } \\
\text { per } \\
1,000 \\
\text { PEVs }\end{array}$ & $\begin{array}{l}\text { DCFC } \\
\text { Plugs } \\
\text { per } \\
1,000 \\
\text { PEVs }\end{array}$ & $\begin{array}{l}\text { DCFC } \\
\text { Stations } \\
\text { per } \\
1,000 \\
\text { sq.mi. }\end{array}$ \\
\hline $\begin{array}{l}\text { Los Angeles-Long } \\
\text { Beach-Anaheim, } \\
\text { CA }\end{array}$ & 4,543 & 357 & 1,229 & 152 & 53.2 & 4.2 & 87.5 \\
\hline $\begin{array}{l}\text { San Francisco- } \\
\text { Oakland, CA }\end{array}$ & 1,786 & 200 & 535 & 81 & 45.4 & 5.1 & 154.7 \\
\hline San Jose, CA & 1,592 & 88 & 382 & 37 & 43.3 & 2.4 & 129.5 \\
\hline $\begin{array}{l}\text { New York-Newark, } \\
\text { NY-NJ-CT }\end{array}$ & 1,087 & 130 & 603 & 54 & 56.9 & 6.8 & 15.7 \\
\hline Atlanta, GA & 1,140 & 150 & 433 & 75 & 60.7 & 8.0 & 28.4 \\
\hline San Diego, CA & 1,224 & 102 & 363 & 39 & 72.4 & 6.0 & 53.2 \\
\hline Seattle, WA & 1,102 & 78 & 448 & 39 & 74.4 & 5.3 & 38.6 \\
\hline Concord, CA & 265 & 50 & 113 & 20 & 23.7 & 4.5 & 98.1 \\
\hline $\begin{array}{l}\text { Mission Viejo-Lake } \\
\text { Forest-San } \\
\text { Clemente, CA }\end{array}$ & 76 & 14 & 31 & 4 & 8.2 & 1.5 & 26.6 \\
\hline Chicago, IL-IN & 785 & 80 & 382 & 41 & 86.1 & 8.8 & 16.8 \\
\hline
\end{tabular}




\section{Non-Residential L2 and DCFC for Community Charging}

Most driving in the United States consists of habitual trips in and around the communities where people live, making convenient access to charging in these communities crucial to widespread PEV adoption. Although the majority of PEV charging currently takes place at home, access to charging away from home at long dwell time locations, commercial entities, and along freeways is highly valued by drivers as it dispels range anxiety and enables a greater share of electric miles. The analysis in this section estimates charging requirements in cities, towns, and rural areas to support the growing PEV market. First, coverage estimates are made for a minimum level of DCFC stations within cities and towns to support BEV intra-city long distance travel and emergency situations such as failing to charge overnight at home. Next, the National Renewable Energy Laboratory's (NREL's) Electric Vehicle Infrastructure Projection (EVI-Pro) tool is used to estimate nonresidential charging requirements for a baseline scenario of 15 million PEVs on U.S. roads in 2030. Finally, a sensitivity analysis is presented to document model uncertainty with respect to key factors such as technology development, PEV market evolution, and consumer charging behavior.

\subsection{DCFC Coverage Estimates}

This section presents a straightforward approach to estimating the number of DCFC stations required to provide minimum coverage for PEVs in cities and towns. L2 station coverage is not considered, assuming that non-residential L2 is primarily used for charging within walking distance of a destination (based on the low charge power and long charge time of L2 stations), and coverage for every destination is unrealistic for the early PEV market. Coverage estimates are also omitted for DCFC stations in rural areas, because coverage provided by stations in cities/towns and along interstate corridors (see Section 4) is deemed to be sufficient. Given that PHEVs are assumed to perform most charging at home and can use an internal combustion engine for backup power, they are naturally excluded from this calculation of a minimum charging coverage requirement. Consequently, attention is paid to DCFC stations supporting BEVs in cities and towns.

As a simplifying assumption, coverage estimates assume DCFC stations are spaced uniformly on a square grid across a two-dimensional area within each community. For BEV drivers to never be more than 3 linear miles from a DCFC station in a given city, 56 stations per 1,000 square miles would be required (for reference, there are currently 960 gasoline stations per 1,000 square miles in U.S. cities). This station density is applied to the 108,246 square miles occupied by cities and towns in the United States, resulting in a national DCFC station count of 8,072 (4,861 in cities and 3,211 in towns).

For comparison, the public DCFC station density per 1,000 square miles in major PEV markets ranges from 16 in New York and 17 in Chicago to 130 in San Jose and 155 in San Francisco (as of June 2017). The average DCFC density per 1,000 square miles in the top 10 U.S. PEV markets is 65 . This number drops to 18 across all cities and towns nationwide.

\subsection{Non-Residential EVSE Community Demand Estimates}

This section describes methods for estimating non-residential EVSE (work L2, public L2, and public DCFC) demand requirements for community charging. NREL has developed three regional models using EVI-Profor California, Massachusetts (Wood et al. 2017), and the Columbus, Ohio, area (Wood et al. forthcoming). The findings from those models are extended to estimate nominal ratios of EVSE per 1,000 PEVs for the national study. These nominal ratios are adjusted for the various communities across the United States. Adjustments to the nominal EVSE/PEV ratios are based on population density, PEV concentration, and local ambient temperature.

PEV stock for all communities (486 cities, 3,087 towns, and 50 rural areas with state-level aggregation) is calculated by disaggregating a national PEV count (15 million in the baseline 2030 scenario) proportionally to existing registration data from IHS Markit. Three variations on PEV disaggregation are considered based on: 1) all existing LDV registrations, 2) existing HEV registrations, and 3) existing PEV registrations. Among 
these three options, basing disaggregation on existing PEV registrations maximizes the number of PEVs in cities and ZEV states, whereas basing it on existing LDV registrations places a comparatively larger share of PEVs in towns, rural areas, and non-ZEV states (see Section 2). Basing disaggregation on existing HEV registrations produces results that are in between the results of the other two approaches in terms of geographic PEV distribution. The central scenario uses the HEV-based disaggregation approach, and the other approaches are used for sensitivity analysis.

After individual EVSE/PEV ratios and PEV stocks for each geography are calculated, the ratio and stock values are simply multiplied to generate a localized estimate of consumer demand for non-residential charging. A schematic of this approach is shown in Figure 5.

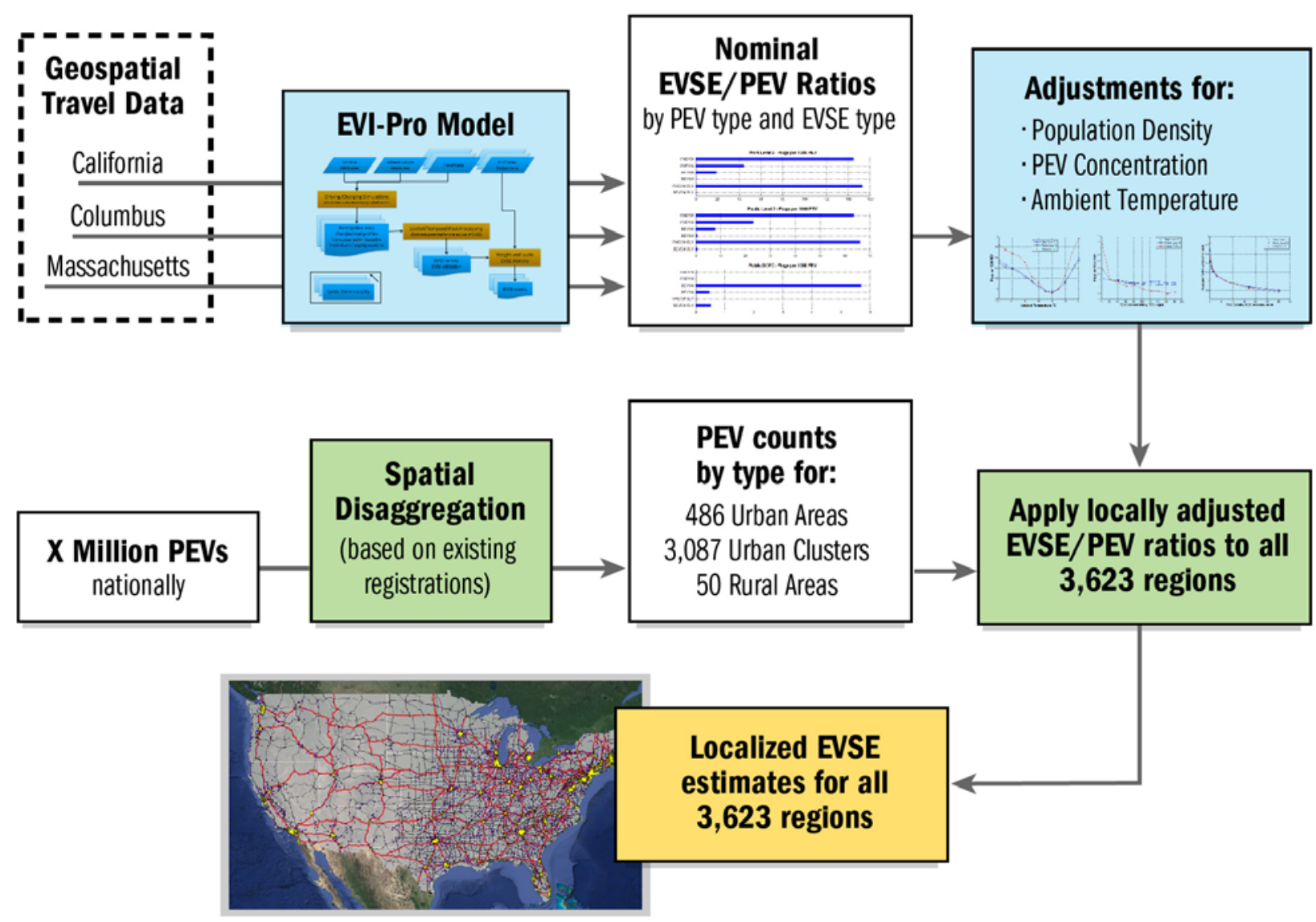

Figure 5. Schematic for estimating community charging requirements.

(Satellite imagery credit: (c) 2017 Google, Map Data (C) 2017 Tele Atlas)

\subsubsection{Electric Vehicle Infrastructure Projection (EVI-Pro) Tool}

Consumer demand for non-residential L2 and DCFC is estimated using EVI-Pro. NREL developed EVI-Pro in partnership with the California Energy Commission to estimate regional requirements for charging infrastructure that supports consumer adoption of light-duty PEVs. EVI-Pro uses real-world travel data to simulate spatially and temporally resolved demand for PEV charging at homes, workplaces, and public destinations. It anticipates consumer charging behavior while capturing variations with respect to housing type (single- versus multi-unit dwellings [MUDs]), travel period (weekdays versus weekends), and regional differences in travel behavior and vehicle adoption. Its fundamental assumption is that consumers prefer charging scenarios that enable them to complete all their existing travel with maximum eVMT and minimum operating cost. For more information about EVI-Pro's functionality, see the methodology section of Wood et al. (2017). 


\subsubsection{Estimating Non-Residential EVSE/PEV Nominal Ratios}

A mix of PEVs selected to emulate the 2030 PEV market is shown in Table 4. EVSE attributes assumed for charging infrastructure are summarized in Table 5.

Table 4. Modeled Vehicles

\begin{tabular}{|c|c|c|c|c|c|c|}
\hline Modeled PEVs & PHEV20 & PHEV50 & BEV100 & BEV250 & $\begin{array}{l}\text { PHEV20 } \\
\text { SUV }\end{array}$ & $\begin{array}{l}\text { BEV250 } \\
\text { SUV }\end{array}$ \\
\hline Chassis Type & Sedan & Sedan & Sedan & Sedan & SUV & SUV \\
\hline $\begin{array}{l}\text { Nominal Electric } \\
\text { Driving Range, mi }\end{array}$ & 20 & 50 & 100 & 250 & 20 & 250 \\
\hline $\begin{array}{l}\text { Nominal Efficiency, } \\
\text { Wh/mi (excludes } \\
\text { charger efficiency) }\end{array}$ & 225 & 225 & 225 & 230 & 315 & 330 \\
\hline $\begin{array}{l}\text { Assumed } 2030 \text { PEV } \\
\text { Registration Shares } \\
\text { (central scenario) }\end{array}$ & $10 \%$ & $35 \%$ & $15 \%$ & $30 \%$ & $5 \%$ & $5 \%$ \\
\hline $\begin{array}{l}\text { Existing Registration } \\
\text { Shares }\end{array}$ & $25 \%$ & $21 \%$ & $34 \%$ & $14 \%$ & $2 \%$ & $3 \%$ \\
\hline $\begin{array}{l}\text { Existing Example } \\
\text { PEVs }\end{array}$ & $\begin{array}{l}\text { Ford } \\
\text { Fusion } \\
\text { Energi, } \\
\text { Toyota } \\
\text { Prius } \\
\text { Prime }\end{array}$ & $\begin{array}{l}\text { Chevrolet } \\
\text { Volt }\end{array}$ & $\begin{array}{l}\text { Nissan } \\
\text { Leaf, } \\
\text { Fiat 500e }\end{array}$ & $\begin{array}{l}\text { Tesla } \\
\text { Model S, } \\
\text { Chevrolet } \\
\text { Bolt }\end{array}$ & $\begin{array}{l}\text { BMW X5 } \\
\text { xDrive } 40 e, \\
\text { Volvo } \\
\text { xc90 T8 }\end{array}$ & $\begin{array}{l}\text { Tesla } \\
\text { Model X }\end{array}$ \\
\hline
\end{tabular}

Table 5. Modeled Charging Infrastructure

\begin{tabular}{llll}
\hline Location & Level & Power & Comment \\
\hline Home & L1 & $\begin{array}{l}1.4 \mathrm{~kW} \\
3.6 \mathrm{~kW}\end{array}$ & $\begin{array}{l}\text { BEVs simulated with L2 power above 3.6 kW to } \\
\text { enable full overnight charge }\end{array}$ \\
Work & L2 & $6.2 \mathrm{~kW}$ & $\begin{array}{l}\text { PHEV on-board charger limits max power to } 3.6 \\
\text { kW in model }\end{array}$ \\
\hline Public & L2 & $6.2 \mathrm{~kW}$ & $\begin{array}{l}\text { PHEV on-board charger limits max power to } 3.6 \\
\text { kW in model } \\
\text { BEVs only; charge rate tapers at high state of } \\
\text { charge; BEV100 limited to 50 kW max }\end{array}$ \\
\hline
\end{tabular}

$$
\text { L1 = level } 1 \text { charging station }
$$

Global positioning system travel trajectories for the Columbus area from commercial traffic/mapping provider INRIX were used as the input data set to the EVI-Pro model (Wood et al. forthcoming). Results from the Columbus model were harmonized with PEV/EVSE ratios from the California model (based on the 2012 California Household Travel Survey) and Massachusetts model (based on the 2011 Massachusetts Travel Survey). This process yields a nominal set of EVSE/PEV ratios for each charger location and power level. Figure 6 shows the nominal EVSE/PEV ratios in terms of plugs per 1,000 PEVs for work L2, public L2, and 
public DCFC infrastructure. These estimates assume a home-dominant charging pattern in which consumers have access to home charging and prefer to do most charging at home owing to their electricity rate structures and the perceived level of convenience.

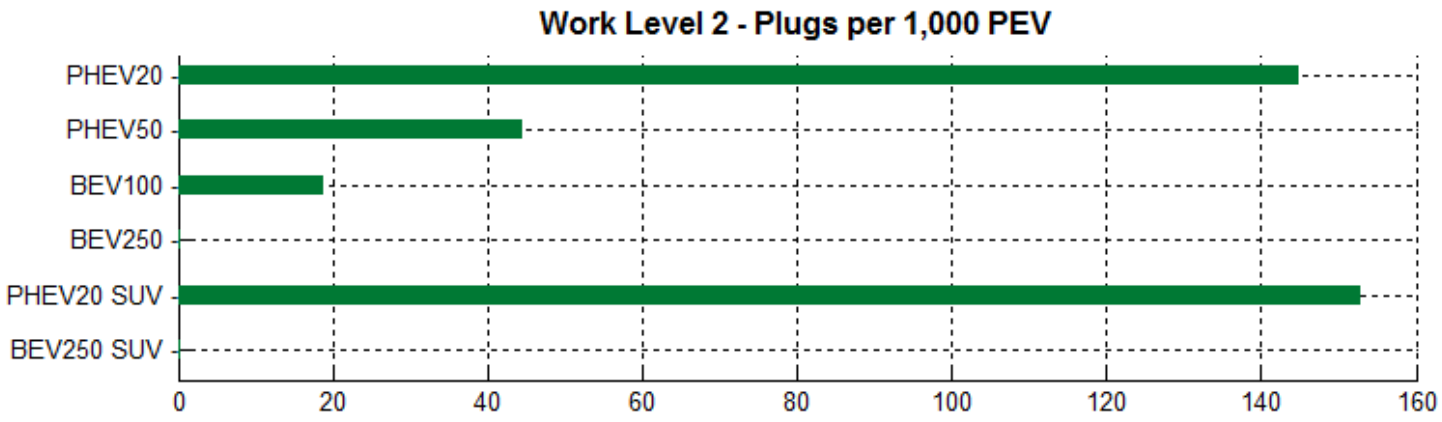

Public Level 2 - Plugs per 1,000 PEV

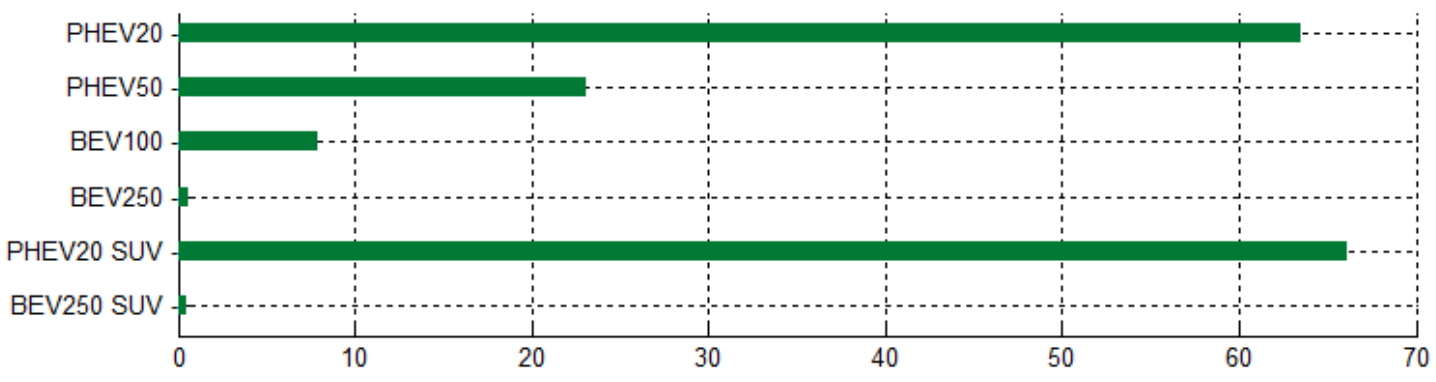

Public DCFC - Plugs per 1,000 PEV

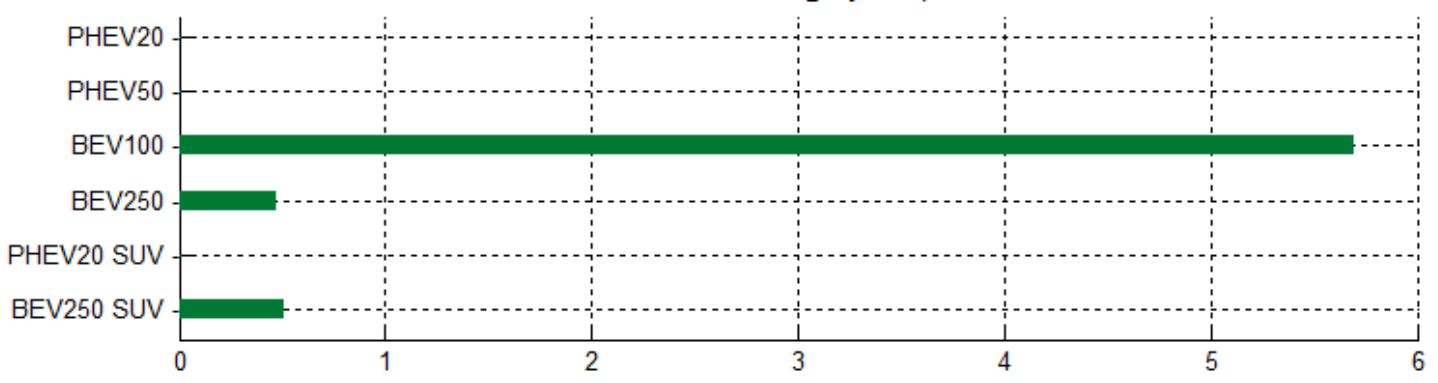

Figure 6. Nominal non-residential EVSE/PEV ratios (home dominant charging behavior).

The relationship between electric range and estimated infrastructure requirements is clear in these results. PEVs with longer electric ranges are less dependent on work and public charging to maximize eVMT (e.g., the BEV250 results in almost non-existent L2 charging requirements at work and public locations). Because PHEVs are incompatible with fast charging in this analysis, by definition they have no DCFC requirements.

The resulting charging load profile from home-dominant EVI-Pro simulations is shown in Figure 7. Note that $88 \%$ of charging in the EVI-Pro simulations is from residential EVSE (either L1 or L2). The simulations do not account for electricity pricing mechanisms or consumer incentives (such as time-of-use pricing) designed to shift load from the early evening into overnight hours. These effects have significant impacts on the operation of the electricity grid, but do not impact the non-residential EVSE/PEV ratios estimated in this report. 


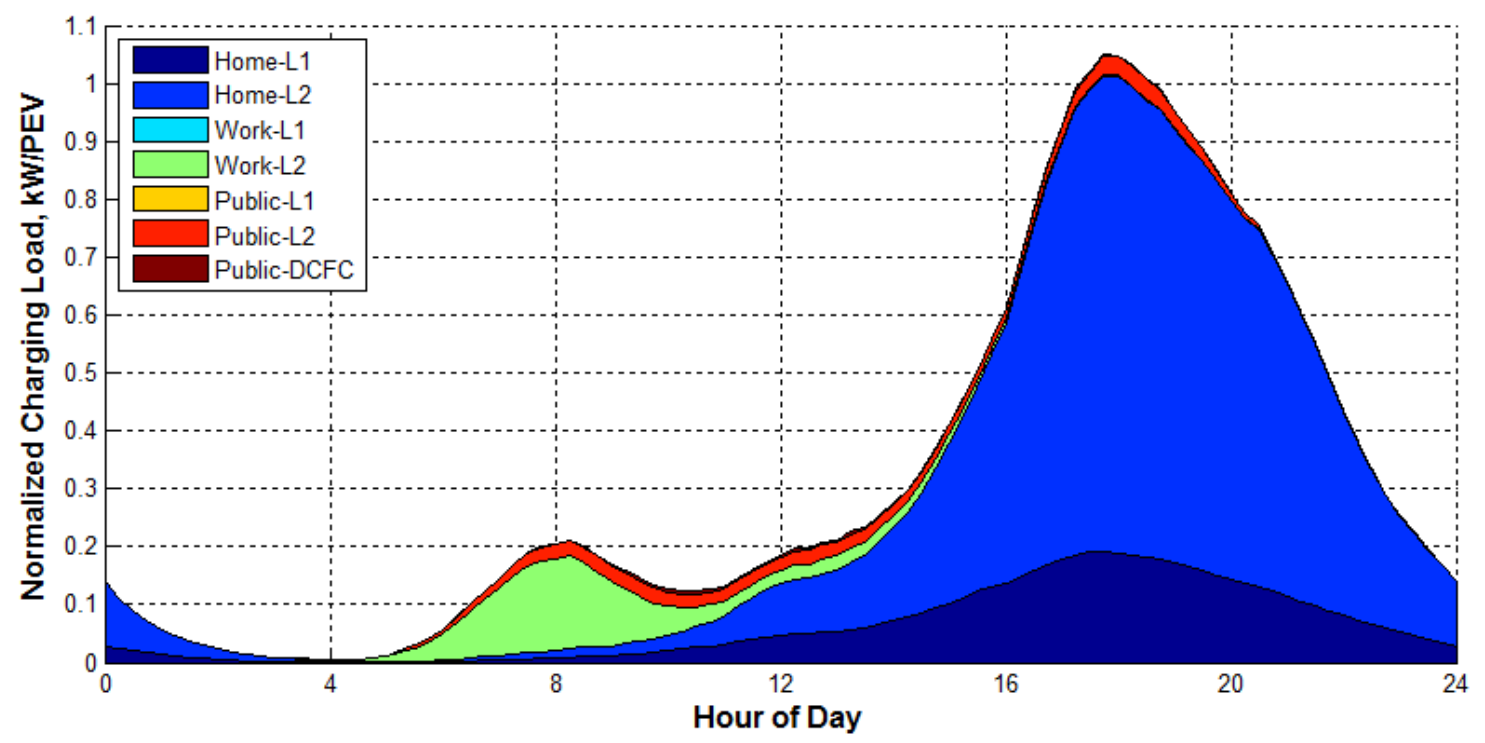

Figure 7. Nominal charging load profile from EVI-Pro simulations (home dominant charging behavior).

The nominal set of EVSE/PEV ratios is adjusted to account for the unique characteristics of all U.S. geographies based on population density, PEV concentration, and ambient temperature, as discussed in Appendix .

\subsubsection{National Results in the Central Scenario}

A set of national simulations is run using the settings from the central scenario (discussed in Section 1.2.2). Table 6 shows the modeled estimates for PEVs and EVSE for the top 10 urban areas from simulation of the central scenario. Results by community type and national totals are shown in Table 7, and state-level results are shown in Appendix . In 2030, approximately 600,000 L2 plugs (work and public) and 25,000 DCFC plugs are projected to serve 15 million PEVs across the United States. These estimates normalize to $40 \mathrm{~L} 2$ plugs per 1,000 PEVs and 1.7 DCFC plugs per 1,000 PEVs.

Present day public charging infrastructure represents approximately $13 \%$ of the plug count estimates modeled for 2030 (under PEV market assumptions in the central scenario). However, cities such as San Jose, California (73\%), San Francisco, California (43\%), and Seattle, Washington (41\%) are much closer to the estimated requirements for the 15 million PEVs simulated in the central scenario. 
Table 6. Central Scenario PEV and Non-Residential EVSE Estimates in 2030, Top 10 Urban Areas

\begin{tabular}{lllll}
\hline Urban Area & PEV Total & $\begin{array}{l}\text { Work L2 } \\
\text { Plugs }\end{array}$ & $\begin{array}{l}\text { Public L2 } \\
\text { Plugs }\end{array}$ & $\begin{array}{l}\text { Public DCFC } \\
\text { Plugs }\end{array}$ \\
\hline Los Angeles-Long Beach-Anaheim, CA & $1,213,000$ & 22,000 & 13,000 & 700 \\
New York-Newark, NY-NJ-CT & 553,000 & 13,000 & 7,000 & 600 \\
San Francisco-Oakland, CA & 497,000 & 7,000 & 4,000 & 400 \\
Washington, DC-VA-MD & 407,000 & 9,000 & 5,000 & 400 \\
Chicago, IL-IN & 399,000 & 8,000 & 5,000 & 500 \\
Seattle, WA & 316,000 & 5,000 & 3,000 & 500 \\
San Diego, CA & 297,000 & 5,000 & 3,000 & 300 \\
Boston, MA-NH-RI & 266,000 & 7,000 & 4,000 & 300 \\
San Jose, CA & 260,000 & 4,000 & 2,000 & 200 \\
\hline Philadelphia, PA-NJ-DE-MD & 235,000 & 6,000 & 4,000 & 300 \\
\hline
\end{tabular}

Table 7. Central Scenario PEV and Non-Residential EVSE Estimates in 2030, by Community Type (with National Total)

\begin{tabular}{lllll}
\hline & PEV Total & $\begin{array}{l}\text { Work L2 } \\
\text { Plugs }\end{array}$ & $\begin{array}{l}\text { Public L2 } \\
\text { Plugs }\end{array}$ & $\begin{array}{l}\text { Public DCFC } \\
\text { Plugs }\end{array}$ \\
\hline Cities & $12,411,000$ & 278,000 & 173,000 & 19,000 \\
Towns & $1,848,000$ & 56,000 & 43,000 & 4,000 \\
Rural Areas & 642,000 & 28,000 & 23,000 & 2,000 \\
National Total & $15,000,000$ & 362,000 & 239,000 & 25,000 \\
\hline
\end{tabular}

\subsubsection{Sensitivities of National Results to Various Assumptions}

This section illustrates the sensitivity of the national results to potentially important assumptions. Figure 8 shows the results in terms of total national plug requirements, whereas Figure 9 shows the results in terms of normalized requirements (EVSE/PEV ratios). For example, increasing the number of PEVs from the central value of about 15 million to 21 million increases the number of non-residential L2 plugs from 600,000 to 820,000 , and it increases the number of DCFC plugs from 25,000 to 33,000 (Figure 8). The effects of changing PEV penetration are smaller on a normalized basis, especially for non-residential L2 plugs. Otherwise, the ranking of influential variables is similar for total and normalized non-residential L2 plugs: 1) PHEV support, 2) range preference, 3) percent home charging, 4) PHEV:BEV ratio, 5) percent of PEVs cities, and 6) SUV share. For DCFC plugs, PHEV support has no impact as PHEVs are not modeled as supporting DCFC. Range preference has the largest impact, followed — on a normalized basis - by percent home charging, PHEV:BEV ratio, PEV count, and percent of PEVs in cities. 
This analysis also enables comparison of the input variables' impacts on the L2 and DCFC total plug counts. Supporting PHEVs boosts L2 plug counts significantly since PHEVs are modeled as using non-residential L2 EVSE at significantly higher rates than BEVs, whereas it has no effect on DCFC plug counts as PHEVs cannot use DCFC. Similarly, a high ratio of PHEVs to BEVs favors L2 EVSE, and a high ratio of BEVs to PHEVs favors DCFC. The need for both power levels rises as the range of PEVs declines, since shorter-range PEVs require more non-residential charging. The need for both types of charging infrastructure decreases as the share of PEVs in cities increases, because daily average vehicle miles traveled (VMT) is lower in denser urban areas (see Appendix B). More home charging also reduces the need for both types of charging infrastructure.
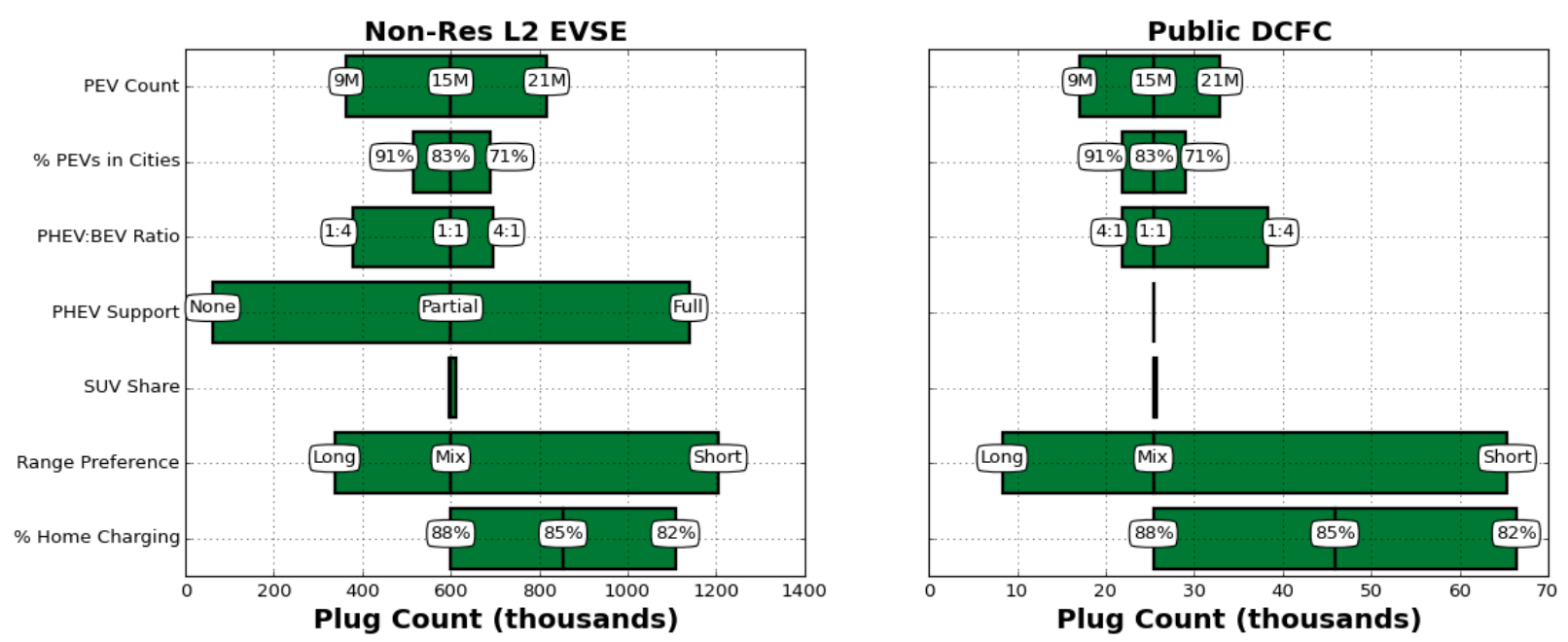

Figure 8. Effects of input variables on estimated total national plug requirements.
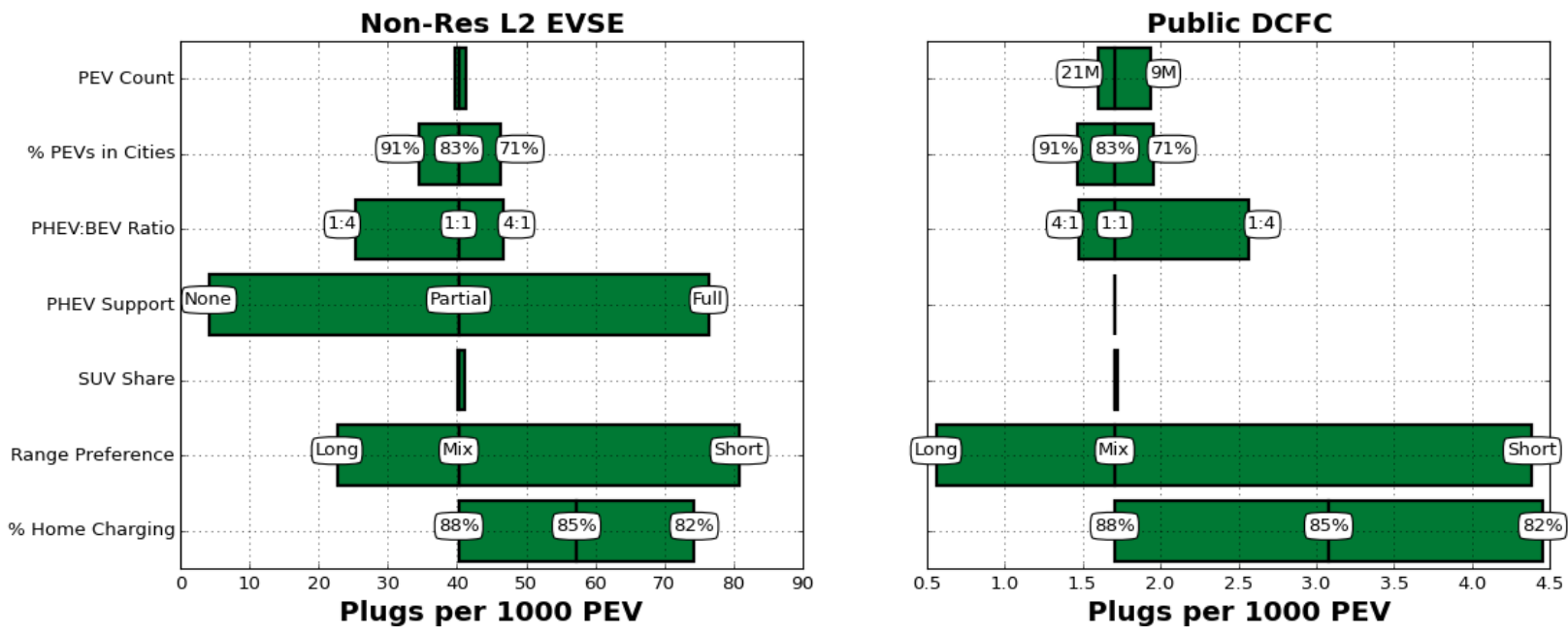

Figure 9. Effects of input variables on normalized national plug requirements (EVSE/PEV ratios). 


\section{DCFCs for Corridor Charging}

Long-distance travel has been a critical barrier to BEV adoption, which has been exacerbated by the real and perceived range anxiety of drivers in the United States. While most single-day travel surveys suggest that a large majority of daily driving can be accommodated with a relatively short driving range (approximately 100 miles), analysis of longitudinal driving patterns reveals that a large segment of U.S. drivers routinely use personal vehicles for long-distance travel, with an average vehicle traveling 100 miles or more on 6 days per year (see Appendix ). These drivers would presumably require long-distance single-charge ranges and DCFC support along travel corridors to consider adopting BEVs as fully capable replacements for their existing vehicles. Even drivers who seldom make LDTs might exhibit similar adoption requirements based on their perceived need for long-distance driving.

This issue can be alleviated by providing access to an extensive and convenient network of DCFC stations along corridors that enable reliable long-distance intercity travel. The U.S. Interstate Highway System is an ideal basis for such a long-distance DCFC network. Its extensive, high-speed, controlled-access highways connect population centers and cross the country via various routes. Yet providing comprehensive DCFC coverage for the Interstate System presents a much smaller and simpler task compared with providing comprehensive coverage based on all other U.S. highways and state routes. Interstate-based coverage that is already underway and planned could result in a robust, national network within a few years, whereas community DCFC coverage of the scope described in Section 3 will likely take longer.

This section estimates the number of DCFC stations necessary to provide charging coverage across several network designs based on the Interstate System. Next, charging demand requirements are estimated to quantify the number of plugs at interstate corridor DCFC stations needed to support long-distance travel and minimize queuing during periods of high traffic. Then, a set of challenges associated with constructing and maintaining Interstate corridor DCFC stations is discussed. The analyses in these sections (Sections 4.1 to 0 ) consider only highways that are part of the Interstate System. Section 0 provides a brief discussion of the corridor charging support that could be enabled by the community-based DCFC stations discussed in Section 3.

\subsection{DCFC Interstate Corridor Coverage Calculations}

This section first defines the full Interstate network as a basis for developing hypothetical DCFC networks (Section 4.1.1). Because the full Interstate network is large, Section 4.1.2 prioritizes corridors to develop four alternative national DCFC network scenarios, forming a total of five hypothetical DCFC corridor networks as shown in Table 8. Finally, Section 0 discusses station spacing requirements for corridors. National corridor DCFC methodology and sensitivities are summarized in Figure 10.

Table 8. National DCFC Coverage Scenarios along U.S. Interstate Corridors

\begin{tabular}{ll}
\hline DCFC Corridor Scenario & Comment \\
\hline Full Interstate Network & DCFC coverage is provided across all U.S. Interstate corridors \\
Mega-Regions & $\begin{array}{l}\text { DCFC coverage within U.S. mega-regions (per America 2050 } \\
\text { study), but not between mega-regions }\end{array}$ \\
DOT Alternative Fuel Corridors & $\begin{array}{l}\text { DCFC coverage provided on all corridors specified in U.S. DOT } \\
\text { Alternative Fuel Corridors for Electric Vehicles (DOT 2017a) }\end{array}$ \\
HPMS-Based Coverage (80\%) & $\begin{array}{l}\text { DCFC coverage on corridors representing 80\% of FHWA } \\
\text { Highway Performance Monitoring System annual average } \\
\text { daily travel for interstate corridors }\end{array}$ \\
TAF-Based Coverage (80\%) & $\begin{array}{l}\text { DCFC coverage on corridors representing 80\% of FHWA } \\
\text { Traveler Analysis Framework annualized automobile trips on } \\
\text { interstate corridors }\end{array}$ \\
\hline
\end{tabular}




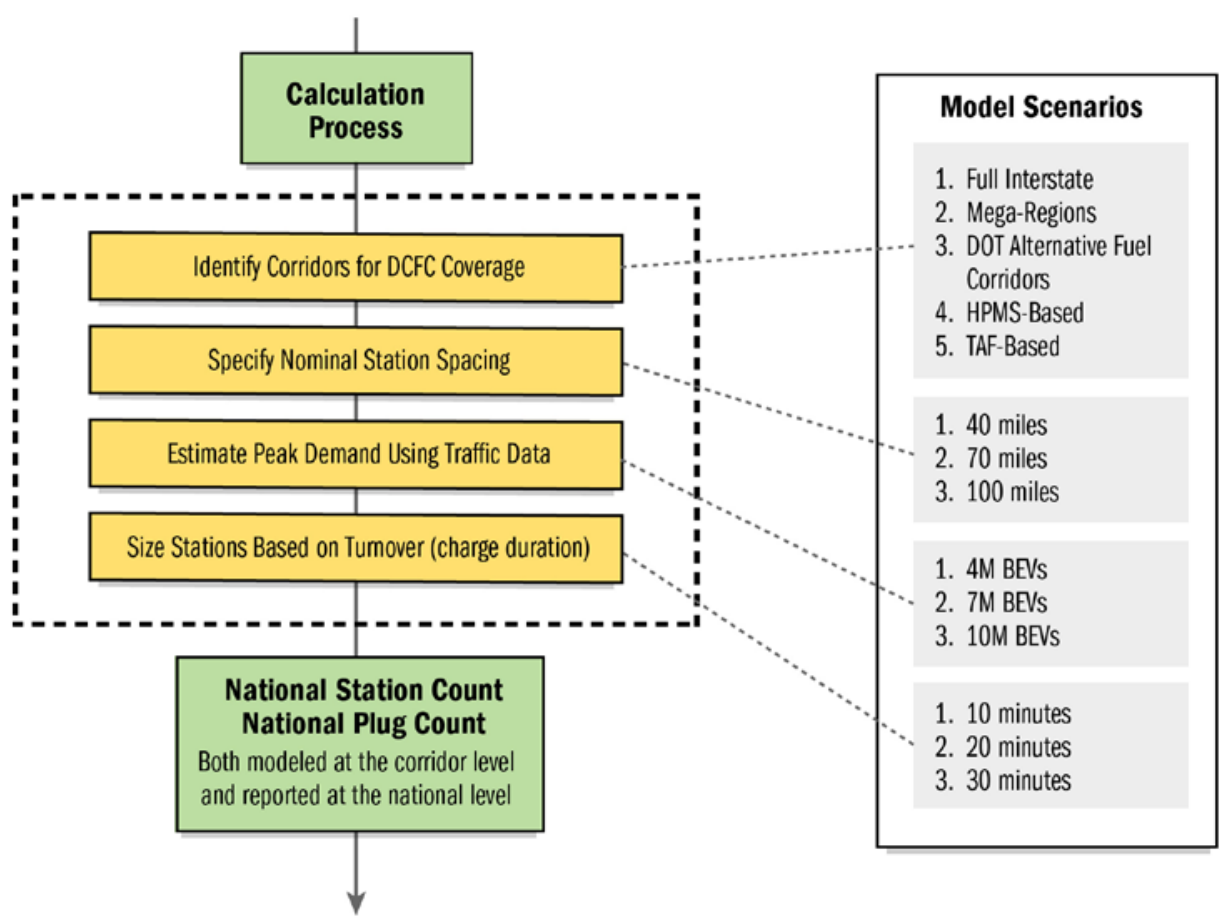

Figure 10. Methodology and sensitivity schematic for corridor DCFC analysis.

Table 9 and Figure 11 summarize the station-count results for each coverage scenario assuming three different average station-spacing values. The national station count ranges from 96 (for the mega-region network with 100-mile spacing) to 713 stations (for the full Interstate network with 40-mile spacing). Although this range is large, all scenarios are relatively modest compared with the regional DCFC investments that already have been made. As of June 2017, a total of 2,164 DCFC stations have been installed (357 by Tesla alone). However, most of these stations have been concentrated in urban areas, and the small number of corridor DCFC stations has been concentrated in areas of high PEV adoption - most notably along the West Coast, through northeast sections of the I-95 corridor, and in rural areas around Atlanta. Again, using the Tesla network as an example, as of June 2017 there were a total of 161 corridor DCFC stations in Tesla's Supercharger network, enabling long-distance travel across most of the United States.

Table 9. Estimated National DCFC Station Counts to Cover Corridors under Different Scenarios

\begin{tabular}{llll}
\hline Station Spacing & $\mathbf{4 0}$ miles & $\mathbf{7 0}$ miles & $\mathbf{1 0 0}$ miles \\
\hline Full Interstate Network & 713 & 408 & 285 \\
Mega-Regions & 239 & 137 & 96 \\
DOT Alternative Fuel Corridors & 306 & 175 & 122 \\
HPMS-Based Coverage (80\%) & 530 & 303 & 212 \\
TAF-Based Coverage (80\%) & 436 & 249 & 174 \\
\hline
\end{tabular}




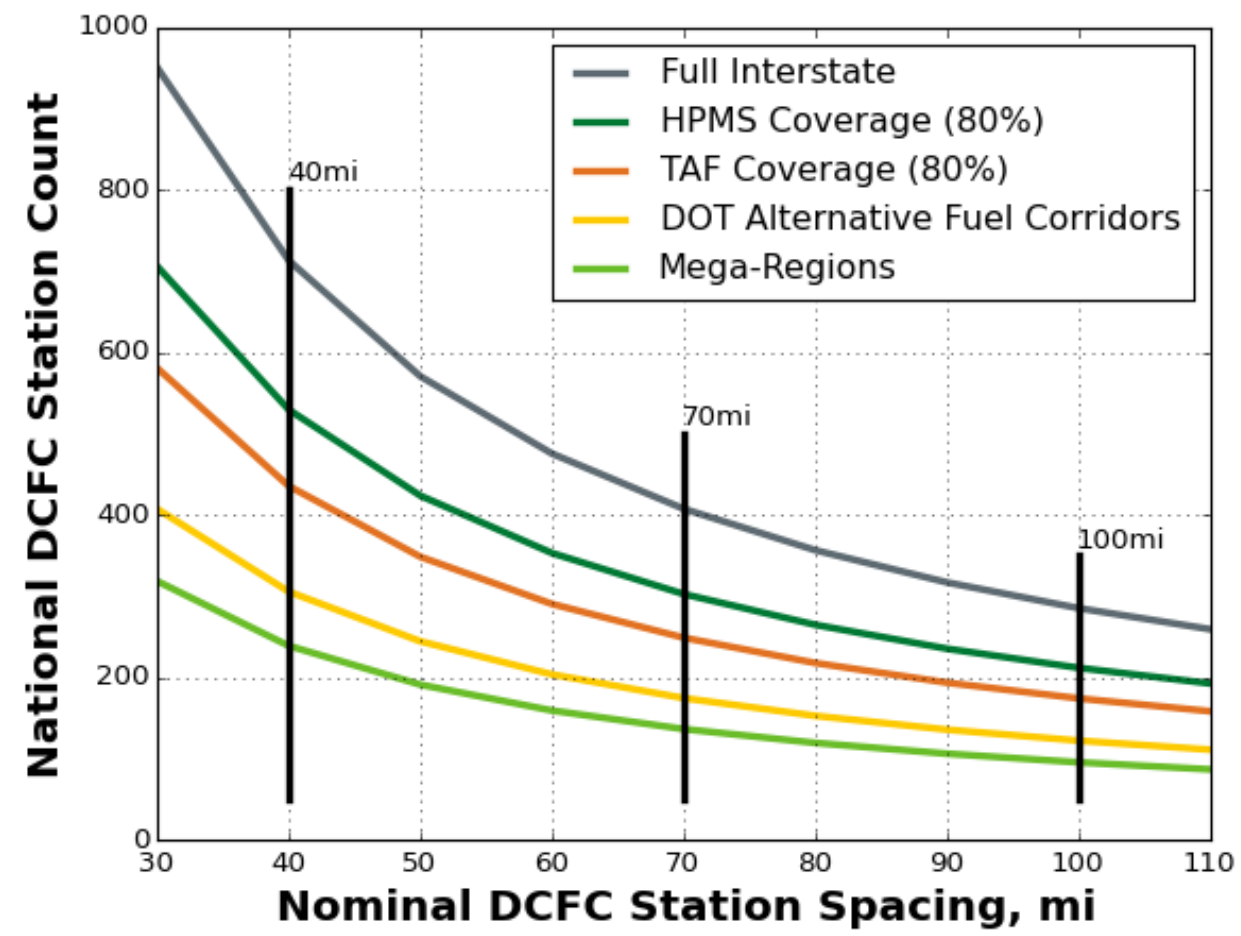

Figure 11. Nationwide DCFC station counts to cover corridors as a function of station spacing for different scenarios.

\subsubsection{Full Interstate Network}

This section's proposed network for hypothetical DCFC stations consists of Interstate segments connecting cities with a total length of 31,510 miles. This network excludes segments of Interstates within cities since DCFC stations within urban areas are assumed to be available; station count estimates for DCFC in cities are developed in Section 3. Excluding segments shorter than 25 miles (resulting from cities in close proximity), the relevant Interstate network is scaled down to a total length of 28,530 miles, illustrated in Figure 12, which also shows the network with 70-mile-radius buffers (approximating network coverage). This mile count does not consider double miles for both directions of travel or number of lanes on individual corridors, because a single DCFC station is assumed to serve both directions of travel and all lanes (assuming sufficient capacity, which is discussed in Section 4.2).

This road network was derived from the DOT's National Highway Planning Network (v14.05) data set available through the Federal Highway Administration (FHWA) in shapefile format (FHWA 2017c). The full source data set was initially filtered to a set of Interstate highways. Next, a spatial overlay process clipped the filtered set of lines to exclude all segments and portions of line segments overlapping urban areas. A shapefile derived from the U.S. Census Bureau's 2015 MAF/TIGER geographic database filtered to just urban areas provided the clipping bounds (U.S. Census Bureau 2015). Finally, post-processing routines assembled the many small remaining road segments into contiguous network segments. These segments were further separated at junctions where three or more original road segments converged. 


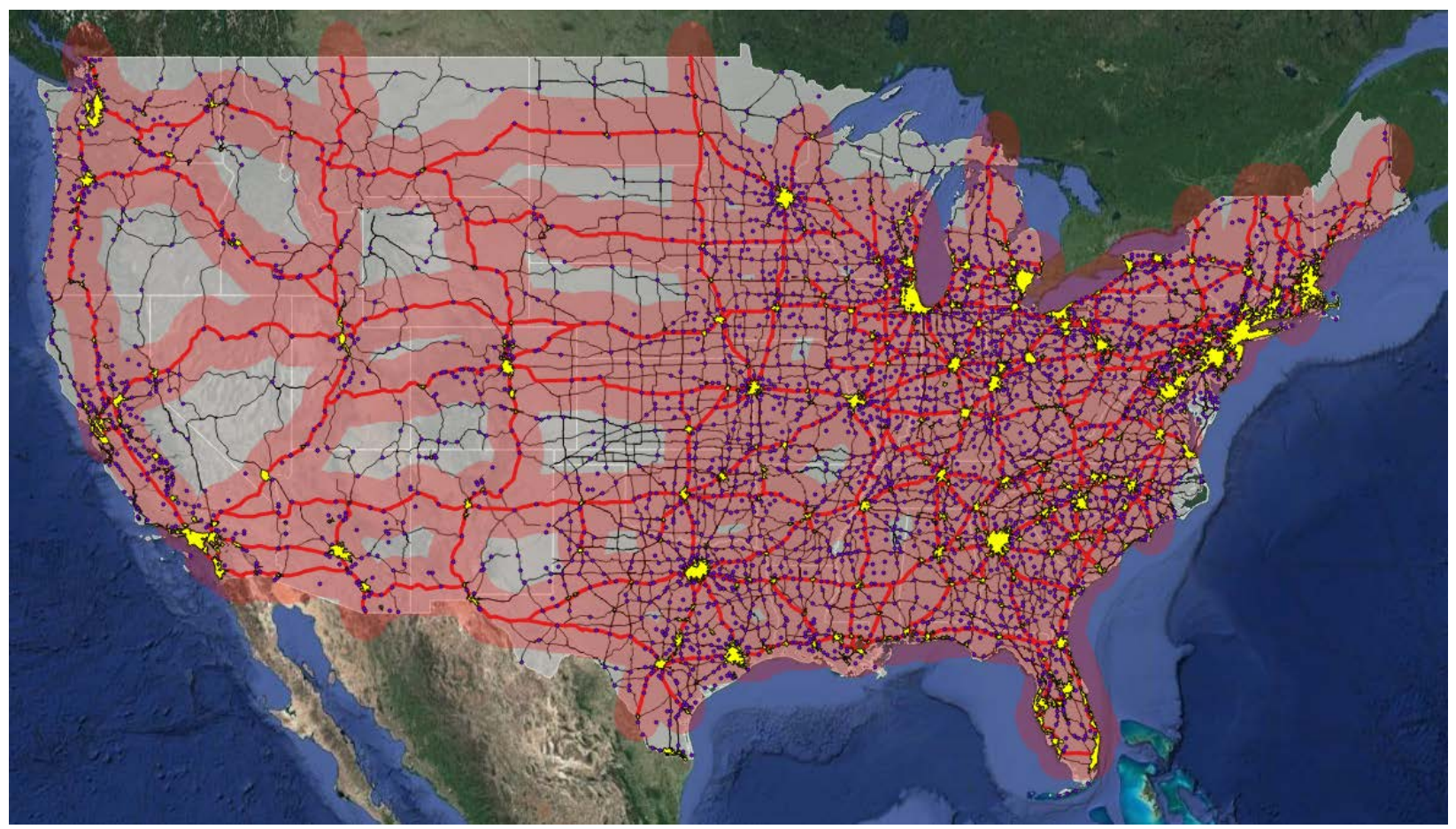

Figure 12. Interstate corridor network (thick red lines) considered in this analysis (70-mile radius red buffer approximates areas that would be served by the proposed DCFC network). Included for reference: yellow polygons represent cities, purple points represent towns, and thin black lines represent the national highway system.

(Satellite imagery credit: @ 2017 Google, Map Data @ 2017 Tele Atlas)

Providing full coverage to this Interstate Highway network would require many stations, some of which would be poorly utilized owing to the uneven distribution of traffic volume on the network. Hence, it is desirable to prioritize corridors that will provide the highest utility to BEV drivers traveling beyond their vehicle's range. In the next section, this prioritization is discussed for four alternative scenarios.

\subsubsection{Corridor Prioritization}

Here the Mega-region, DOT Alternative Fuel Corridors, Highway Performance Monitoring System (HPMS), and Traveler Analysis Framework (TAF) scenarios are described. 


\subsubsection{Mega-regions (Scenario 1)}

Mega-regions are an interesting geographical trend that has emerged over the last few decades. Interlocking economic systems, shared natural resources and ecosystems, and common transportation systems link these population centers together. Most of the nation's rapid population growth, and an even larger share of its economic expansion, are expected to take place in these large networks of metropolitan areas. The America 2050 initiative defines 11 U.S. mega-regions, reported in America 2050 (2017). Providing coverage for PEV charging along Interstates within each mega-region (that is, enabling reliable PEV travel within each megaregion, but not among different mega-regions) would result in the DCFC network shown in Figure 13, encompassing 96 to 239 DCFC stations (depending on station spacing). In Figure 13 and subsequent similar figures, the yellow buffer represents areas that hypothetically would be served by the proposed DCFC network.

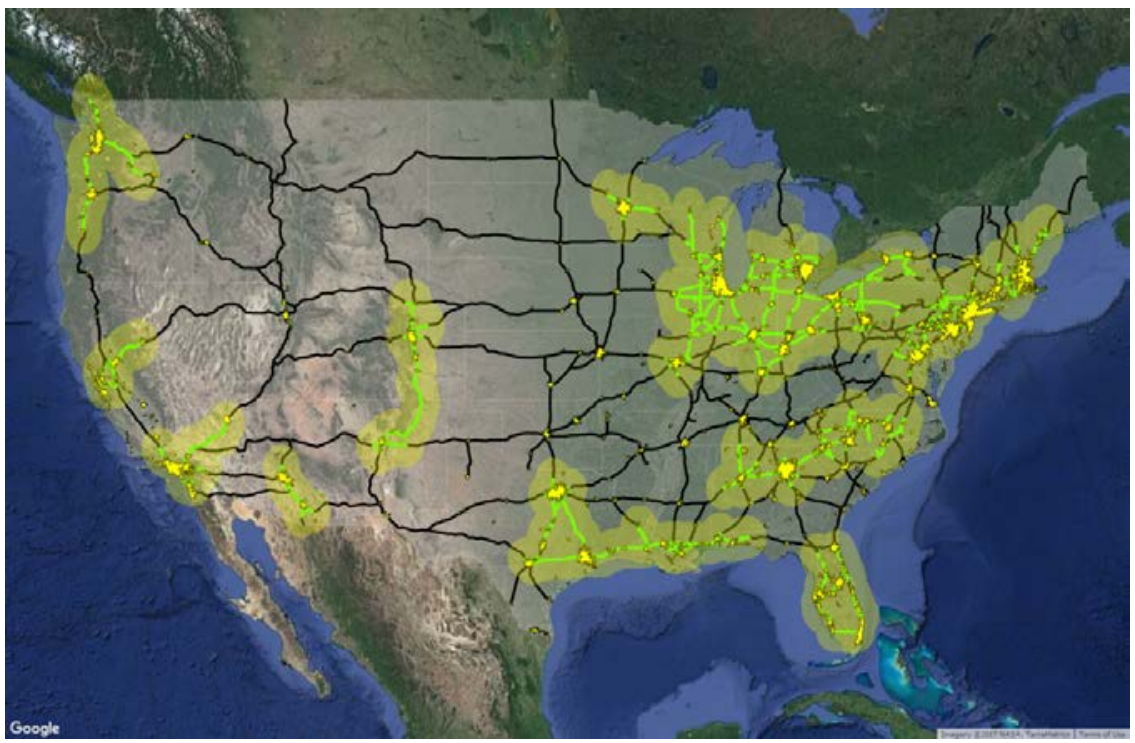

Figure 13. DCFC corridors providing coverage to intra-mega-region travel (70-mile radius yellow buffer approximates areas that would be served by the proposed DCFC network).

(Satellite imagery credit: (c) 2017 Google, Map Data @ 2017 Tele Atlas) 


\subsubsection{DOT Alternative Fuel Corridors (Scenario 2)}

The DOT Alternative Fuel Corridor Map for PEVs, shown in Figure 14, is also proposed as a scenario for a hypothetical DCFC network along U.S. highways (DOT 2017a). DOT has designated national PEV charging corridors in strategic locations along major highways to improve the mobility of electric vehicles (DOT 2017a). These corridors were nominated by state and local officials and elaborated in partnership with industry stakeholders. Every 5 years, DOT will issue a report reviewing charging and fueling infrastructure, analyzing standardization needs for fuel providers and purchasers, and reestablishing the goal of achieving strategic installation of fueling infrastructure in each corridor. Providing coverage for PEV charging along Interstates designated in the DOT Alternative Fuel Map would result in the DCFC network shown in Figure 15, encompassing 122 to 306 DCFC stations (depending on station spacing).

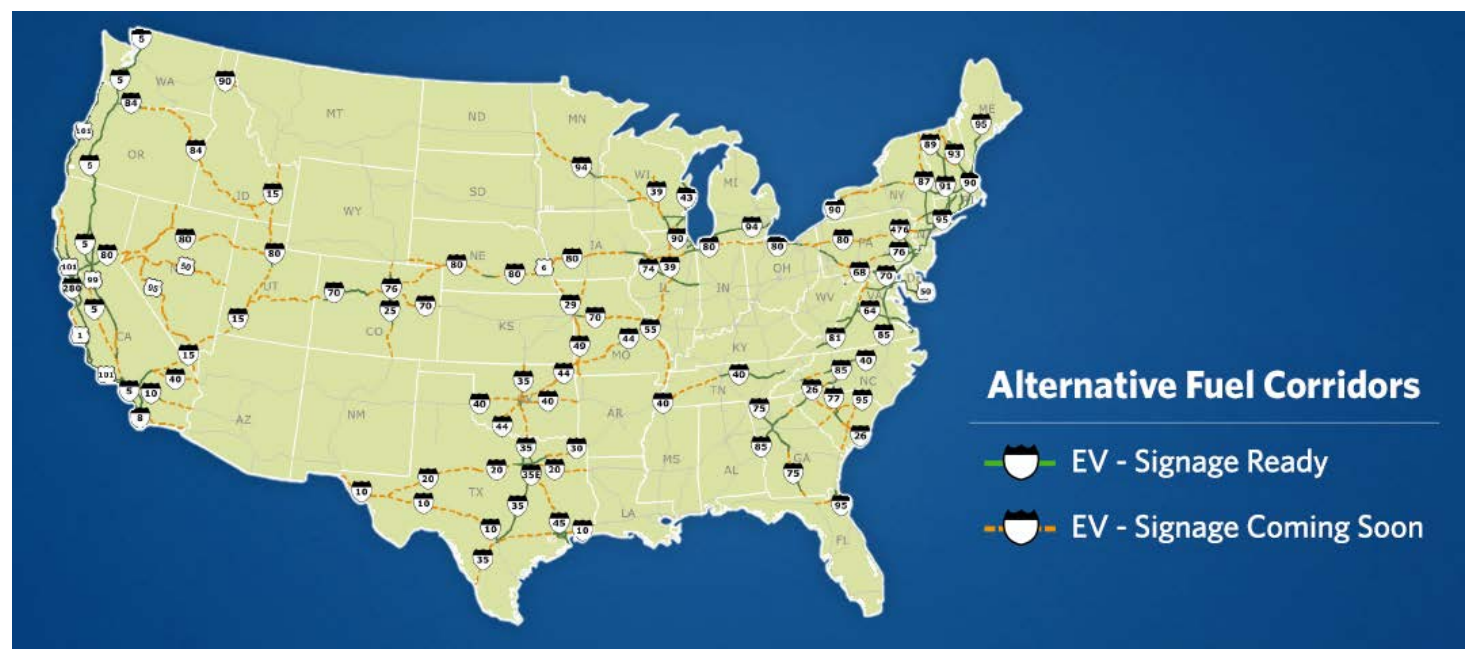

Figure 14. PEV Alternative Fuel Corridors as designated by DOT Alternative Fuel Corridor Map

(DOT 2017a)

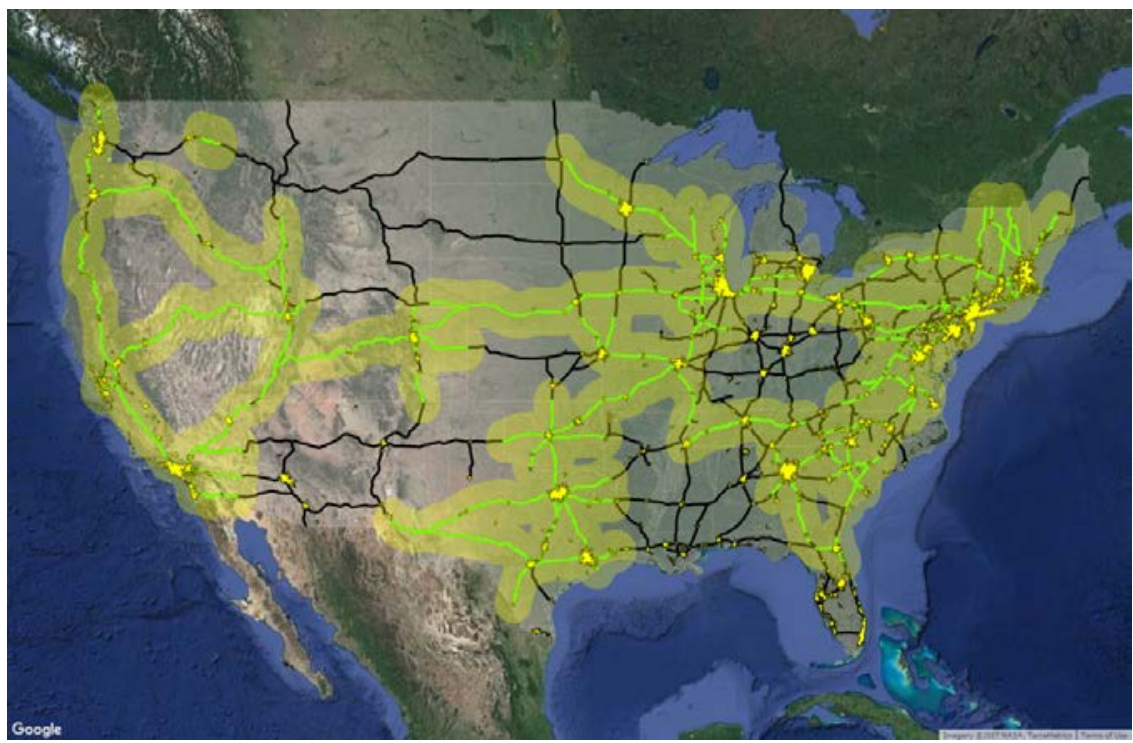

Figure 15. DCFC corridors providing coverage as designated by the DOT Alternative Fuel Corridor Map (DOT 2017a) (70mile radius yellow buffer approximates areas that would be served by the proposed DCFC network).

(Satellite imagery credit: (c) 2017 Google, Map Data @ 2017 Tele Atlas) 


\subsubsection{Highway Performance Monitoring System (Scenario 3)}

The HPMS is a freely available national-level data set that provides a wide array of detailed information on the nation's highways (DOT 2017b). The HPMS contains information on most public roads as well as a combination of measured and estimated annual averaged daily traffic volumes. The latter is highly valuable for infrastructure planning purposes, because it enables traffic-based prioritization. Figure 16, in which line thickness is proportional to average traffic volume, shows that most road traffic is concentrated around major urban areas near the coasts and in the Midwest and South Central regions.

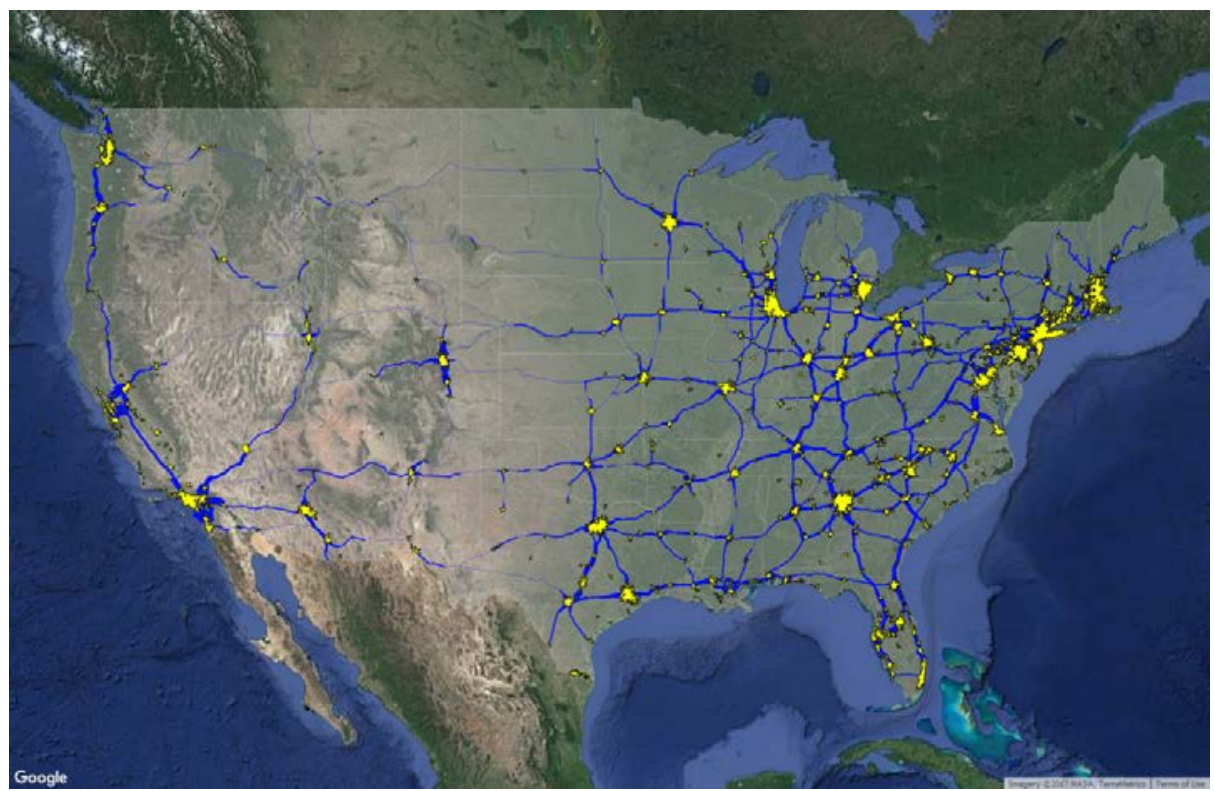

Figure 16. U.S. Interstate Highway corridors. Line thickness is proportional to HPMS average daily traffic.

(Satellite imagery credit: @ 2017 Google, Map Data @ 2017 Tele Atlas)

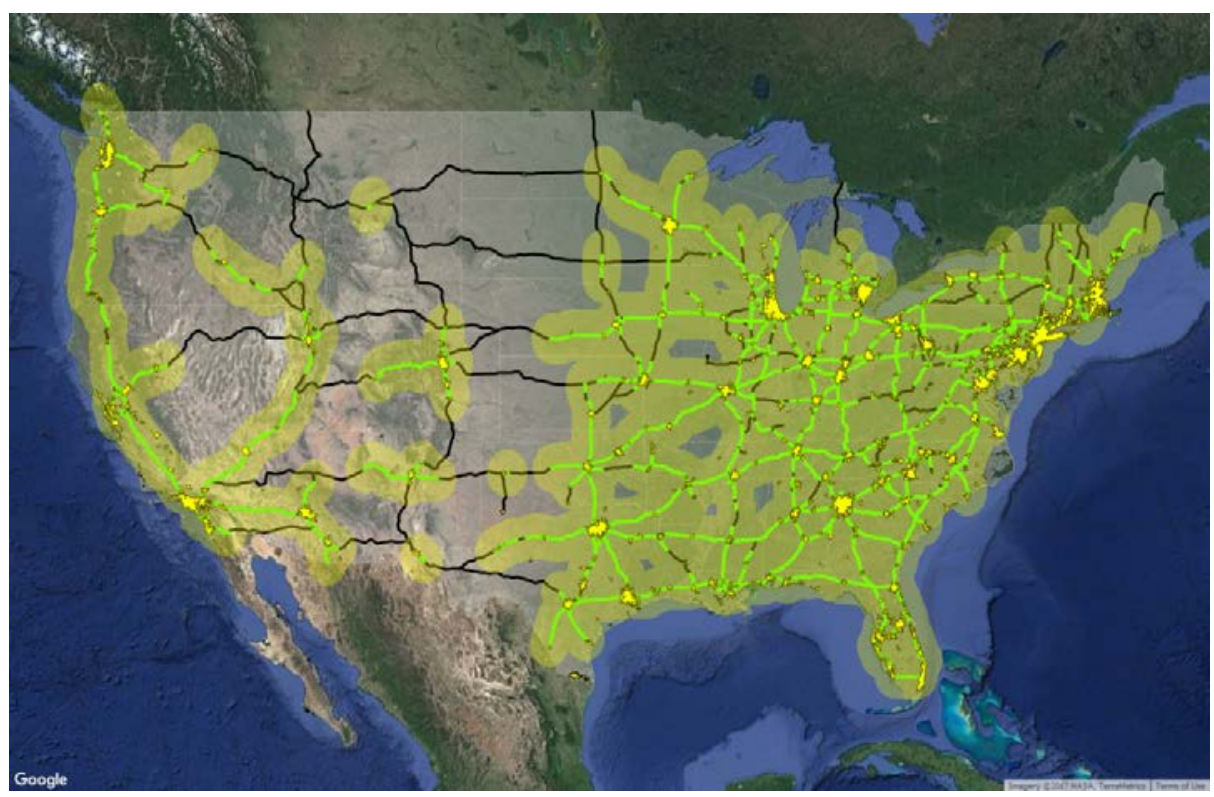

Figure 17. DCFC corridors providing coverage to the top $80 \%$ of HPMS annual average daily traffic (70-mile radius yellow buffer approximates areas that would be served by the proposed DCFC network).

(Satellite imagery credit: @ 2017 Google, Map Data @ 2017 Tele Atlas) 
Providing coverage to the corridors capturing $80 \%$ of the traffic volume of the HPMS corridors would result in the DCFC network shown in Figure 17, encompassing 212 to 530 DCFC stations (depending on station spacing). Although it provides excellent coverage in the eastern half of the country and on the west coast, it does not enable cross-country travel. Another shortcoming of this network is that the total traffic volumes reported by HPMS are dominated by short-distance, routine commuting trips, which are unlikely to require DCFC. To address this shortcoming, another travel data set is investigated, as described in the following section.

\subsubsection{Traveler Analysis Framework (Scenario 4)}

Because it is impossible to single out LDTs from overall traffic volume, the FHWA created a synthetic data set to estimate long-distance passenger travel. FHWA's TAF was modeled using a variety of predictors, such as population and economic activity, and calibrated to a large travel survey (FHWA 2013). TAF consists of a set of county-to-county trip tables for long-distance passenger trips (defined as trips longer than 100 miles) by automobile, bus, air, and rail. The TAF projects person-trip flows for the base year (2008) and for 2040, shown in Figure 18. This data set is valuable because it enables isolation of LDTs, which are typically difficult to isolate from standard single-day travel surveys owing to the relatively low frequency of such travel events. Isolating long-distance travel is of particular importance in the analysis of charging stations along intercity corridors.
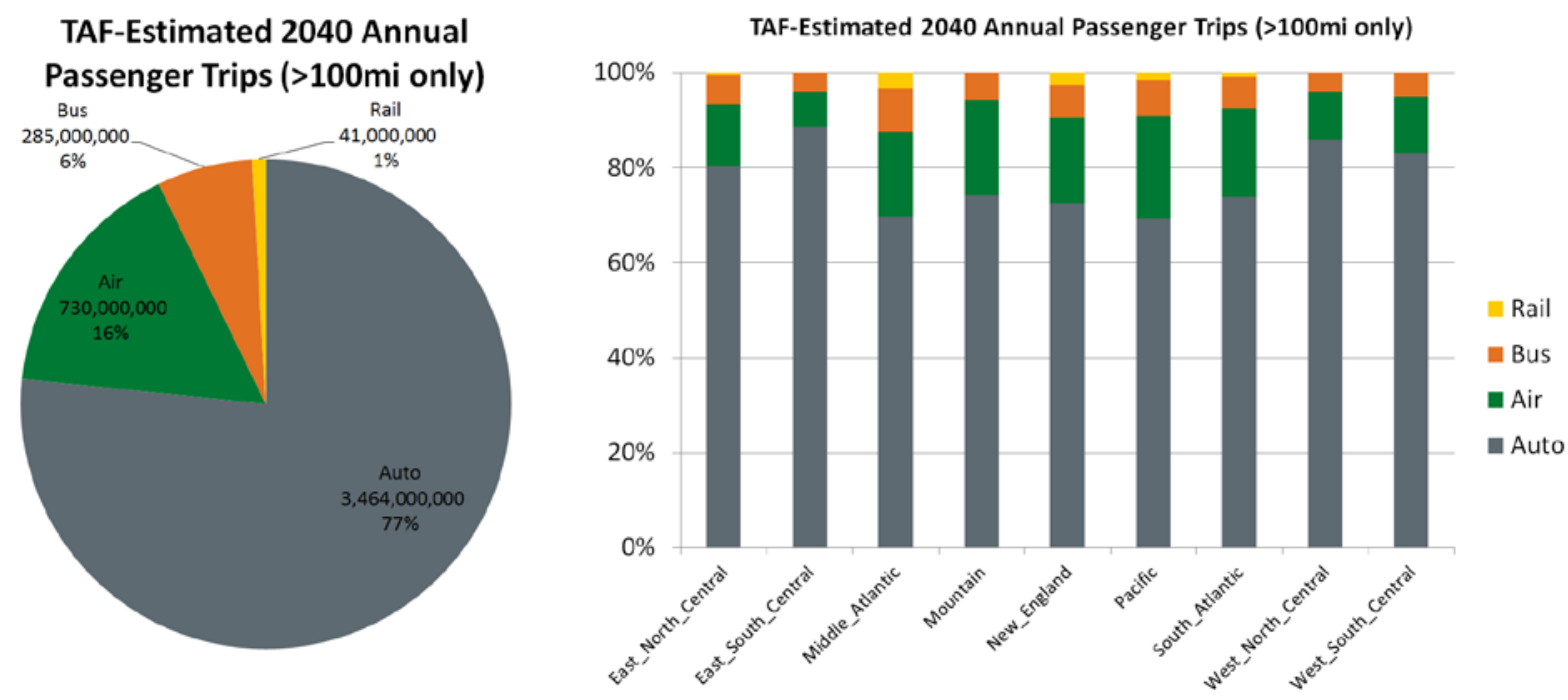

Figure 18. TAF summary statistics

Data from (FHWA 2013)

Figure 19 provides a visualization of the qualitative trip differences between travel modes. Air travel is the dominant mode for very long, cross-country trips. Bus and auto trips are mainly intra-regional, whereas passenger rail travel is restricted to a few routes where railways are available. 

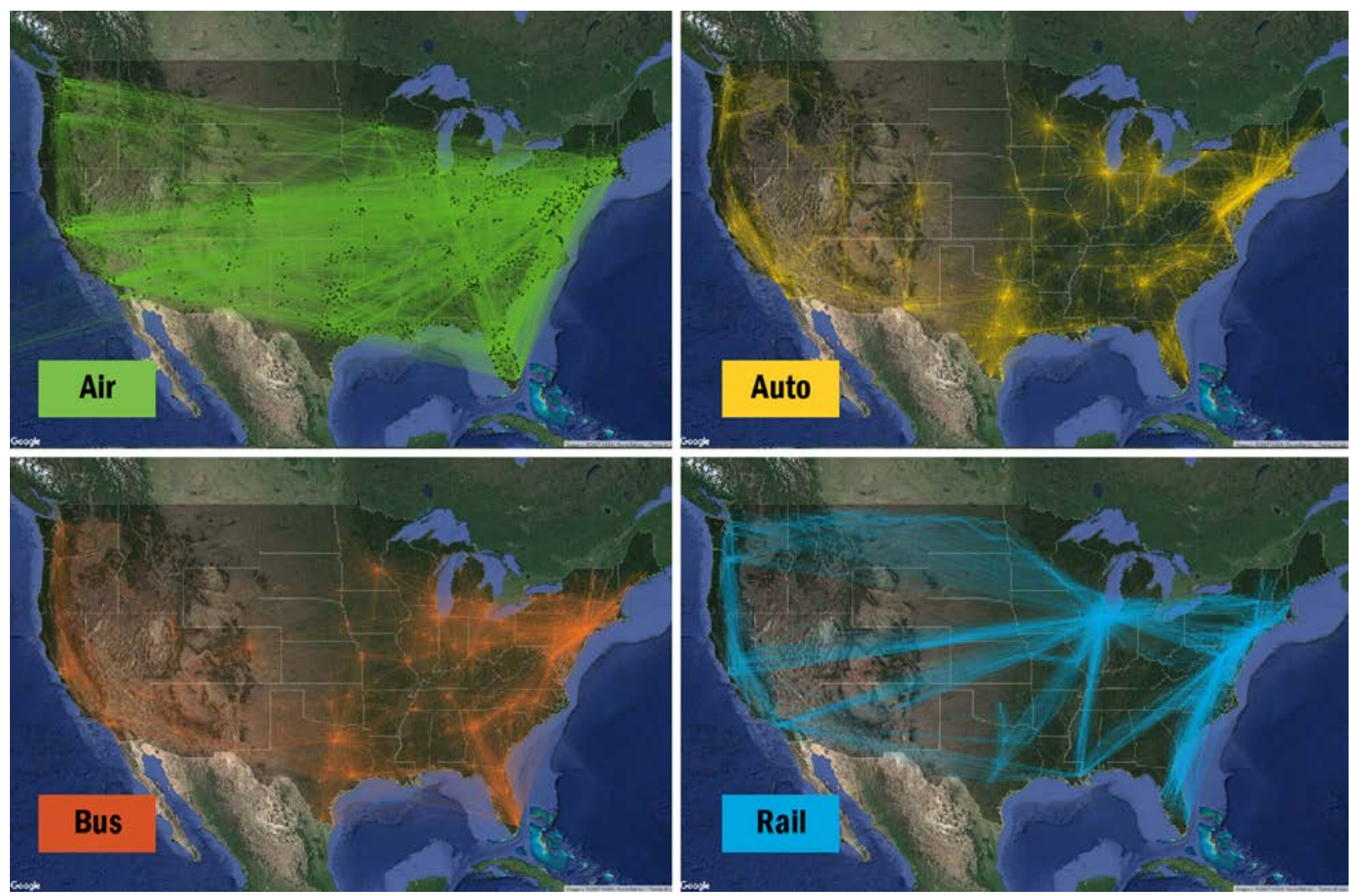

Figure 19. TAF long-distance travel origin-destination pairs by mode; only top $10 \%$ visualized here for clarity.

(Satellite imagery credit: @ 2017 Google, Map Data @ 2017 Tele Atlas) Data from FHWA (2013)

The county-level resolution of TAF is highly valuable for long-distance traffic volume estimation, but it is too granular for meaningful visualization. Aggregating TAF data at the census division level, shown in Figure 20, reveals deep insights into intra- and inter-regional travel for different modes. A chord diagram (Krzywinski et al. 2009) provides a visually compelling way to visualize the travel volumes within and between regions. In such a diagram, the outermost band displays the relative share of trips originating from or ending in a given region. The innermost band shows the absolute volume in million passenger-trips per year. Finally, the chords connecting two regions are sized according to the volume of travel between them. Figure 21 shows an enlarged image of the TAF auto routes (top 10\% of origin-destination pairs), and Figure 22 shows a chord diagram for the automobile TAF data set (top 10\% of origin-destination pairs) by Census Division. Results in Figure 22 show that the South Atlantic, West South Central, and Pacific regions together account for nearly half the nation's annual long-distance auto passenger trips. In addition, more than $80 \%$ of trips taking place in the Pacific division are within that division, whereas most LDTs in the East South Central division connect it with neighboring divisions. 


\section{U.S. Census Divisions}

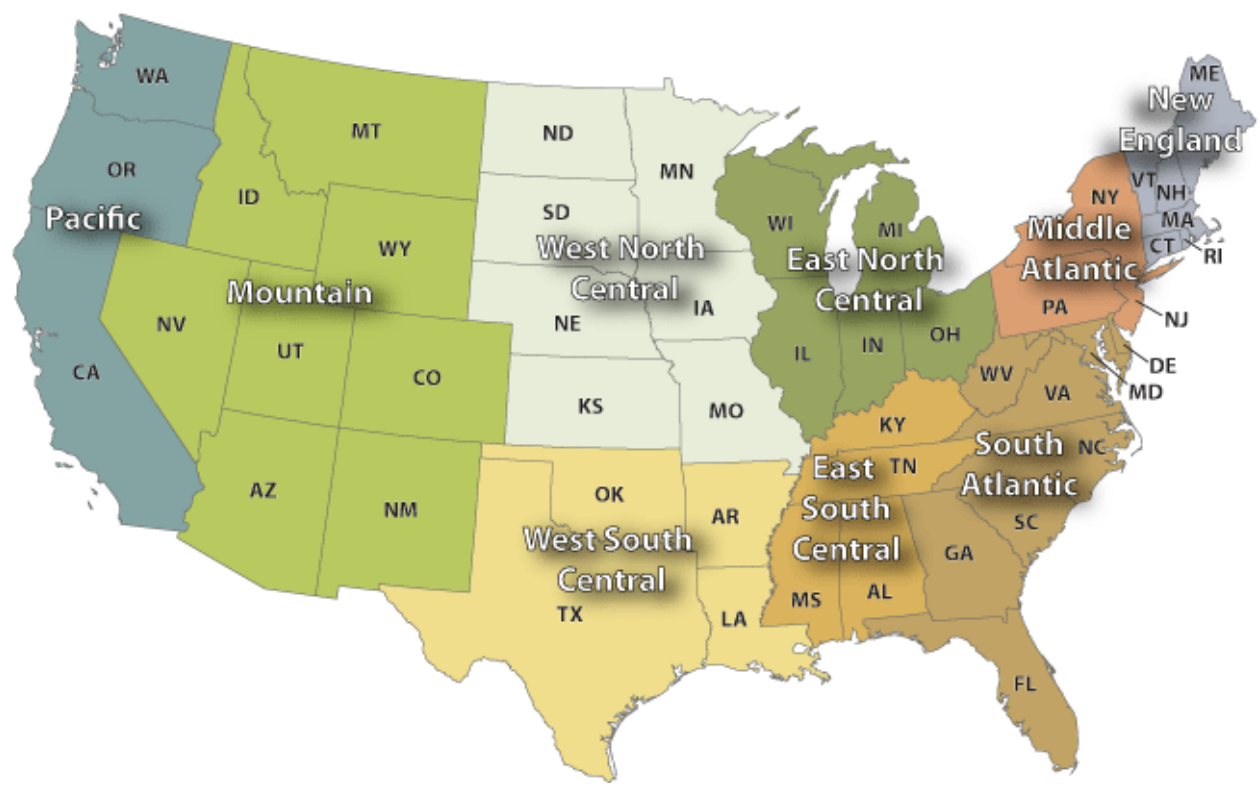

Figure 20. Map of U.S. Census divisions

(National Oceanic and Atmospheric Administration 2017)

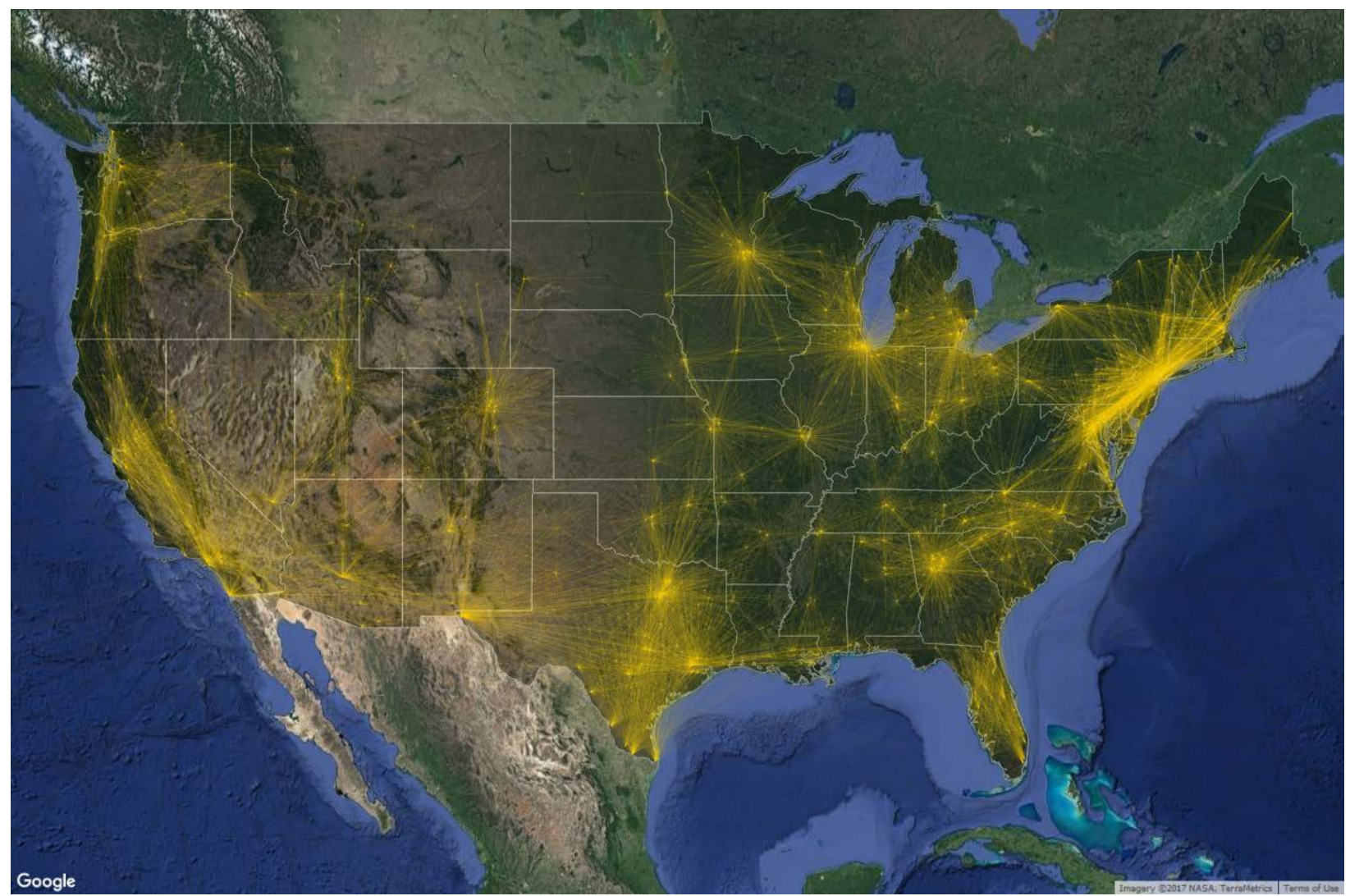

Figure 21. TAF long-distance auto passenger trip origin-destination pairs; only top $10 \%$ visualized here for clarity.

(Satellite imagery credit: @ 2017 Google, Map Data @ 2017 Tele Atlas) Data from FHWA (2013) 


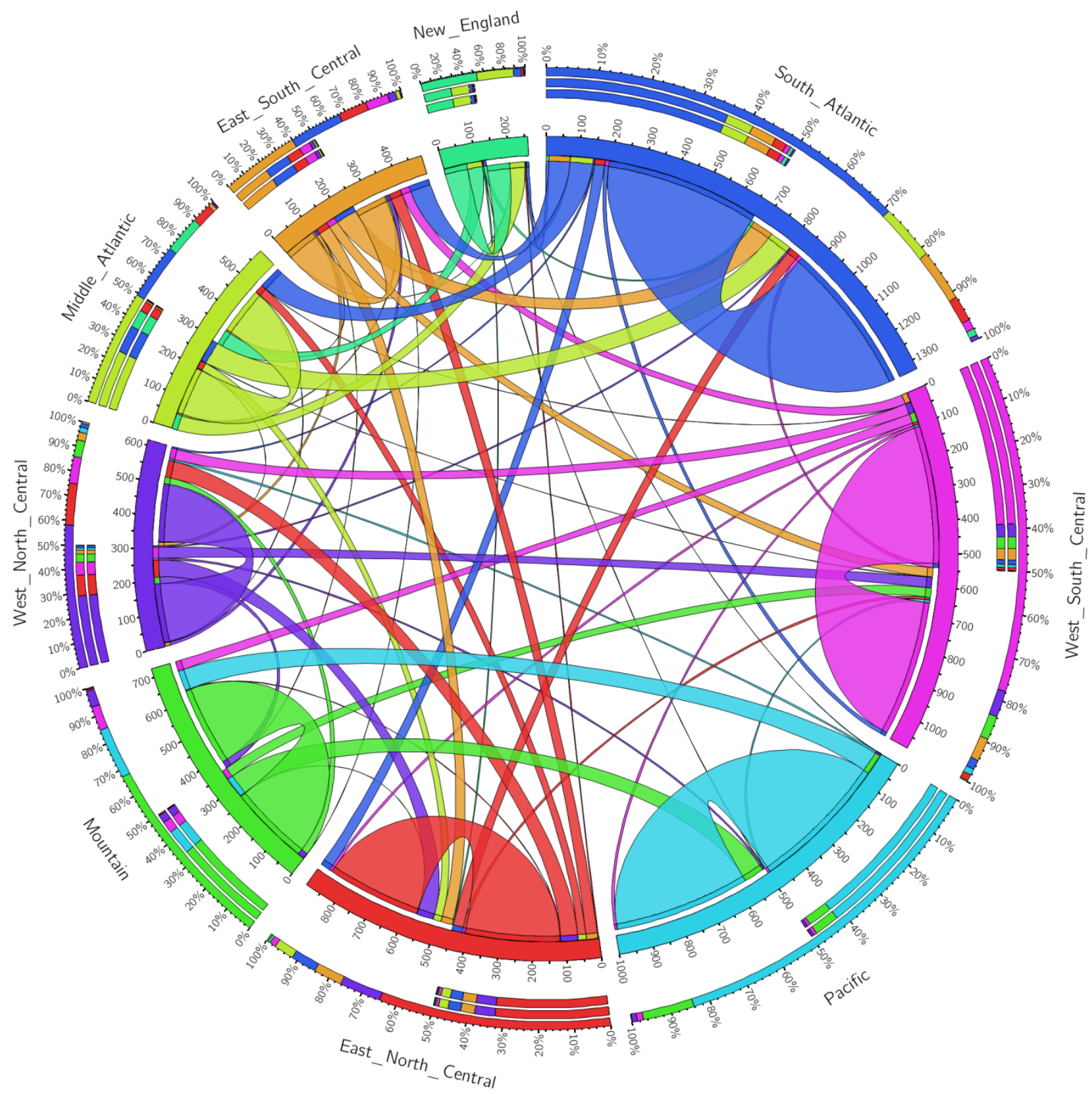

Figure 22. Chord diagram generated using TAF long-distance auto passenger travel volume

(FHWA 2013)

To estimate long-distance travel volumes by highway corridor, the county-level origin-destination pairs in the TAF data set were routed onto the interstate network using a web-based mapping service that seeks to minimize travel time, the MapQuest Directions API (MapQuest 2017). Use of the MapQuest API is intended to approximate routes consumers actually take when completing LDTs. Figure 23 shows the results of this routing process where the thickness of each corridor corresponds to the total number of estimated annual LDTs on that corridor. Providing coverage to the corridors capturing $80 \%$ of the traffic volume of the TAF corridors would result in the DCFC network shown in Figure 24, encompassing 174 to 436 DCFC stations (depending on station spacing). 


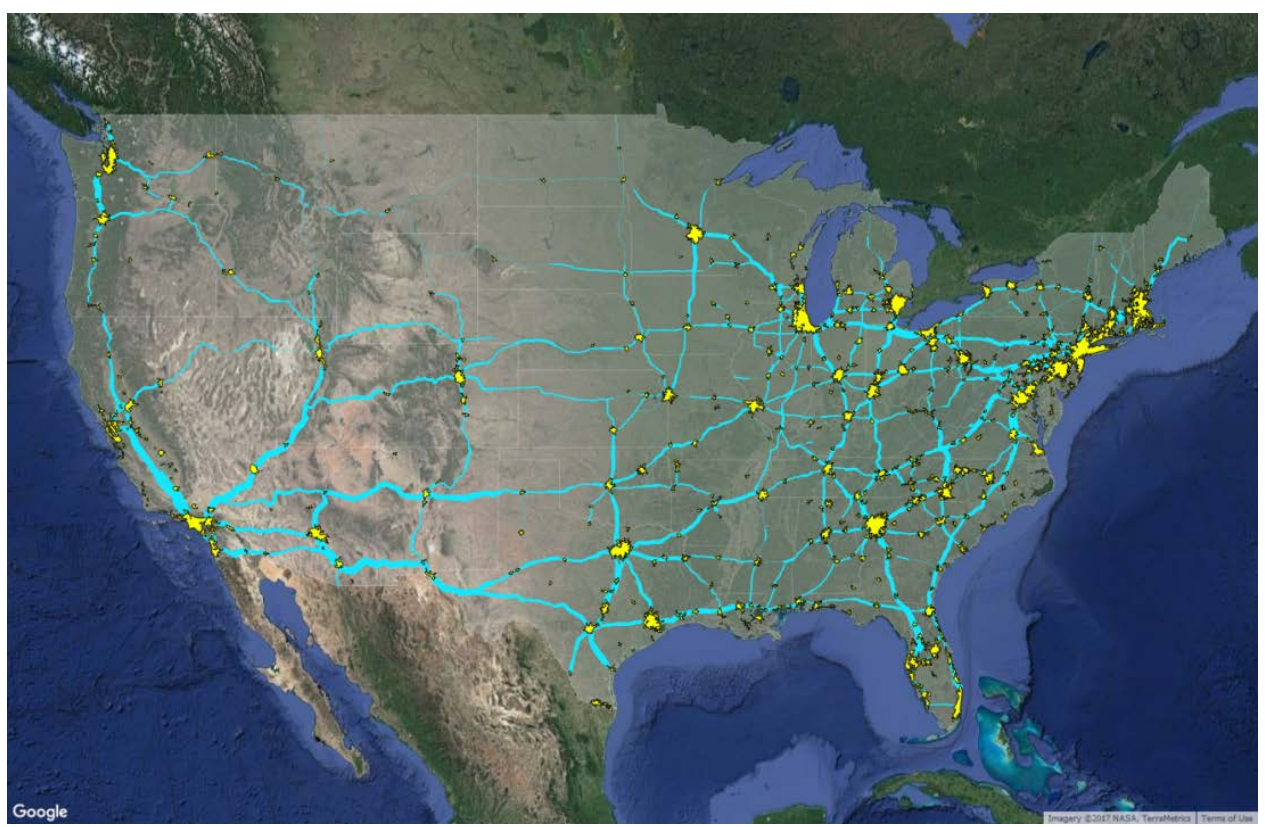

Figure 23. U.S. Interstate Highway corridors. Line thickness proportional to TAF Iong-distance auto traffic.

(Satellite imagery credit: @ 2017 Google, Map Data @ 2017 Tele Atlas)

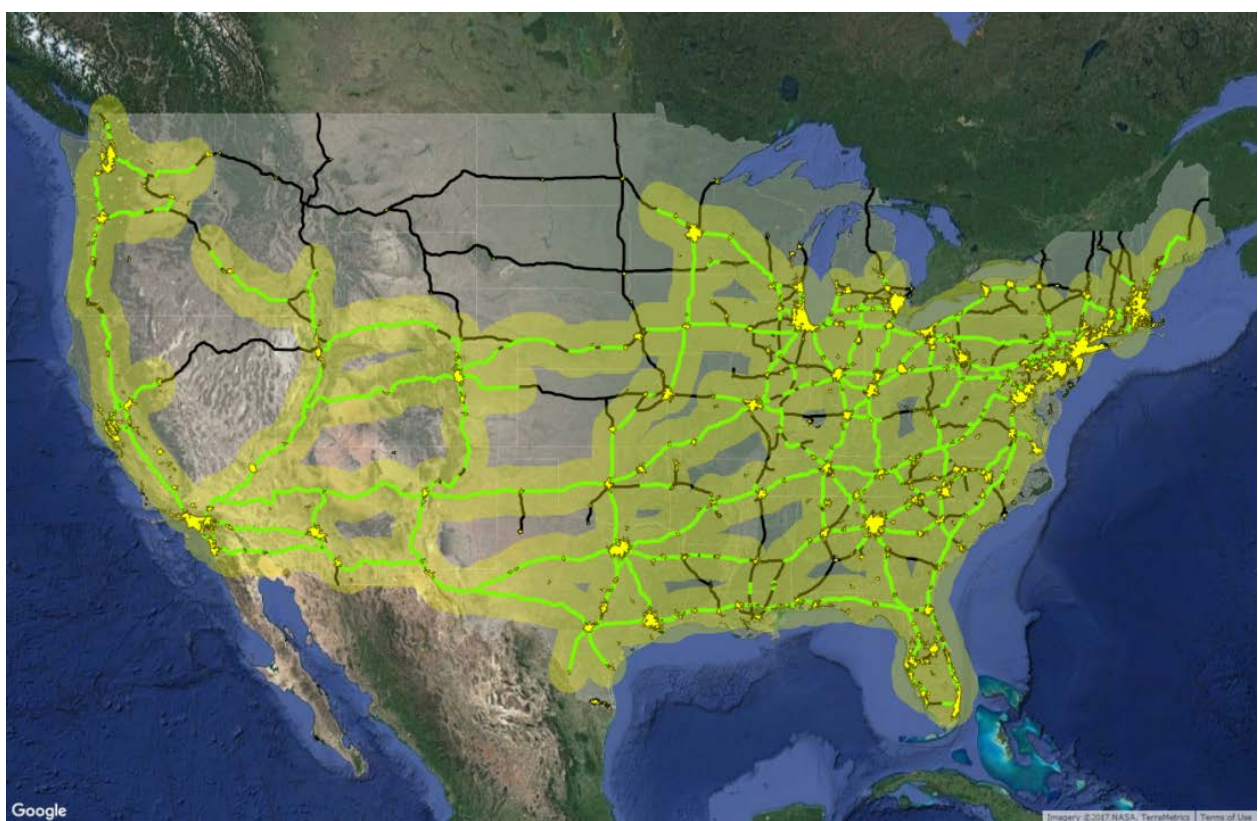

Figure 24. DCFC corridors providing coverage to the top $80 \%$ of the TAF long-distance auto traffic (FHWA 2013) (70-mile radius yellow buffer approximates areas that would be served by the proposed DCFC network).

(Satellite imagery credit: (C) 2017 Google, Map Data (C) 2017 Tele Atlas)

NREL's processing of TAF data onto the interstate network was compared against the HPMS data. Figure 25 shows NREL-derived TAF auto volume as a percentage of HPMS volume; green corridors have low TAF percentages and are primarily composed of short-distance trips, and magenta corridors have high TAF percentages and are primarily composed of LDTs. This map suggests that the majority of Interstate traffic in the Southwest consists of long distance (i.e., >100 miles) driving trips, whereas LDTs represent less than 20\% of total traffic volume in most of the eastern half of the country. The fact that TAF-derived Interstate volumes 
are a fraction of HPMS-estimated volumes helps to establish confidence that the corridor volumes derived from $\mathrm{TAF}$ are within a reasonable range.
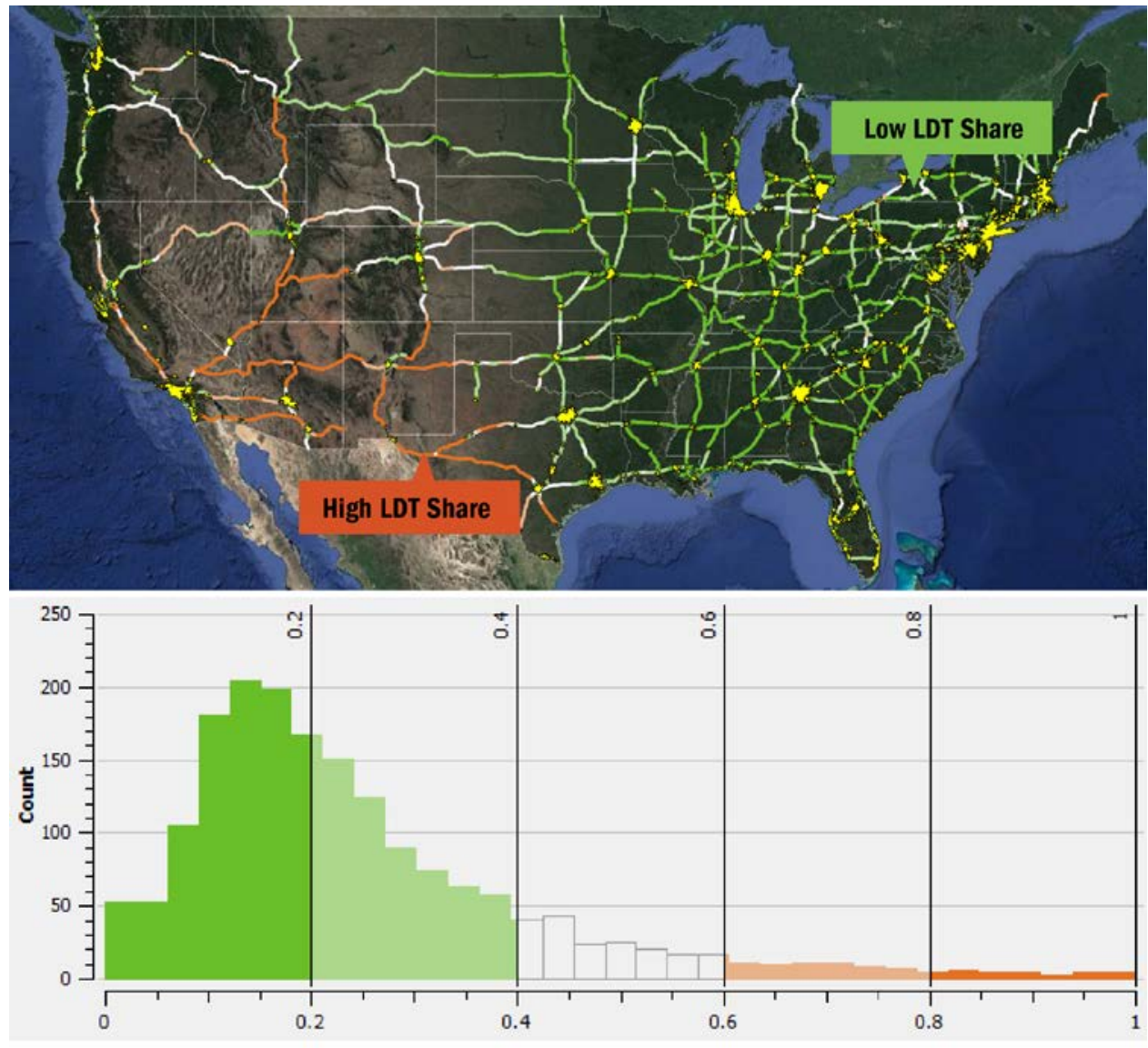

LDT Share (TAF volume/HPMS volume)

Figure 25. Comparison of TAF and HPMS volumes (color scale proportional to TAF:HPMS ratio). (Satellite imagery credit: (c 2017 Google, Map Data @ 2017 Tele Atlas) 


\subsubsection{Station Spacing}

Another important consideration for planning effective DCFC networks is the spacing between two consecutive DCFC stations, here estimated based on the effective BEV range. Although the U.S.

Environmental Protection Agency-rated range (Fueleconomy.gov 2017) provides a good estimate of vehicle ranges under typical driving conditions, the effective range often varies based on ambient and road conditions as well as driving style (Lohse-Busch et al. 2013, Neubauer and Wood, 2013). Moreover, battery capacity tends to slowly degrade over time, negatively affecting the real driving range of BEVs (Shirk and Wishart 2015, Neubauer and Wood 2015). In addition to technical considerations limiting the effective range of BEVs, consumer travel logistics and convenience play a significant role in how far a BEV driver is willing to drive on a single charge. Drivers are typically reluctant to wait until their battery is completely drained before recharging, resulting in an "arrival allowance." Moreover, the rate of charge at DCFC stations tends to decrease toward high battery state-of-charge levels owing to battery safety considerations, and consumers are likely to depart a DCFC station before a BEV battery is fully charged to reduce their time spent charging, resulting in an "early departure penalty." To capture these behavioral effects, it is assumed that under realistic conditions a BEV will be recharged with an arrival allowance of 30 miles of remaining range, and it will depart the DCFC station early with only $80 \%$ of charge. Figure 26 summarizes the factors determining the effective BEV range considered in this study.

Three scenarios are proposed for nominal station spacing (100, 70, and 40 miles), providing various levels of support for longer- and shorter-range BEVs. These station spacing scenarios are believed to cover the range of nominal station spacing ranges being pursued by industry. Electrify America has announced an average station spacing of 70 miles for its DCFC corridor network (Electrify America 2017). This spacing is almost identical to the Tesla supercharger network; nearest-neighbor analysis was performed on the Tesla Supercharger station locations publically available in the Alternative Fuels Data Center data set (DOE 2017b), revealing an average Tesla station spacing of 67 miles. Additionally, Navigant Research proposes two station spacing scenarios in its DC Charging Map for the United States: 130 miles for long-range BEVs, and 75 miles to also support short-range BEVs (Navigant Research 2016). 


\section{BEV Single-Charge Driving Range \& DCFC Spacing Considerations}

Rated driving range is intended to represent the distance a fully charged BEV can cover until fully depleted under typical conditions. However, it is well documented that real-world range can be significantly different depending on driving speed and aggression, use of cabin climate control, and long-term battery degradation. Thus, rated single-charge driving range is a poor yardstick for designing a robust DCFC network that empowers consumers to drive BEVs on long distance trips in a variety of traffic and weather conditions (as they currently do with conventional vehicles). This study proposes a set of consumer considerations (i.e., arrival allowance and early departure penalty) that can be taken in concert with variability of single-charge driving range to estimate station spacing for a reliable DCFC network.

\section{DCFC Station Spacing Considerations}

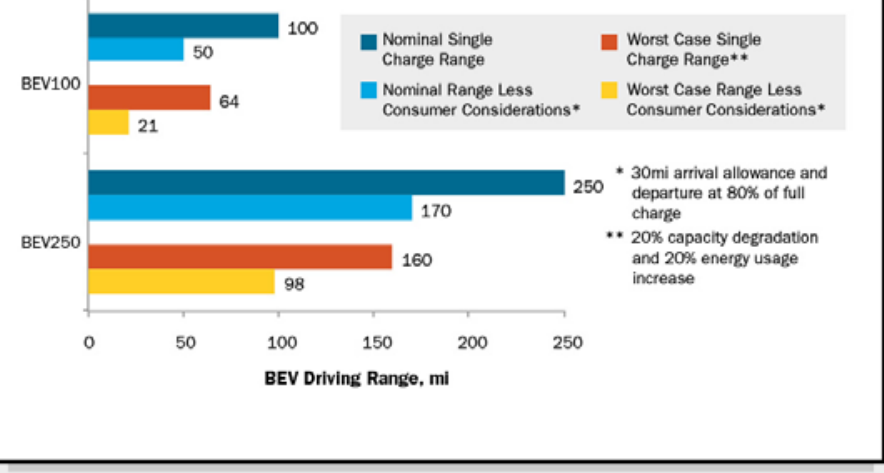

\section{Arrival Allowance}

Assume consumers will prefer to stop at DCFC stations well before fully depleting their BEV range. This project assumes a typical arrival allowance of 30 miles.

\section{Early Departure Penalty}

Due to battery limitations, BEVs typically experience reduced DCFC rates near top of charge. Consequently, consumers are likely to depart DCFC stations prior to receiving a full charge. This project assumes consumers will typically depart DCFC stations with $80 \%$ of a full charge.

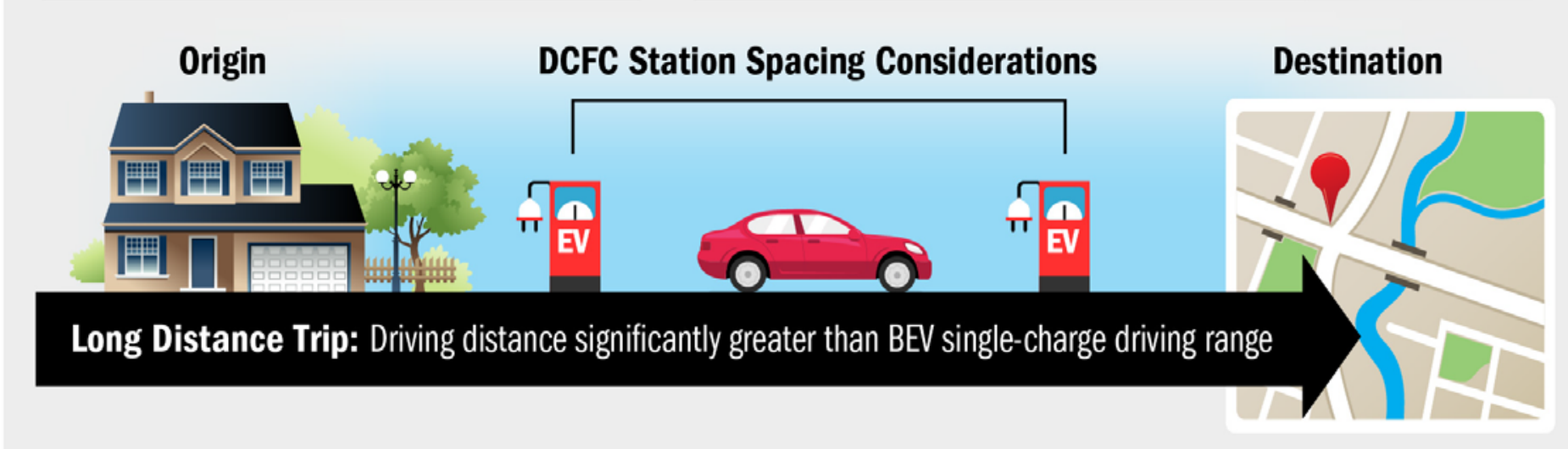

Figure 26. Station spacing methodology proposed in this study. 


\subsection{DCFC Interstate Corridor Demand Calculations}

The number of stations required to cover the proposed U.S. corridor network has been determined for a variety of coverage and station spacing scenarios. The utilization of these stations, however, will vary significantly depending on their location and on the size of the regional and national PEV markets. This section estimates the number of plugs required at each station to adequately respond to corridor charging demand as the PEV market evolves over time.

Plug count per station estimates are calculated for each corridor station as a function of DCFC charging time, BEV adoption level, peak traffic volume, and station spacing. This model assumes that faster DCFC charging times will decrease plug count requirements (faster vehicle turnover), that high peak traffic volumes from $\mathrm{BEV}$ s on long distance trips will increase plug count requirements (more vehicles to serve at individual stations), and that decreasing station spacing will decrease plug count requirements per station (allowing consumers to occasionally skip stations while on long distance trips).

\subsubsection{DCFC Power Level}

Extreme fast charging, with power levels from $120 \mathrm{~kW}$ up to $400 \mathrm{~kW}$, has gained significant interest in recent years. These very high charge rates could provide 200 miles of range in 20 minutes for a $150-\mathrm{kW}$ charger and under 10 minutes for a 400-kW charger, making BEVs more attractive to customers. The Tesla supercharger network currently provides up to $120 \mathrm{~kW}$ of power, while most other installed DCFC stations are currently rated at $50 \mathrm{~kW}$.

Higher DCFC power levels are modeled as lowering the number of plugs per station required to support longdistance travel in BEVs: faster turnover of vehicles warrants less redundancy in terms of plugs per station. This report considers $150 \mathrm{~kW}$ per plug DCFC power levels providing a 20-minute charge to a BEV250 in the central scenario, with sensitivities explored between 10 and 30 minutes per fast charge event. Additionally, assumptions from Section 0 are carried over, namely that BEVs would on average arrive with 30 miles of range remaining and depart with $80 \%$ of a full charge.

\subsubsection{TAF Volumes}

Annualized estimates of LDT volume were developed for each segment of the corridor network using TAF projections (interpolated between 2008 and 2040 to represent 2030 long distance traffic volumes). Person-trips were converted to vehicle-trips using an average occupancy factor of 3.0, in accordance with the TAF documentation (FHWA 2013); note that the estimated occupancy factor on long-distance auto trips is significantly higher than urban occupancy factors, which include large shares of single-occupancy vehicles.

FHWA's Traffic Monitoring Analysis System was used to estimate peak traffic ratios along Interstate corridors (FHWA 2017b). To estimate charging requirements for DCFC stations along corridors, the ratio between peak and average traffic volume was calculated for interstate corridor traffic count stations in California; California represents the largest PEV market, and results have been spot checked against other states for representativeness.

The peak hourly volume at the average Interstate corridor traffic count station in California was found to be 4.5 times greater than the annual average volume. Sizing for peak traffic using this factor would imply near elimination of queueing and potentially oversize the system. As such, a $90^{\text {th }}$ percentile value traffic volume was found to be 2.3 times greater than the annual average volume. The peak factor of 2.3 is used in this work.

\subsubsection{Results and Discussion}

Plug requirements from individual corridors are aggregated to obtain an average number of plugs per DCFC station as a function of station spacing and projected BEV adoption. Figure 27 presents these aggregate results for three market adoption scenarios. They range from two plugs per station at a station spacing of 40 miles and a BEV adoption of 4 million to 12 plugs per station at a station spacing of 100 miles and a BEV adoption of 10 million. Six plugs per station are required for the central values of 70-mile spacing and 7 million BEVs. For 
comparison, Electrify America's plans include five plugs per station with an average station spacing of 70 miles to support a BEV market of up to 10 million vehicles in 2030. Tesla's existing proprietary network features an average of seven plugs per station and a spacing of 67 miles on average.

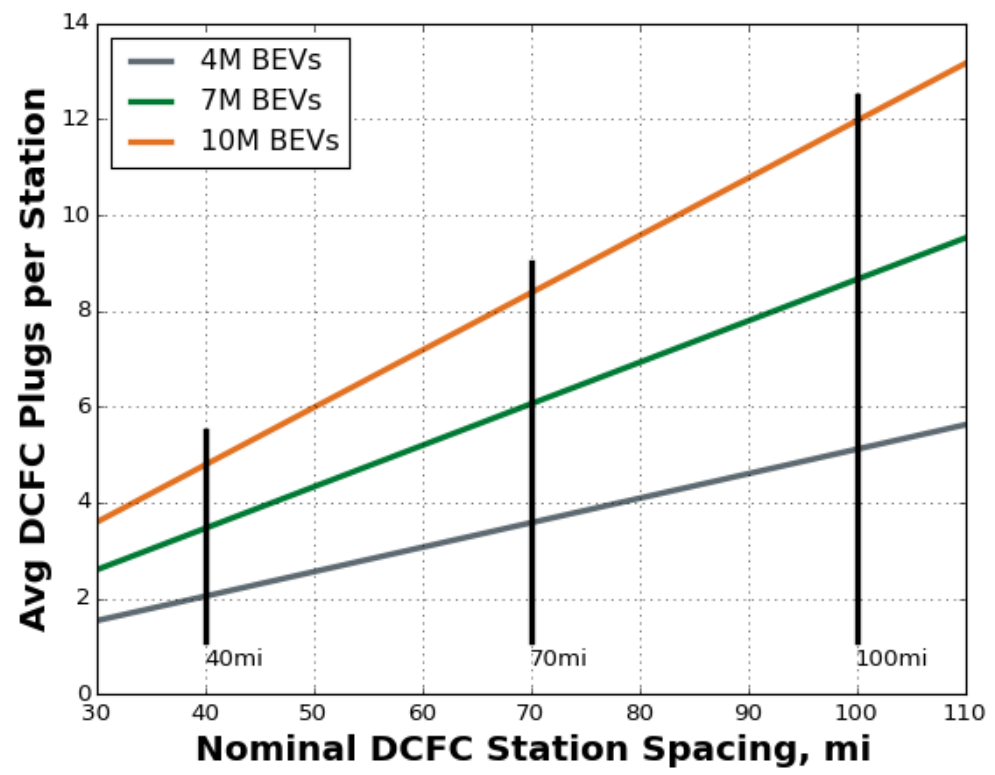

Figure 27. Nationwide corridor DCFC station count versus station spacing, annual average volume.

Plug requirements at individual stations vary based on the long-distance travel associated with a given corridor. Figure 28 illustrates this variance using the central scenario as an illustrative example (full interstate coverage, 7 million BEVs, and 70 mile average station spacing). The majority of hypothetical DCFC stations are located on lower-traffic corridors for coverage purposes, some featuring plug requirements that are only $10 \%$ of the average station's requirements (average station requiring 6 plugs to meet peak demand).

Conversely, a minority of stations on very high traffic corridors are expected to require up to $450 \%$ as many plugs as the average station to adequately serve charging demand.

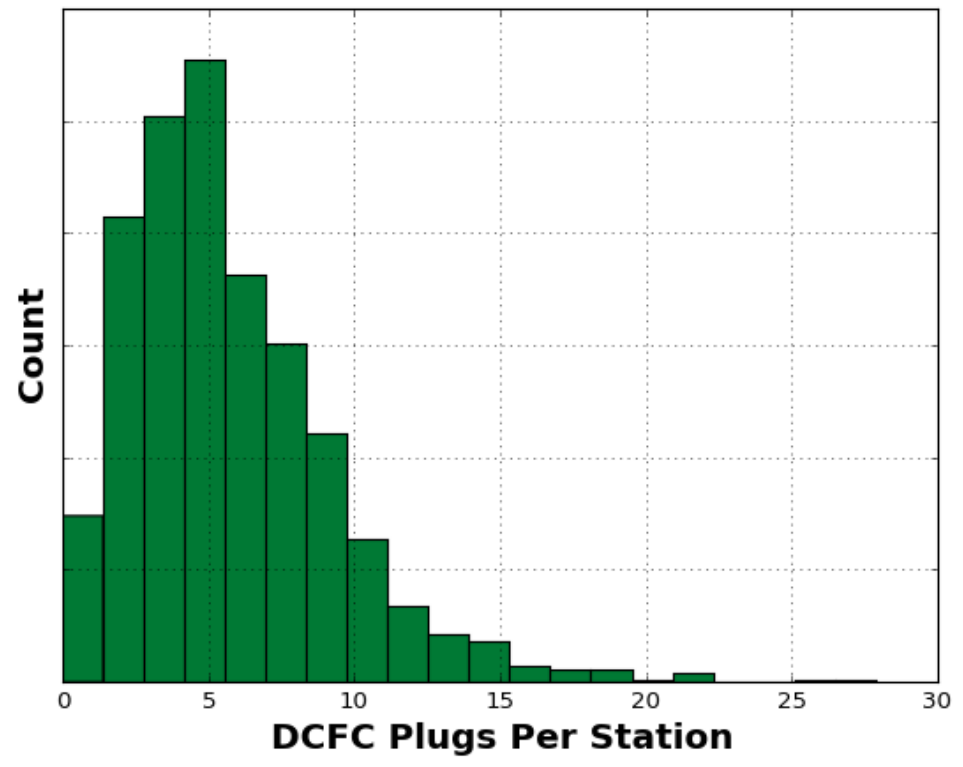

Figure 28. Plug requirement variance between stations. 
Figure 29 puts the results in terms of total station counts and plug counts, and it shows the sensitivity of these counts to the corridor network selected, station spacing, BEV count, and charge time. The station counts chart (at left) illustrates the corridor coverage results from Table 9; because coverage requirements are independent of vehicle penetration, BEV count and charge time have no effect on them. In the plug counts chart (at right), the "network" bar multiplies the plugs per station results from Figure 27 by the mega-region, TAF, and full Interstate scenarios' coverage requirements from Table 9. Assuming an average station spacing of 70 miles and 7 million BEVs, 822 plugs are required in the mega-region scenario, 1,494 in the TAF scenario, and 2,448 in the full Interstate scenario. The full Interstate network is used to explore the remaining sensitivities. National corridor DCFC station estimates range from 285 to 713 for average spacing values from 100 to 40 miles. Notably, national corridor DCFC plug count estimates show no sensitivity to average station spacing between 40 and 100 miles. While both station counts and plugs per station are sensitive to station spacing, they are inversely related (implying conservation of aggregate national demand) and result in no sensitivity between average station spacing and national corridor DCFC plug count estimates. The effect of the number of BEVs results in plug counts ranging from about 1,461 at 4 million BEVs to 3,419 at 10 million BEVs, under the central network scenario (full Interstate). Finally, charge time sensitivity was explored from 10 to 30 minutes, resulting in national plug counts from 1,236 to 3,709.
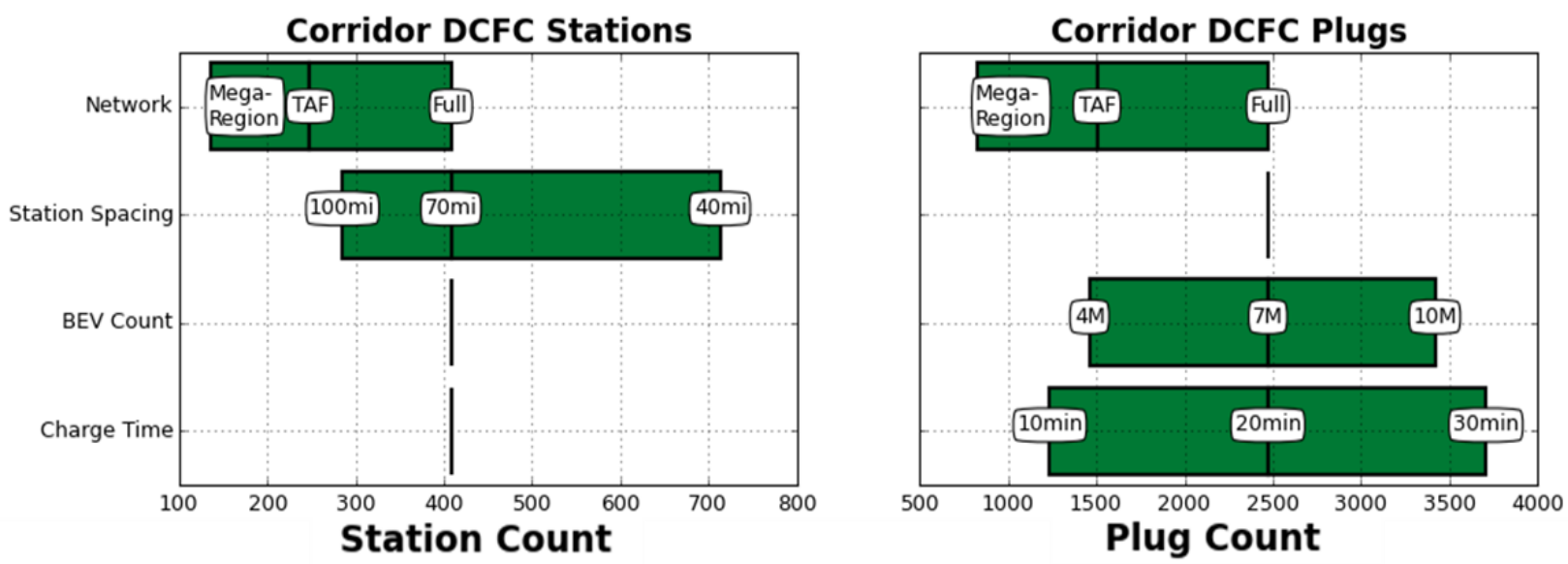

Figure 29. Sensitivity of corridor DCFC station and plug counts to network, station spacing, BEV count, and charge time. 


\subsection{Challenges to Interstate Corridor Charging Infrastructure}

The development of a comprehensive network of corridor DCFC stations presents several challenges, primarily related to sustainable business models, to address the substantial costs associated with deploying and operating a network of DCFC stations (Francfort et al. 2017, Svitak et al. 2017, Melaina et al. 2016, Alternative Energy Systems Consulting 2015) as well as minimizing the impact on the electric grid. Although there appears to be sufficient generation capacity to electrify the U.S. LDV fleet (Denholm and Short 2006, Duvall et al. 2007), large-scale PEV adoption and charging station installations might affect the electric infrastructure in several ways. Some of the long-term impacts are reduction in transformer life expectancy, accelerated wear and tear of feeder networks, power quality considerations, and capacity upgrades at the substation level to handle the incremental charging demand (Green et al. 2011). At the same time, the network of stations could represent a business opportunity for the electric industry, and smart charging could be used to optimize power demand in demand response programs where the DCFC stations vary the timing of their demand to reduce requirements on the electric power generation infrastructure (Muratori and Rizzoni 2016).

Moreover, two geographic challenges are associated with the development of a national network of DCFC stations: 1) availability of commercial land for siting DCFC stations, and 2) proximity of electric substations to the interstate corridor network. These are explored below in a limited geographic information system analysis.

\subsubsection{Retail Land Use Availability}

A publically available land use data set (Conservation Science Partners 2017) with a spatial resolution of 30 meters was used to identify all retail and commercial land parcels in the United States (Theobald 2014). A 1 $\mathrm{km}$ buffer on either side of the interstate corridor network served as a mask to clip the nationwide data set to the immediate vicinity of the highway network. The remaining adjacent retail land use polygons were then consolidated to generate potential candidate sites. The network distance between two potential consecutive sites was calculated by cutting the highway network into smaller segments linking candidate sites to each other, and measuring the length of resulting sub-segments.

Figure 30 shows the resulting national map with the Interstate network colored by the maximum spacing interval between consecutive parcels of commercial land use. Overall, it appears that the frequency of retail sites along the Interstate highway network would not be a significant obstacle to the installation of a national DCFC network along Interstate corridors. The average distance between consecutive parcels of commercial land use was 5.4 miles, and across the entire network of Interstate corridors only $0.8 \%$ features intervals between consecutive commercial land use types of over 50 miles.

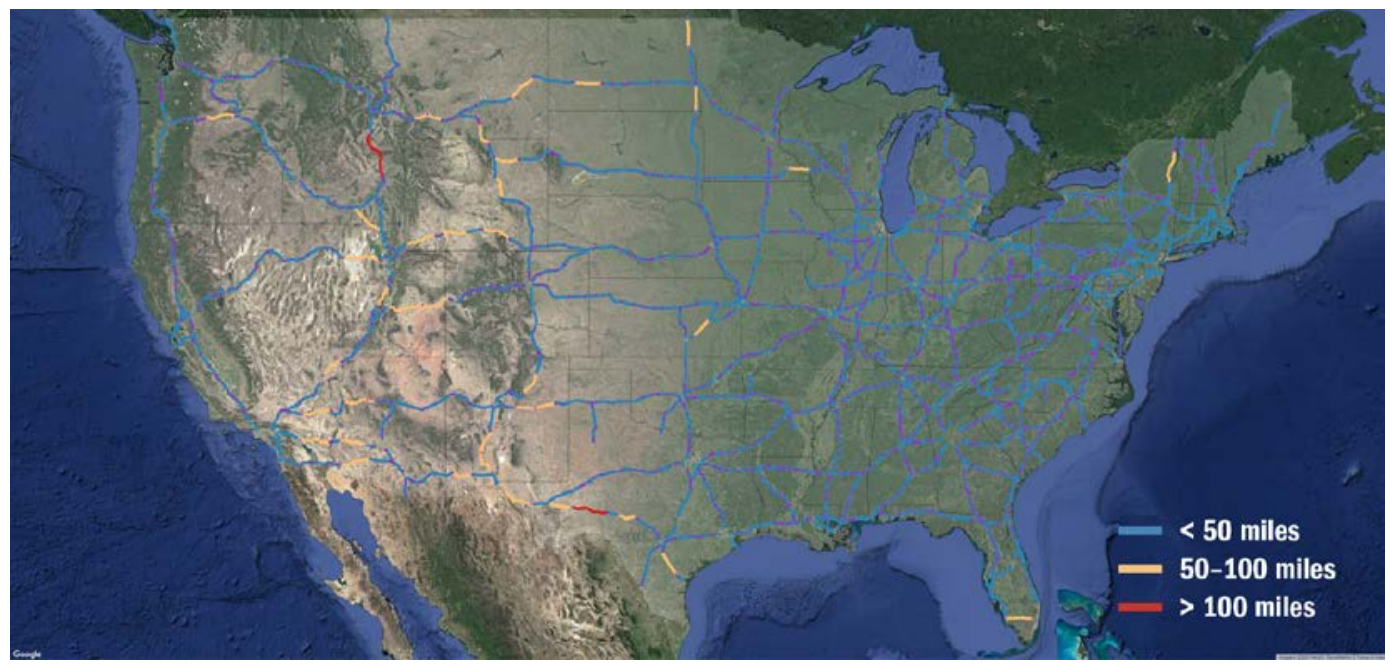

Figure 30. Distance between consecutive candidate retail sites. (Satellite imagery credit: (c) 2017 Google, Map Data @ 2017 Tele Atlas) 


\subsubsection{Existing Electrical Infrastructure: Proximity between Interstate Exits and Electrical Substations}

In order to minimize the capital cost associated with corridor DCFC station installations, it is desirable to locate DCFC stations close to existing electrical substations. A spatial analysis was performed to combine an electrical substation data set to Interstate exits to measure relative proximity between the two. The substation data were extracted from ABB Energy Velocity Suite, (C2017. Results indicate the median distance between a highway exit and the closest electrical substation is 2.2 miles, while the average distance is 2.9 miles. Out of the 11,710 Interstate exits along the entire corridor highway network, only $3 \%$ are farther than 10 miles from the nearest electrical substation, 16\% farther than 5 miles, and 35\% farther than 3 miles. The map in Figure 31 shows that the majority of exits with poor proximity to electrical substations are located in the western part of the United States. Overall, it appears that the frequency of retail sites along the interstate highway network would not be a significant obstacle to the installation of a national DCFC network along interstate corridors.

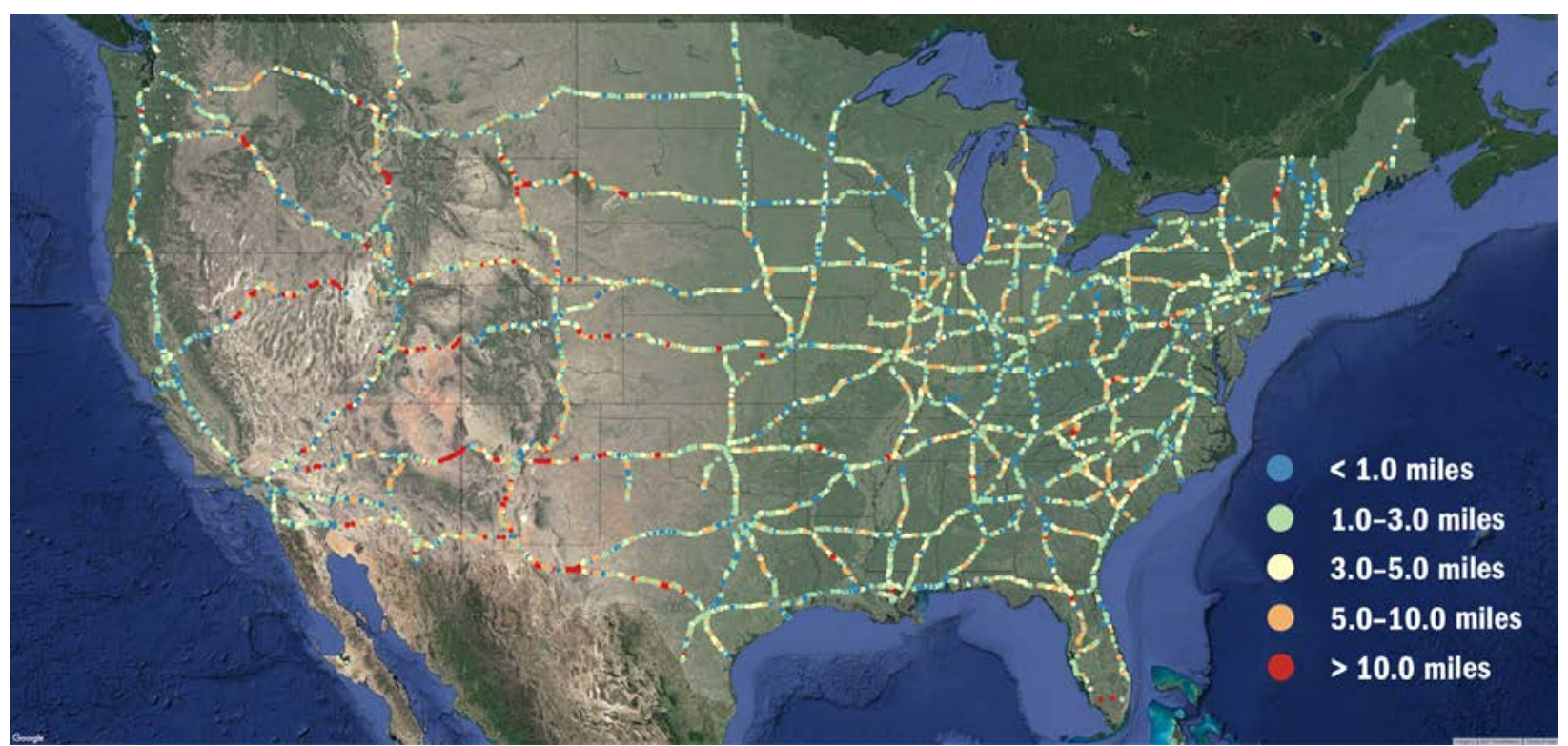

Figure 31. Highway exits color-coded by distance to the nearest electrical substation. (Satellite imagery credit: (c) 2017 Google, Map Data (c) 2017 Tele Atlas) 


\subsection{Corridor Charging Support from Community-Based DCFC}

As described above, the U.S. Interstate System provides a basis for DCFC infrastructure that can efficiently satisfy long-distance driving demands in the near term. The Interstate System is not, however, entirely isolated from community-based DCFC infrastructure. Although full community-based infrastructure may take longer to establish, it could provide travel corridors with charging backup options, route flexibility, and additional coverage along U.S. highways and state routes. Figure 34 shows the national DCFC station coverage enabled by providing the level of community-based charging station coverage quantified in Section 3. Each covered city and town has a 70-mile radius buffer around it, approximating station coverage.

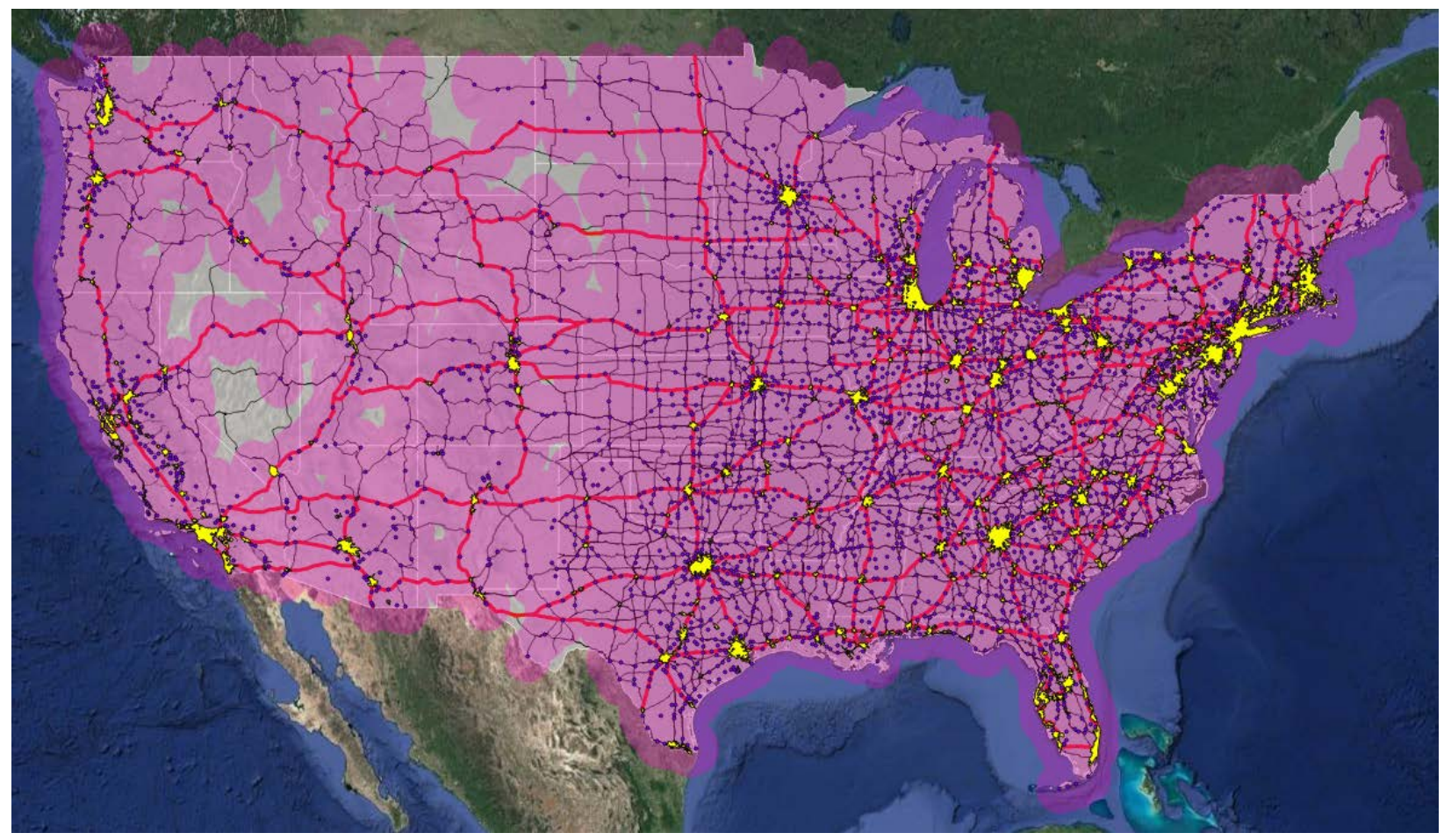

Figure 32. National charging station coverage enabled by providing minimum DCFC station coverage (70-mile buffers placed around all cities and towns).

(Satellite imagery credit: (c) 2017 Google, Map Data (c) 2017 Tele Atlas) 


\section{Conclusions}

An analytic process for estimating national PEV non-residential charging requirements within communities and along Interstate corridors has been presented. Scenario analysis was conducted to illustrate EVSE requirements for a range of potential PEV markets. The analysis makes no assumptions regarding which PEV market scenarios are more or less likely. Rather, a range of plausible PEV markets with unique features is developed to explore the relationship between the evolution of the PEV fleet and charging infrastructure requirements.

\subsection{Major Conclusions}

To facilitate understanding, this report separates PEV charging infrastructure requirements by area served (cities, towns, rural areas, and Interstate corridors) and role during the PEV market growth trajectory (providing coverage to early PEVs versus satisfying demand due to high PEV penetration).

Cities are expected to have the greatest charging infrastructure requirements under both the coverage and demand assessments. About 8,000 DCFC stations would be required to provide a minimum level of coverage nationwide in cities and towns (based on uniform station spacing assuming BEVs are never more than 3 miles from a charging station). Such a network would provide consumer support for long-distance intra-city travel, serve as a safety net for emergency charging situations, and dampen range anxiety concerns.

Demand analysis of community charging demonstrates how utilization of the DCFC coverage network would be expected to grow in a high PEV penetration market. Modeled results for a 15-million PEV market estimate a DCFC plug requirement of 25,000 in U.S. communities (approximately 3.1 plugs per average DCFC station and 3.4 plugs required to support 1,000 BEVs under a home-dominant charging assumption). Demand for nonresidential L2 EVSE (including work and public charging) is estimated at 600,000 plugs necessary to support 15 million PEVs (approximately 40 plugs per 1,000 PEVs).

Sensitivity analysis of the community results for consumer charging demand indicates a strong relationship between the evolution of the PEV and EVSE markets. As this analysis attempts to arrive at charging infrastructure solutions that fill the eVMT gaps between consumer travel patterns and PEV electric ranges, infrastructure requirements are not only proportional to the total number of PEVs in the system, but also inversely proportional to the electric range characteristics of these PEVs. Manufacturer and consumer preferences with respect to electric range, charging power, and utilization of residential EVSE have direct and dramatic consequences on the level of charging demand calculated in this study.

Results suggest that relatively few corridor DCFC stations could enable long-distance BEV travel between U.S. cities, where vehicles are concentrated. Under most scenarios, the number of required stations is similar to the number of corridor DCFC stations already established by Tesla or the number planned by Electrify America within the next two years.

Understanding driving patterns and vehicle characteristics and then prioritizing corridors and setting station spacing accordingly - as illustrated in the network scenarios - could help optimize the utility and economics of early-market corridor-coverage stations. The analysis identifies the majority of consumer long-distance automobile travel as being regional rather than truly cross-country, which emphasizes the importance of multistate DCFC corridor planning (such as the West Coast Electric Highway, corridor planning across Colorado/Utah/Nevada, and the I-95 Fast-Charge ARC led by Nissan and EVgo).

Despite the relatively low number of corridor DCFC stations estimated by this analysis, establishing the financial viability of these stations will be difficult, particularly in the face of low initial utilization and high capital/operating costs. Requirements for the average DCFC complex necessary to support peak traffic volume for 7 million BEVs is estimated at six plugs per station (assuming 70-mile station spacing). Given a national BEV stock of approximately 250,000 through the end of 2016, this implies that the average corridor DCFC 
station should expect relatively low levels of utilization as the PEV market continues to mature. Utilization expectations for corridor DCFC stations are further tempered when considering the current segmentation of DCFC protocols (Tesla, CHAdeMO, and SAE CCS).

Regardless of geographic scope, organizations planning for charging infrastructure to support consumer adoption of PEVs should be aware of the importance of consumer preferences with respect to electric range and charging behavior. Furthermore, planners are encouraged to focus efforts on providing consumers with adequate charging coverage (particularly DCFC supporting adoption of BEVs) with the expectation to monitor station utilization and grow charging capacity (both in terms of rated power and number of plugs) as the PEV market continues to grow over time.

\subsection{Summary of Modeling Limitations}

One of the fundamental assumptions of this study is that consumers will attempt to operate their PEVs in the future as they have operated their conventional gasoline vehicles in the past. This assumption places the burden on PEVs that they are able to serve as 1-to-1 replacements for gasoline vehicles in a given consumer's household fleet of vehicles. In the real world, it is uncertain if consumers will hold PEVs up to this requirement. For instance, National Household Travel Survey (NHTS) data suggest that over $80 \%$ of consumer vehicles are owned by multi-vehicle households. Such ownership circumstances may result in corridor charging demand below what is estimated in this analysis as the household gasoline vehicle could be perceived as the more convenient option for long distance travel (based on refueling time, infrastructure availability, or attributes unrelated to driving range).

Similarly, the baseline travel data used to calibrate EVSE estimates in this analysis assume consistent personal mobility patterns out to 2030. In reality, the world of personal mobility is poised to undergo a paradigm shift as the sophistication and adoption of automated driving technology continues to grow. Interactions between evolving mobility patterns and refueling infrastructure supporting advanced technology vehicles are currently being investigated by the consortium of national laboratories participating in the DOE's SMART Mobility Initiative (DOE 2017c).

The EVI-Pro model used in this analysis assumes charging infrastructure must be sufficient to enable any consumer to maximize eVMT in any PEV. In reality, some degree of consumer self-selection in the new and used PEV markets is likely to reduce the need for non-residential charging as households right-size PEV purchases to meet the daily driving needs of their individual household. While the extent to which consumers are able to successfully right-size PEV purchases is largely unknown, its effect would reduce infrastructure requirements relative to estimates made in this analysis.

EVI-Pro's fundamental objective of maximizing consumer eVMT enforces no minimum utilization criteria on individual charging stations, likely resulting in a percentage of stations with insufficient revenue potential. Incremental eVMT benefits and utilization of individual stations have been explored in regional simulation studies (Wood et al. 2015a, 2015b, 2017). Detailed financial analysis of the national EVSE networks explored in this study remains an ongoing area of research.

This study is intentionally vague with respect to the percentage of PEVs adopted by residents of MUDs. Inconsistent access to home charging for residents of MUDs is often cited as an infrastructure barrier to increased PEV adoption. Yet even at 15 million PEVs nationally (5\% of LDV stock), this analysis is well below the threshold where MUD residents would be required to participate in the PEV market. As such, no distinction is made for MUD residents in this analysis, but sensitivities are explored for portions of PEV owners who adopt non-home-dominant charging behaviors. 


\section{References}

Alternative Energy Systems Consulting. (2015). Considerations for Corridor Direct Current Fast Charging Infrastructure in California. Carlsbad, CA: Alternative Energy Systems Consulting. http://www.energy.ca.gov/2015publications/CEC-600-2015-015/CEC-600-2015-015.pdf

America 2050 (2017). “Megaregions.” Accessed June 2017. http://www.america2050.org/megaregions.html

California Air Resources Board. (2017). "Zero Emission Vehicle (ZEV) Program.” Accessed June 2017. https://www.arb.ca.gov/msprog/zevprog/zevprog.htm

Campbell, K.L. (2012). "The SHRP 2 Naturalistic Driving Study: Addressing Driver Performance and Behavior in Traffic Safety." TR News (282): 30-35. onlinepubs.trb.org/onlinepubs/trnews/trnews282SHRP2nds.pdf

Clean Vehicle Rebate Project. (2017). “Drive Clean and Save.” Accessed June 2017. https://cleanvehiclerebate.org/eng

Conservation Science Partners. (2017). Datasets used to construct the national land use database. Accessed June 2017. http://www.csp-inc.org/public/

Denholm, P.; Short, W. (2006). An Evaluation of Utility System Impacts and Benefits of Optimally Dispatched Plug-In Hybrid Electric Vehicles. National Renewable Energy Laboratory Technical Report, NREL/TP620-40293. Accessed September 12, 2017. https://www.nrel.gov/docs/fy07osti/40293.pdf

Dingus, T.A.; Hankey, J.M.; Antin, J.F.; Lee, S.E.; Eichelberger, L.; Stulce, K.E.; McGraw, D.; Perez, M.; Stowe, L. (2015). Naturalistic Driving Study: Technical Coordination and Quality Control. The Second Strategic Highway Research Program SHRP 2, Report S2-S06-RW-1. Washington, DC: Transportation Research Board. Accessed September 2017. http://www.trb.org/Main/Blurbs/170935.aspx

Duvall, M.; Knipping, E.; Alexander, M.; Tonachel, L.; Clark, C. (2007). "Environmental Assessment of PlugIn Hybrid Electric Vehicles." EPRI, Nationwide Greenhouse Gas Emissions, Vol. 1. Accessed September 2017. http://miastrada.com/yahoo site admin/assets/docs/epriVolume1R2.36180810.pdf

Electrify America. (2017). “Our Plan.” Accessed June 2017. https://www.electrifyamerica.com/our-plan

Federal Highway Administration (FHWA). (2013). Final Report to FHWA for Traffic Analysis Framework Part IIA: Establishing Multimodal Interregional Passenger Travel Origin Destination Data. Washington, DC: FHWA. https://www.fhwa.dot.gov/policyinformation/analysisframework/docs/taf final report.pdf

Federal Highway Administration (FHWA). (2017a). "National Household Travel Survey (NHTS)." Accessed June 2017. https://www.fhwa.dot.gov/policyinformation/nhts.cfm

Federal Highway Administration (FHWA). (2017b). "Travel Monitoring and Traffic Volume: Traffic Monitoring Guide.” Accessed June 2017. https://www.fhwa.dot.gov/policyinformation/tmguide/

Federal Highway Administration (FHWA). (2017c). "The National Highway Planning Network.” Accessed June 2017. https://www.fhwa.dot.gov/planning/processes/tools/nhpn/index.cfm

Francfort, J.; Salisbury, S.; Smart, J.; Garetson, T.; Karner, D. (2017). Considerations for Corridor and Community DC Fast Charging Complex System Design. INL/EXT-17-40829. Idaho Falls: INL. https://avt.inl.gov/sites/default/files/pdf/reports/DCFCChargingComplexSystemDesign.pdf 
Fueleconomy.gov. (2017). "Electric Vehicles: Learn More About the New Label.” Accessed June 2017. http://www.fueleconomy.gov/feg/label/learn-more-electric-label.shtml

Green Car Reports. (2017). “Volkswagen Diesel Scandal.” Accessed June 2017. http://www.greencarreports.com/news/volkswagen-diesel-scandal

Green R.C.; Wang, L.; Alam, M. (2011). "The Impact of Plug-In Hybrid Electric Vehicles on Distribution Networks: A Review and Outlook.” Renewable and Sustainable Energy Reviews (15:1); pp. 544-553.

Hallmark, S.; McGehee, D.; Bauer, K.M.; Hutton, J.M.; Davis, G.A.; Hourdos, J.; Chatterjee, I.; Victor, T.; Bärgman, J.; Dozza, M.; Rootzén, H.; Lee, J.D.; Ahlström, C.; Bagdadi, O.; Engström, J.; Zholud, D.; Ljung-Aust. M. (2013). Initial Analyses from the SHRP 2 Naturalistic Driving Study: Addressing Driver Performance and Behavior in Traffic Safety. The Second Strategic Highway Research Program SHRP 2, Safety Project S08. Washington, DC: Transportation Research Board.

Idaho National Laboratory (INL). (2013). Public Blink Charging Units Reporting Data in The EV Project: Project to Date Through June 2013. INL/MIS-12-2607. Idaho Falls: INL. https://energy.gov/sites/prod/files/2014/02/f8/blink_commercial_by_region_q22013.pdf

Idaho National Laboratory (INL). (2015). Plugged-In: How Americans Charge Their Electric Vehicles. INL/EXT-15-35584. Idaho Falls: INL. https://avt.inl.gov/sites/default/files/pdf/arra/PluggedInSummaryReport.pdf

Idaho National Laboratory (INL). (2016). 2013 Nissan Leaf BEV - VINs 0545, 0646, 7885 \& 9270: Advanced Vehicle Testing-DC Fast Charging at Temperature Test Results. Idaho Falls: INL. https://avt.inl.gov/sites/default/files/pdf/fsev/2013LeafDCFCAtTempBOT.pdf

IHS Markit. (2017). "MarketInsight: Registrations and Vehicles-in-Operation.” Accessed June 2017. https://www.ihs.com/products/automotive-market-data-analysis.html

International Energy Agency (IEA). (2017). Global EV Outlook 2017. Paris: IEA. http://www.iea.org/publications/freepublications/publication/GlobalEVOutlook2017.pdf

Kahn, M.E.; Vaughn, R.K. (March 2009). "Green Market Geography: The Spatial Clustering of Hybrid Vehicles and LEED Registered Buildings" The B.E. Journal of Economic Analysis \& Policy (9:2). https://www.degruyter.com/view/j/bejeap.2009.9.2/bejeap.2009.9.2.2030/bejeap.2009.9.2.2030.xml

KPMG. (2017). Global Automotive Executive Survey 2017. Amstelveen, Netherlands: KPMG. Accessed September 2017. https://assets.kpmg.com/content/dam/kpmg/xx/pdf $/ 2017 / 01 /$ global-automotiveexecutive-survey-2017.pdf

Krzywinski, M.I.; Schein, J.E.; Birol, I.; Connors, J.; Gascoyne, R.; Horsman, D.; Jones, S.J.; Marra, M.A. (2009). "Circos: An Information Aesthetic for Comparative Genomics." Genome Research. doi: 10.1101/gr.092759.109.

Lohse-Busch, H.; Duoba, M.; Rask, E.; Stutenberg, K.; Gowri, V.; Slezak, L.; Anderson, D. (2013). “Ambient Temperature $\left(20^{\circ} \mathrm{F}, 72^{\circ} \mathrm{F}, 95^{\circ} \mathrm{F}\right)$ Impact on Fuel and Energy Consumption for Several Conventional Vehicles, Hybrid and Plug-In Hybrid Electric Vehicles and Battery Electric Vehicle." Presented at the 2013 SAE World Congress, Detroit, MI, April 2013, 2013-01-1462. https://saemobilus.sae.org/content/2013-01-1462

MapQuest. 2017. "Directions API.” Accessed June 2017. https://developer.mapquest.com/documentation/directions-api/ 
Melaina, M.; Bush, B.; Eichman, J.; Wood, E.; Stright, D.; Krishnan, V.; Keyser, D.; Mai, T.; McLauren, J. (2016). National Economic Value Assessment of Plug-In Electric Vehicles: Volume I. NREL/TP-540066980. Golden, CO: National Renewable Energy Laboratory. https://www.afdc.energy.gov/uploads/publication/value_assessment_pev_v1.pdf

Melaina, M.; Eichman, J. (2015). “California Statewide PEV Infrastructure Assessment.” NREL/PR-540064512. Golden, CO: National Renewable Energy Laboratory. http://www.nrel.gov/docs/fy15osti/64512.pdf

Melaina, M.; Helwig, M. (2014). California Statewide Plug-In Electric Vehicle Infrastructure Assessment. Prepared for California Energy Commission. CEC-600-2014-003. Golden, CO: National Renewable Energy Laboratory. http://www.nrel.gov/docs/fy15osti/60729.pdf

Melaina, M.; Muratori, M.; McLaren, J.; Schwabe, P. (2017). "Investing in Alternative Fuel Infrastructure: Insights for California from Stakeholder Interviews.” NREL/CP-5400-67617. Golden, CO: National Renewable Energy Laboratory. http://www.nrel.gov/docs/fy17osti/67617.pdf

Muratori, M.; Rizzoni, G. (2016). "Residential Demand Response: Dynamic Energy Management and TimeVarying Electricity Pricing.” IEEE Transactions on Power Systems (31:2); pp. 1108-1117.

National Oceanic and Atmospheric Administration. (2017). "U.S. Census Divisions.” Accessed June 2017. https://www.ncdc.noaa.gov/monitoring-references/maps/us-census-divisions.php

Navigant Research. (2016). DC Charging Map for the United States. Boulder, CO: Navigant Research. https://www.navigantresearch.com/research/dc-charging-map-for-the-united-states

Neubauer, J.; Wood, E. (2013). Accounting for the Variation of Driver Aggression in the Simulation of Conventional and Advanced Vehicles. NREL/CP-5400-57503. Golden, CO: National Renewable Energy Laboratory. https://www.nrel.gov/docs/fy13osti/58609.pdf

Neubauer, J.; Wood, E. (2015). “Will Your Battery Survive a World with Fast Chargers?” Presented at the 2015 SAE World Congress, Detroit, MI, April 2015, 2015-01-1196. https://www.nrel.gov/docs/fy15osti/63531.pdf

Nissan. (2017). "Nissan and BMW Partner Once Again to Expand DC Fast Charger Access Across the U.S. to Benefit EV Drivers." Press release, January 24. http://nissannews.com/en-US/nissan/usa/channels/usunited-states-nissan/releases/nissan-and-bmw-partner-once-again-to-expand-dc-fast-charger-accessacross-the-u-s-to-benefit-ev-drivers

National Research Council. 2013. Transitions to Alternative Vehicles and Fuels. Washington, DC: National Academies Press. https://www.nap.edu/download/18264

Nykvist, B.; Nilsson, M. (2015). "Rapidly Falling Costs of Battery Packs for Electric Vehicles." Nature Climate Change 5(4): 329-332.

Orsi, F.; Muratori, M.; Rocco, M.; Colombo, E.; Rizzoni, G. (2016). "A Multi-Dimensional Well-to-Wheels Analysis of Passenger Vehicles in Different Regions: Primary Energy Consumption, $\mathrm{CO}_{2}$ Emissions, and Economic Cost." Applied Energy 169; pp. 197-209.

Plug-in Hybrid \& Electric Vehicle Research Center (PH\&EV Research Center). (2011). "Developing a Charging Network for PEVs in California." Presented at the California Energy Commission Committee Workshop on Transportation Fuel Infrastructure Issues, May 11. http://www.energy.ca.gov/2011 energypolicy/documents/2011-0511_workshop/presentations/UC_Davis.pdf 
Shirk, M.; Wishart, J. (2015). "Effects of Electric Vehicle Fast Charging on Battery Life and Vehicle Performance." Presented at the SAE 2015 World Congress, Detroit, MI, April 2015, 2015-01-1190. Accessed September 2017. https://avt.inl.gov/sites/default/files/pdf/vehiclebatteries/FastChargeEffects.pdf

Svitak, T.; Salisbury, M.; Toor, W. (2017). Opportunities for Vehicle Electrification in the Denver Metro Area and Across Colorado. Denver, CO: City and County of Denver. Accessed September 2017. http://www.denvergov.org/content/dam/denvergov/Portals/771/documents/EQ/EV/EVFinalReport.pdf

Theobald, D.M. (2014). "Development and Applications of a Comprehensive Land Use Classification and Map for the US.” PLOS, April 11. Accessed September 2017. https://doi.org/10.1371/journal.pone.0094628

U.S. Census Bureau. 2015. MAF/TIGER Database. Accessed June 2017. https://www.census.gov/geo/mapsdata/data/tiger.html

U.S. Department of Energy (DOE) (2014). About the EV Project Reports. Washington, DC: DOE. https://energy.gov/sites/prod/files/2014/02/f8/about_evproj_rpts.pdf

U.S. Department of Energy (DOE). (2017a). Cost and Price Metrics for Automotive Lithium-Ion Batteries. Washington, DC: DOE. Accessed September 2017. https://energy.gov/sites/prod/files/2017/02/f34/67089\%20EERE $\% 20 L I B \% 20$ cost $\% 20 v s \% 20$ price $\% 20 \mathrm{metr}$ ics $\% 20 \mathrm{r} 9 . \mathrm{pdf}$

U.S. Department of Energy (DOE) (2017b). “Alternative Fueling Station Locator.” Accessed June 2017. http://www.afdc.energy.gov/locator/stations/

DOE (U.S. Department of Energy). 2017c. "Energy Efficient Mobility Systems” Accessed September 2017, https://energy.gov/eere/vehicles/energy-efficient-mobility-systems

U.S. Department of Transportation (DOT) (2017a). “Alternative Fuel Corridors.” Accessed June 2017. https://www.fhwa.dot.gov/environment/alternative_fuel_corridors/

U.S. Department of Transportation (DOT) (2017b). "Highway Performance Monitoring System (HPMS)." Accessed June 2017. https://www.fhwa.dot.gov/policyinformation/hpms.cfm

U.S. Energy Information Administration (EIA) (2017). "Energy Use for Transportation.” Accessed June 2017. https://www.eia.gov/energyexplained/index.cfm?page=us energy transportation

Wood, E.; Neubauer, J.; Burton, E. (2015a). "Quantifying the Effect of Fast Charger Deployments on Electric Vehicle Utility and Travel Patterns via Advanced Simulation." Presented at the 2015 SAE World Congress, Detroit, MI, April 2015, 2015-01-1687. Accessed September 2017. https://www.nrel.gov/docs/fy15osti/63423.pdf

Wood, E.; Neubauer, J.; Burton, E. (2015b). "Measuring the Benefits of Public Chargers and Improving Infrastructure Deployments Using Advanced Simulation Tools." Presented at the 2015 SAE World Congress, Detroit, MI, April 2015, 2015-01-1688. Accessed September 2017. https://www.nrel.gov/docs/fy15osti/63422.pdf

Wood, E.; Raghavan, S.; Rames, C.; Eichman, J.; Melaina. M. (2017). Regional Charging Infrastructure for Plug-In Electric Vehicles: A Case Study of Massachusetts. NREL/TP-5400-67436. Golden, CO: National Renewable Energy Laboratory. http://www.nrel.gov/docs/fy17osti/67436.pdf

Wood, E.; Rames, C.; Muratori, M. (Forthcoming). Charging Electric Vehicles in Smart Cities: A Scenario Analysis of Columbus, Ohio. Golden, CO: National Renewable Energy Laboratory. 
Yuksel, T.; Michalek, J.J. (2014). "Regional Effects of Ambient Temperature on Electric Vehicle Efficiency, Range, and Emissions in the US." Poster presentation. Center for Climate and Energy Decision Making. Accessed September 2017. http://cedmcenter.org/wp-content/uploads/2014/05/24-Yuksel.pdf 


\section{Appendix A: Supplementary Statistics on Existing EVSE}

Table A-1 summarizes the number of public EVSE by network, in terms of plugs. Table A-2 summarizes the number of public DCFC plugs and stations by network.

Table A-1. Public Charging Plugs by Network (DOE 2017b)

\begin{tabular}{lllll}
\hline Network & L1 & L2 & DCFC & Totals \\
\hline ChargePoint Network & 1,659 & 17,345 & 511 & 19,515 \\
Not Identified & 1,772 & 11,023 & 542 & 13,337 \\
Tesla & 14 & 3,935 & 2,478 & 6,427 \\
Blink Network & 0 & 3,997 & 209 & 4,206 \\
EVgo Network & 0 & 423 & 1,629 & 2,052 \\
SemaCharge Network & 0 & 2001 & 0 & 2,001 \\
Greenlots & 106 & 394 & 402 & 902 \\
GE WattStation & 0 & 640 & 0 & 640 \\
OpConnect & 104 & 384 & 32 & 520 \\
AeroVironment Network & 0 & 60 & 56 & 116 \\
EV Connect & 0 & 72 & 2 & 74 \\
\hline
\end{tabular}

Table A-2. Public DCFC Plugs and Stations by Network (DOE 2017b)

\begin{tabular}{lll}
\hline Network & $\begin{array}{l}\text { DCFC } \\
\text { Plugs }\end{array}$ & $\begin{array}{l}\text { DCFC } \\
\text { Stations }\end{array}$ \\
\hline Tesla & 2,478 & 357 \\
EVgo Network & 1,629 & 701 \\
Not Identified & 542 & 418 \\
ChargePoint Network & 511 & 295 \\
Greenlots & 402 & 209 \\
Blink Network & 209 & 111 \\
AeroVironment Network & 56 & 56 \\
OpConnect & 32 & 16 \\
EV Connect & 2 & 1 \\
\hline
\end{tabular}




\section{Appendix B: EVSE/PEV Adjustment Factors to Account for Local Conditions}

The nominal set of EVSE/PEV ratios is adjusted to account for the unique characteristics of all geographies based on population density, PEV concentration, and ambient temperature.

As population density increases in a region, the average VMT per vehicle decreases, and thus less EVSE capacity is required. Daily VMT data from the 2009 NHTS are used to quantify this relationship and develop a population density adjustment factor. Figure B-1 shows the daily VMT cumulative distribution functions by population density. Median VMT ranges from 14 miles per day in the most densely populated areas to 31 miles per day in the most sparsely populated areas. The INRIX travel data are resampled to mimic the NHTS daily VMT distributions (Figure B-2). For example, for each U.S. urban area with 2,000-3,999 people per square mile, the INRIX data are sampled so that vehicles modeled have the same VMT distribution as NHTS vehicles from the 2,000-3,999 density bin (see Figure B-1), and so forth. EVI-Pro computed the EVSE/PEV ratio for each population density distribution from the resampled INRIX data to generate the adjustment factor shown in Figure B-3.

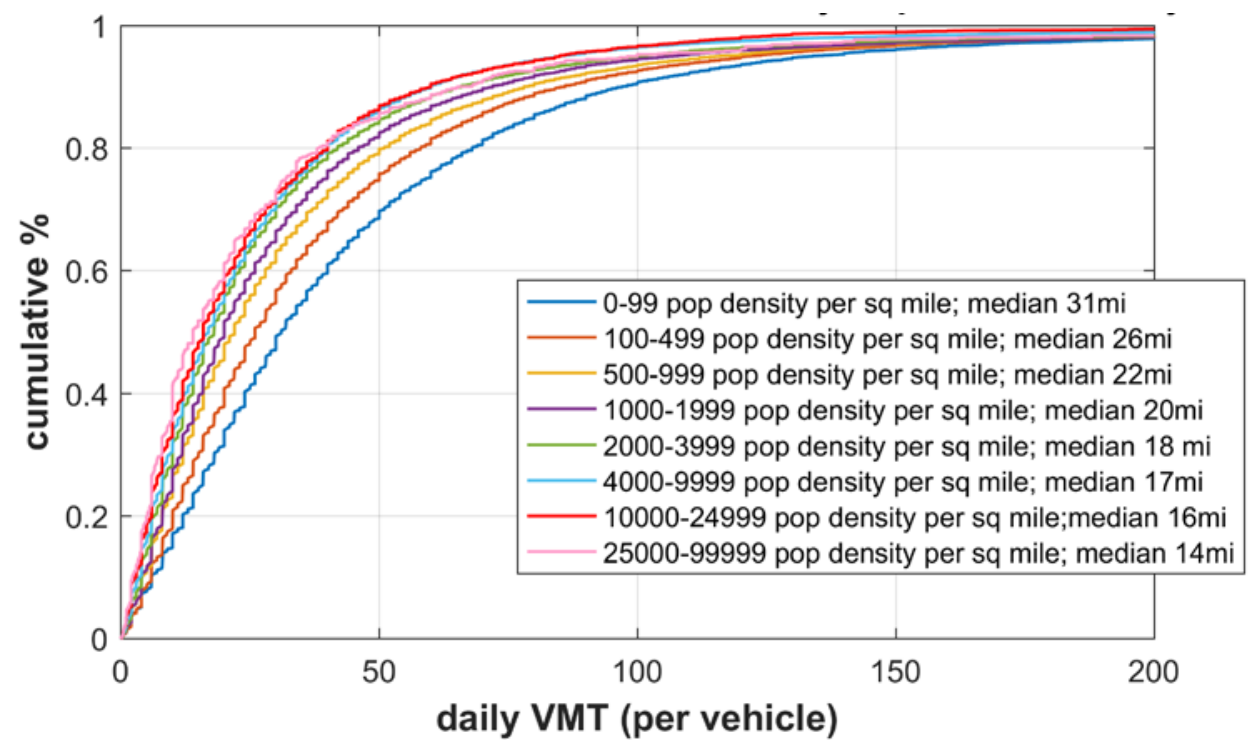

Figure B-1. Daily VMT cumulative distribution functions by population density, from the 2009 NHTS. 


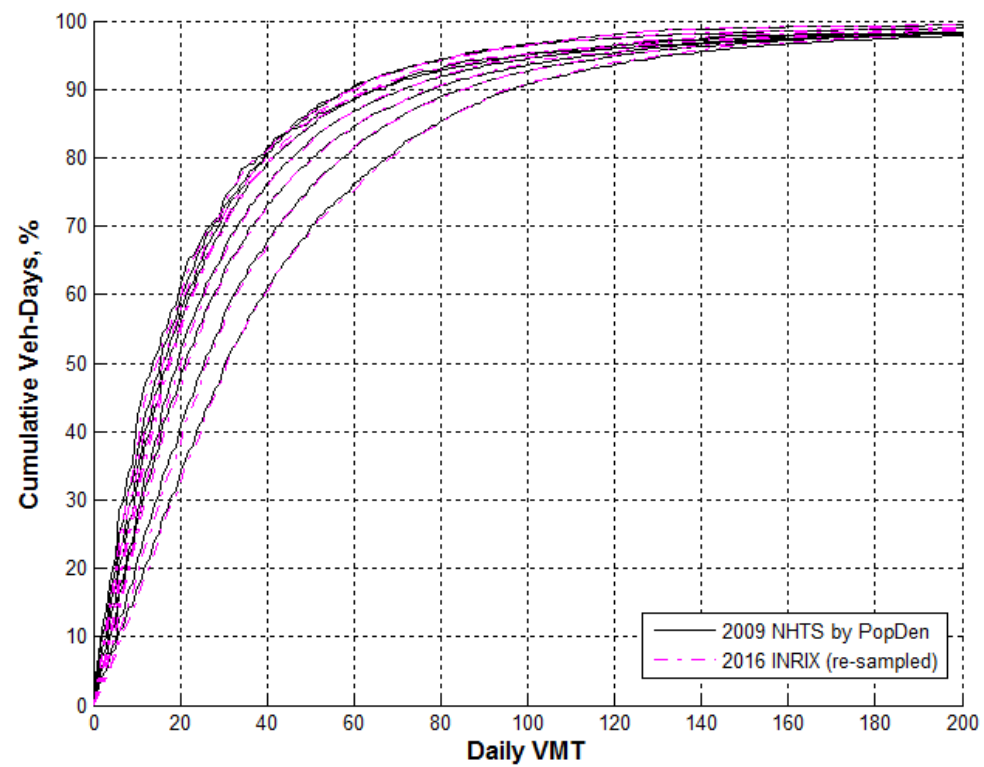

Figure B-2. Mimicking NHTS daily VMT cumulative distribution functions by population density by resampling INRIX travel data.

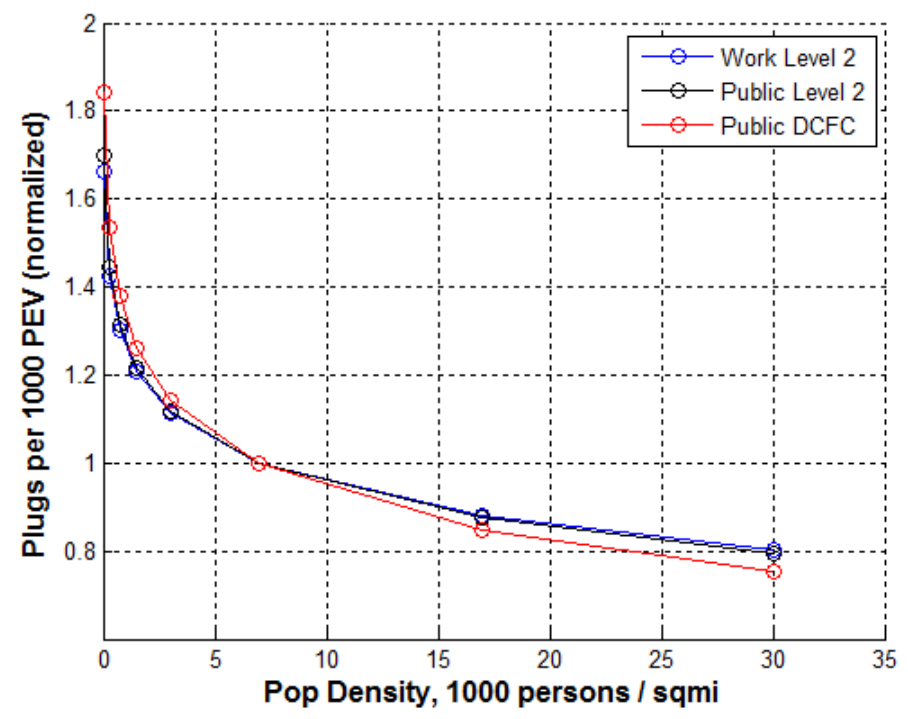

Figure B-3. Adjustment factor: non-residential EVSE/PEV ratio as a function of population density.

Similarly, an adjustment factor based on PEV concentration is generated by running EVI-Pro simulations at various PEV concentrations. Plug requirements are lower at higher PEV concentrations (Figure B-4) due to the greater opportunity for efficient infrastructure sharing. 


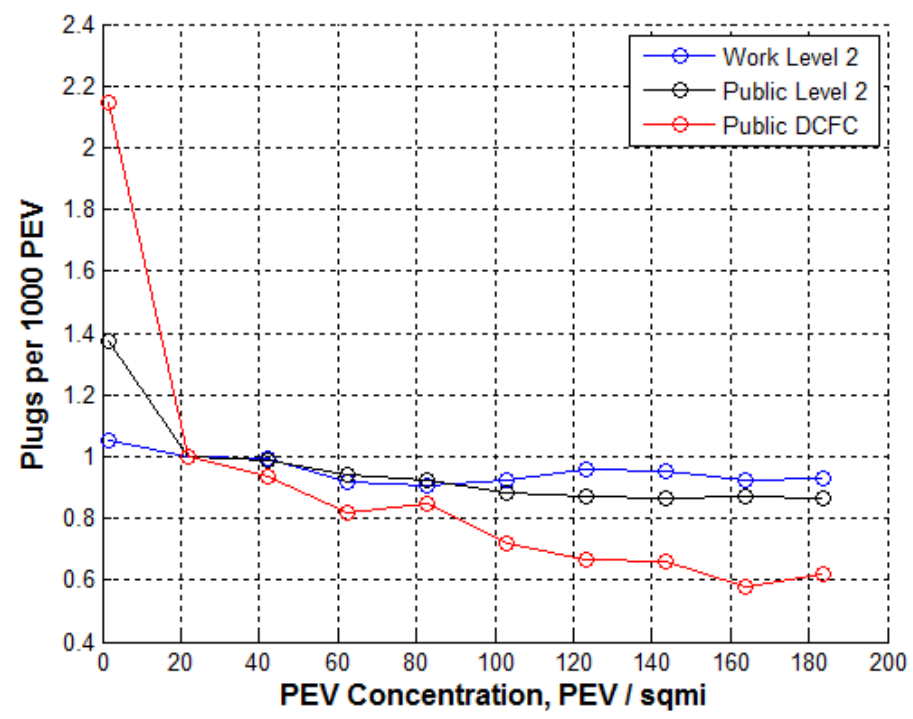

Figure B-4. Adjustment factor: non-residential EVSE/PEV ratio as a function of PEV concentration.

Ambient temperature affects battery charge and discharge rates, and the temperature adjustments applied account for both impacts. Using EVI-Pro, non-uniform discharge rates are applied to driving events depending on trip average speed and ambient temperature, based on the measured effects of temperature on Nissan Leafs (Yuksel and Michalek 2014) over simulated drive cycles (Neubauer and Wood 2013). Table B-1 shows the modeled relative battery discharge rates as a function of ambient temperature and trip average speed: very hot and very cold temperatures drain the battery more quickly at any speed. EVI-Pro also adjusts DCFC charge rates for battery temperature and charge duration, based on INL's testing of a Nissan Leaf (Figure B-5) (INL 2016). Again, temperature has a major impact, for example, reducing the 20 -minute effective DCFC charge rate from over $80 \%$ of rated power at a battery temperature of $25^{\circ} \mathrm{C}$ to $50 \%$ of rated power at $0^{\circ} \mathrm{C}$. These temperature relationships are applied across EVI-Pro simulations at multiple ambient temperatures to derive the temperature adjustment factor shown in Figure B-6.

Table B-1. EVI-Pro Driving Discharge Model: Relative Battery Discharge Rates as a Function of Ambient Temperature and Average Trip Speed

\begin{tabular}{|c|c|c|c|c|c|c|c|c|c|c|c|c|c|c|}
\hline & & \multicolumn{13}{|c|}{ Ambient Temperature, ${ }^{\circ} \mathrm{C}$} \\
\hline & & -20 & -15 & -10 & -5 & 0 & 5 & 10 & 15 & 20 & 25 & 30 & 35 & 40 \\
\hline \multirow{13}{*}{ 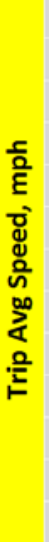 } & 2.5 & $203 \%$ & $193 \%$ & $186 \%$ & $178 \%$ & $167 \%$ & $154 \%$ & $141 \%$ & $132 \%$ & $129 \%$ & $136 \%$ & $153 \%$ & $180 \%$ & $213 \%$ \\
\hline & 7.5 & $77 \%$ & $168 \%$ & $162 \%$ & $155 \%$ & $146 \%$ & $135 \%$ & $123 \%$ & $115 \%$ & $113 \%$ & $119 \%$ & $134 \%$ & $157 \%$ & $186 \%$ \\
\hline & 12.5 & $163 \%$ & $155 \%$ & $149 \%$ & $143 \%$ & $134 \%$ & $124 \%$ & $114 \%$ & $106 \%$ & $104 \%$ & $109 \%$ & $123 \%$ & $145 \%$ & $171 \%$ \\
\hline & 17.5 & $146 \%$ & $139 \%$ & $134 \%$ & $128 \%$ & $121 \%$ & $111 \%$ & $102 \%$ & $95 \%$ & $93 \%$ & $98 \%$ & $110 \%$ & $130 \%$ & $153 \%$ \\
\hline & 22.5 & $135 \%$ & $128 \%$ & $123 \%$ & $118 \%$ & $111 \%$ & $102 \%$ & $94 \%$ & $88 \%$ & $86 \%$ & $90 \%$ & $102 \%$ & $120 \%$ & $141 \%$ \\
\hline & 27.5 & $132 \%$ & $125 \%$ & $120 \%$ & $115 \%$ & $108 \%$ & $100 \%$ & $92 \%$ & $85 \%$ & $84 \%$ & $88 \%$ & $99 \%$ & $117 \%$ & $138 \%$ \\
\hline & 32.5 & $135 \%$ & $128 \%$ & $123 \%$ & $118 \%$ & $111 \%$ & $102 \%$ & $94 \%$ & $88 \%$ & $86 \%$ & $90 \%$ & $102 \%$ & $120 \%$ & $141 \%$ \\
\hline & 37.5 & $141 \%$ & $134 \%$ & & $124 \%$ & $116 \%$ & $107 \%$ & $98 \%$ & $92 \%$ & $90 \%$ & $94 \%$ & $106 \%$ & $125 \%$ & $147 \%$ \\
\hline & 42.5 & $147 \%$ & $139 \%$ & $134 \%$ & $129 \%$ & $121 \%$ & $111 \%$ & $102 \%$ & $95 \%$ & $93 \%$ & $98 \%$ & $111 \%$ & $130 \%$ & $154 \%$ \\
\hline & 47.5 & $155 \%$ & $147 \%$ & $142 \%$ & $136 \%$ & $128 \%$ & $118 \%$ & $108 \%$ & $101 \%$ & $99 \%$ & $104 \%$ & $117 \%$ & $138 \%$ & $163 \%$ \\
\hline & 52.5 & $164 \%$ & $156 \%$ & $150 \%$ & $144 \%$ & $135 \%$ & $125 \%$ & $114 \%$ & $107 \%$ & $104 \%$ & $110 \%$ & $124 \%$ & $146 \%$ & $172 \%$ \\
\hline & 57.5 & $168 \%$ & $159 \%$ & $154 \%$ & $147 \%$ & $139 \%$ & $128 \%$ & $117 \%$ & $109 \%$ & $107 \%$ & $113 \%$ & $127 \%$ & $149 \%$ & $176 \%$ \\
\hline & 62.5 & $182 \%$ & $172 \%$ & $166 \%$ & $159 \%$ & $150 \%$ & $138 \%$ & $126 \%$ & $118 \%$ & $115 \%$ & $121 \%$ & $137 \%$ & $161 \%$ & $190 \%$ \\
\hline
\end{tabular}




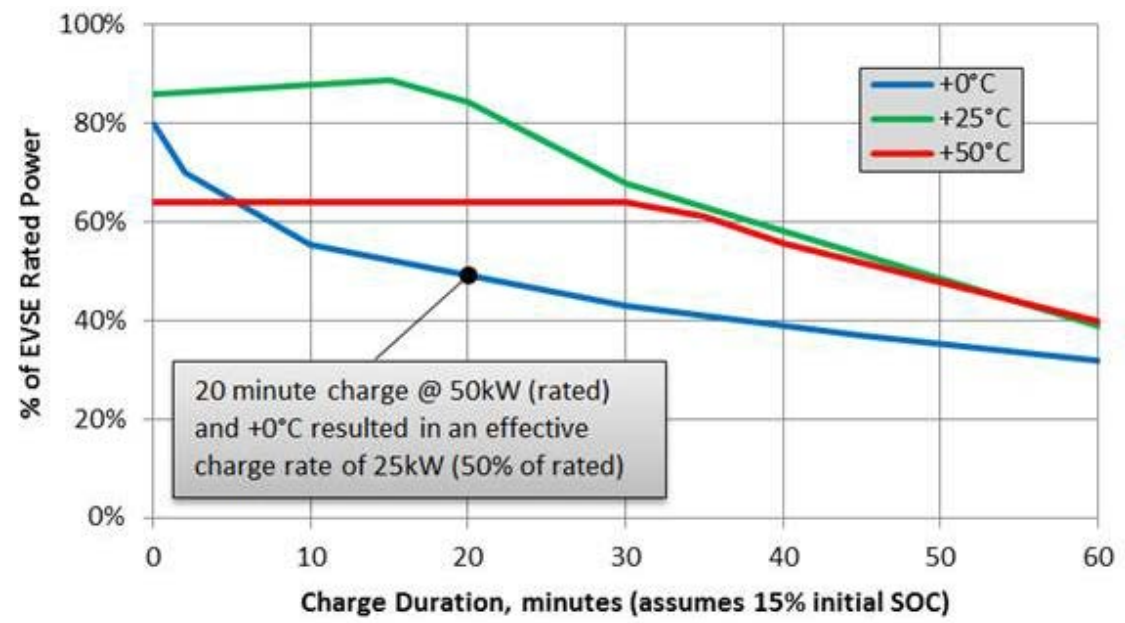

Figure B-5. EVI-Pro DCFC effective charge rate model: percentage of EVSE rated power delivered as a function of charge duration and battery temperature.

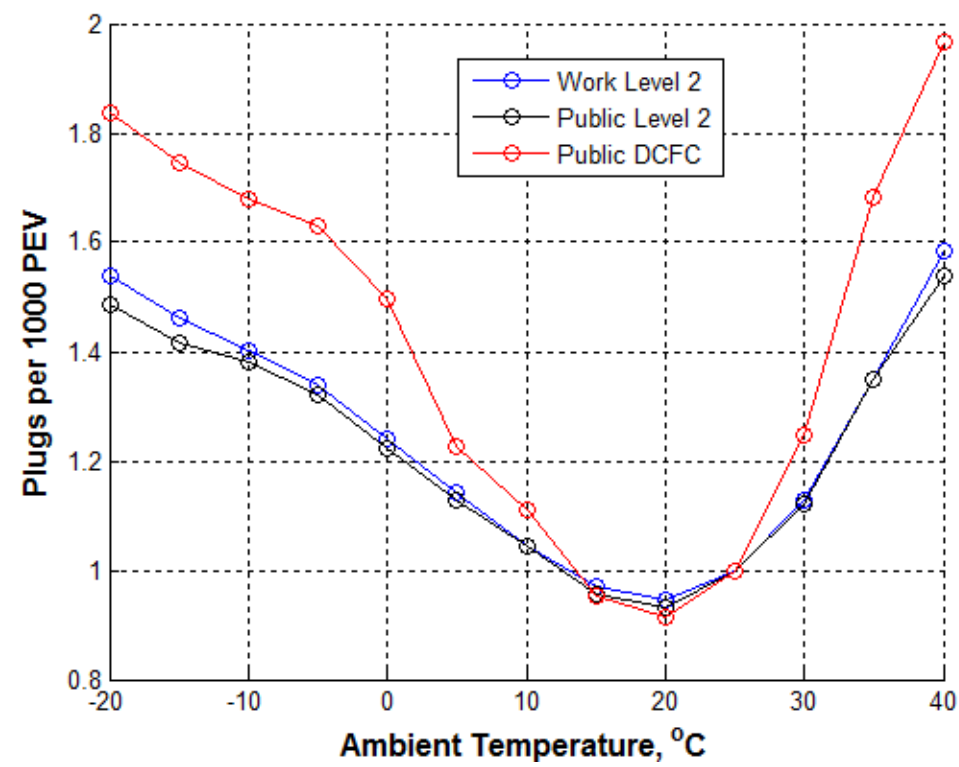

Figure B-6. Adjustment factor: non-residential EVSE/PEV ratio as a function of ambient temperature. 


\section{Appendix C: Central Scenario PEV/EVSE Estimates by State}

\begin{tabular}{|c|c|c|c|c|c|}
\hline State & Total PEVs & $\%$ BEV & Work L2 Plugs & Public L2 Plugs & Public DCFC Plugs \\
\hline $\mathrm{AK}$ & 18,000 & $35 \%$ & 700 & 500 & 40 \\
\hline $\mathrm{AL}$ & 111,000 & $41 \%$ & 3,400 & 2,600 & 270 \\
\hline AR & 68,000 & $33 \%$ & 2,300 & 1,800 & 140 \\
\hline$A Z$ & 345,000 & $54 \%$ & 8,200 & 5,500 & 720 \\
\hline CA & $3,864,000$ & $54 \%$ & 73,800 & 44,600 & 4,380 \\
\hline $\mathrm{CO}$ & 316,000 & $60 \%$ & 6,700 & 4,500 & 670 \\
\hline CT & 197,000 & $40 \%$ & 5,700 & 3,600 & 330 \\
\hline DC & 40,000 & $55 \%$ & 800 & 500 & 40 \\
\hline DE & 50,000 & $31 \%$ & 1,500 & 1,100 & 60 \\
\hline $\mathrm{FL}$ & 837,000 & $51 \%$ & 19,800 & 12,900 & 1,550 \\
\hline GA & 336,000 & $77 \%$ & 5,800 & 4,000 & 1,020 \\
\hline $\mathrm{HI}$ & 102,000 & $78 \%$ & 1,400 & 800 & 240 \\
\hline IA & 99,000 & $30 \%$ & 3,500 & 2,500 & 170 \\
\hline ID & 71,000 & $43 \%$ & 2,100 & 1,600 & 170 \\
\hline IL & 555,000 & $51 \%$ & 13,600 & 8,700 & 880 \\
\hline IN & 210,000 & $37 \%$ & 6,700 & 4,700 & 410 \\
\hline KS & 98,000 & $39 \%$ & 2,900 & 2,000 & 160 \\
\hline $\mathrm{KY}$ & 122,000 & $36 \%$ & 3,900 & 2,800 & 230 \\
\hline LA & 70,000 & $44 \%$ & 2,000 & 1,600 & 170 \\
\hline MA & 388,000 & $44 \%$ & 10,200 & 6,400 & 610 \\
\hline MD & 337,000 & $42 \%$ & 8,700 & 5,400 & 430 \\
\hline ME & 65,000 & $26 \%$ & 2,700 & 2,000 & 110 \\
\hline MI & 258,000 & $20 \%$ & 9,700 & 6,700 & 290 \\
\hline $\mathrm{MN}$ & 228,000 & $43 \%$ & 6,600 & 4,500 & 370 \\
\hline MO & 201,000 & $43 \%$ & 5,900 & 4,100 & 370 \\
\hline MS & 46,000 & $44 \%$ & 1,400 & 1,100 & 130 \\
\hline MT & 39,000 & $47 \%$ & 1,200 & 1,000 & 130 \\
\hline NC & 475,000 & $47 \%$ & 12,900 & 8,900 & 1,020 \\
\hline ND & 13,000 & $26 \%$ & 500 & 400 & 20 \\
\hline NE & 53,000 & $37 \%$ & 1,700 & 1,100 & 100 \\
\hline $\mathrm{NH}$ & 92,000 & $34 \%$ & 3,200 & 2,200 & 170 \\
\hline NJ & 335,000 & $48 \%$ & 7,700 & 5,000 & 480 \\
\hline NM & 89,000 & $42 \%$ & 2,600 & 1,900 & 200 \\
\hline NV & 114,000 & $60 \%$ & 2,500 & 1,700 & 330 \\
\hline NY & 607,000 & $35 \%$ & 17,800 & 11,300 & 740 \\
\hline $\mathrm{OH}$ & 393,000 & $38 \%$ & 11,900 & 8,000 & 690 \\
\hline OK & 97,000 & $45 \%$ & 2,800 & 2,000 & 230 \\
\hline OR & 305,000 & $65 \%$ & 5,800 & 3,900 & 710 \\
\hline PA & 470,000 & $39 \%$ & 13,600 & 9,200 & 810 \\
\hline
\end{tabular}




\begin{tabular}{llllll}
\hline State & Total PEVs & \% BEV & Work L2 Plugs & Public L2 Plugs & Public DCFC Plugs \\
\hline RI & 43,000 & $33 \%$ & 1,300 & 800 & 70 \\
SC & 174,000 & $43 \%$ & 5,000 & 3,500 & 400 \\
SD & 21,000 & $28 \%$ & 800 & 600 & 40 \\
TN & 202,000 & $58 \%$ & 5,000 & 3,600 & 590 \\
TX & 835,000 & $57 \%$ & 18,300 & 12,400 & 1,720 \\
UT & 130,000 & $61 \%$ & 2,800 & 1,900 & 340 \\
VA & 475,000 & $43 \%$ & 12,700 & 8,100 & 690 \\
VT & 42,000 & $28 \%$ & 1,700 & 1,300 & 70 \\
WA & 571,000 & $70 \%$ & 10,200 & 6,600 & 1,370 \\
WI & 243,000 & $36 \%$ & 7,800 & 5,500 & 450 \\
WV & 35,000 & $28 \%$ & 1,300 & 1,000 & 60 \\
WY & 13,000 & $45 \%$ & 400 & 300 & 40 \\
\hline
\end{tabular}




\section{Appendix D: Long-Distance Travel Frequency from the SHRP2 NDS}

FHWA's second Strategic Highway Research Program's Naturalistic Driving Study (SHRP2 NDS) data set is used to evaluate LDT frequency. As a longitudinal safety study, SHRP2 NDS tracked 3,710 vehicles (exclusively non-PEVs, consisting mostly of conventional gasoline vehicles and a small number of HEVs) across six cities for up to 3 years to record crash, near-crash, and baseline driving events, resulting in data on approximately 5.4 million driving trips (Campbell 2012, Hallmark et al. 2013, Dingus et al. 2015). To estimate LDT frequency, the 3,352 vehicles that were tracked for at least one year or more were considered. Trip distances were aggregated on a daily basis using the unique vehicle ID provided in the data set. The resulting SHRP2 NDS sample was compared to the 2009 NHTS (FHWA 2017a) to assess its overall representativeness of driving in the United States. SHRP2 NDS shows a higher share of vehicles classified as "car" compared to the 2009 NHTS (71\% in SHRP2 NDS versus 49\% in the 2009 NHTS), and the average vehicle age across all classifications in the SHRP2 NDS data set is 10.84 years, whereas an average age of 9.33 years is reported in the 2009 NHTS. Figure D-1 and Figure D-2 compare daily and annual VMT distributions between the 2009 NHTS and the SHRP2 NDS. Daily VMT and long-distance driving patterns are mostly consistent between the two data sets; nearly $96 \%$ of SHRP 2 NDS vehicle-days have VMT less than 100 miles, compared with $94 \%$ for the 2009 NHTS. However, a higher share of SHRP2 NDS vehicles had annualized VMT of 4,000 to 10,000 miles compared with vehicles from the 2009 NHTS.

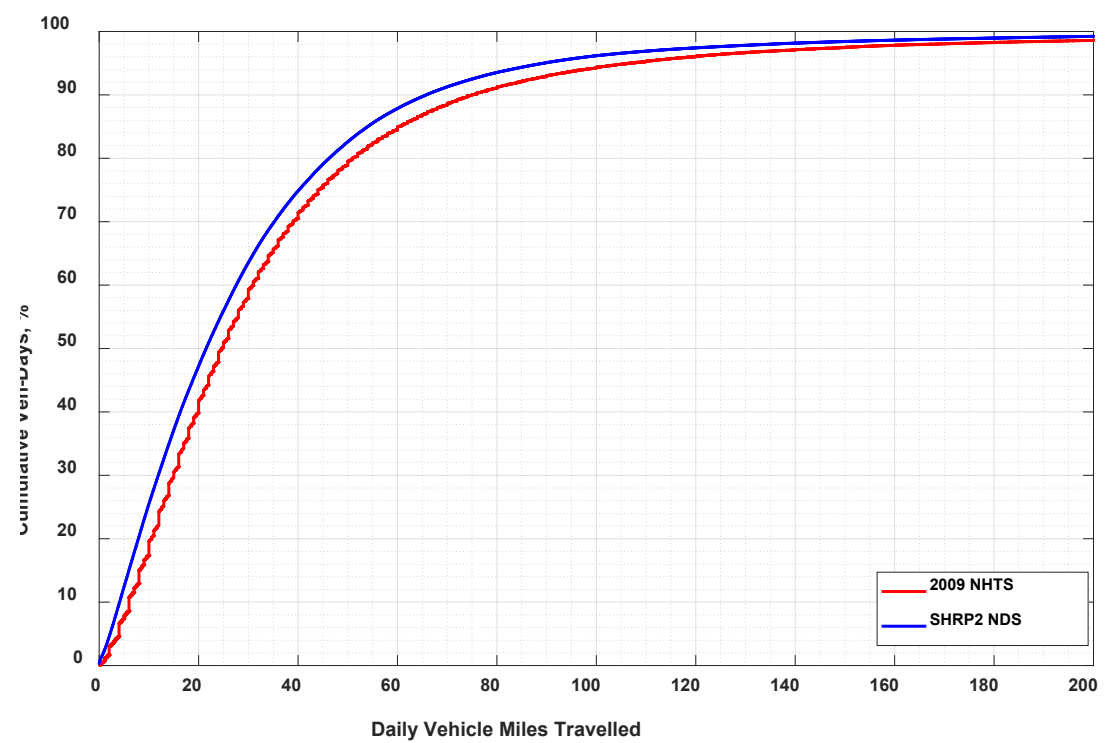

Figure D-1. Cumulative distribution of daily VMT in 2009 NHTS and SHRP2 NDS. 


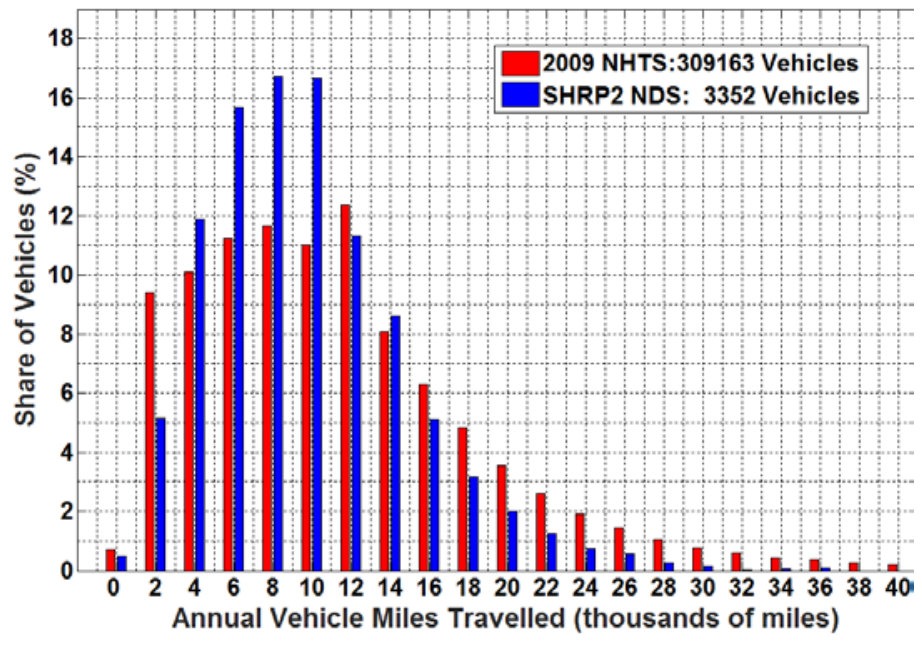

Figure D-2. Annual VMT distribution in 2009 NHTS and SHRP2 NDS.

Of the 3,352 vehicles in the SHRP2 NDS, 1,669 show a daily VMT of above 100 miles for at least 1 day during the tracked period. The average SHRP2 NDS vehicle traveled 100 miles or more 6 days/year (2 days/year for daily VMT greater than 200 miles and 1 day/year with daily VMT greater than 300 miles). These results imply that a large degree of heterogeneity exists between LDT frequencies in the SHRP2 NDS data set. On the one hand, $50 \%$ of the sample never drove more than 100 miles on any travel day, implying a potentially good match with short-range BEVs with approximately 100 miles of single-charge driving range. On the other hand, a large segment of the SHRP2 NDS vehicles exhibits long-distance travel days multiple times per month: travels that could only be accomplished in a BEV with a large single-charge driving range and DCFC support on corridors.

Longitudinal surveys, such as the SHRP2 NDS, are time consuming and expensive to administer. Instead, annual VMT is much easier to estimate using odometer readings from traditional single-day travel surveys (such as the 2009 NHTS), and can serve as a reasonable proxy for LDT frequency. Figure D-3 shows the correlation between annual VMT and LDT frequency. Vehicles with higher annual VMT have generally higher LDT frequency (days/year) for all daily distance thresholds selected (100, 200, and 300 miles).

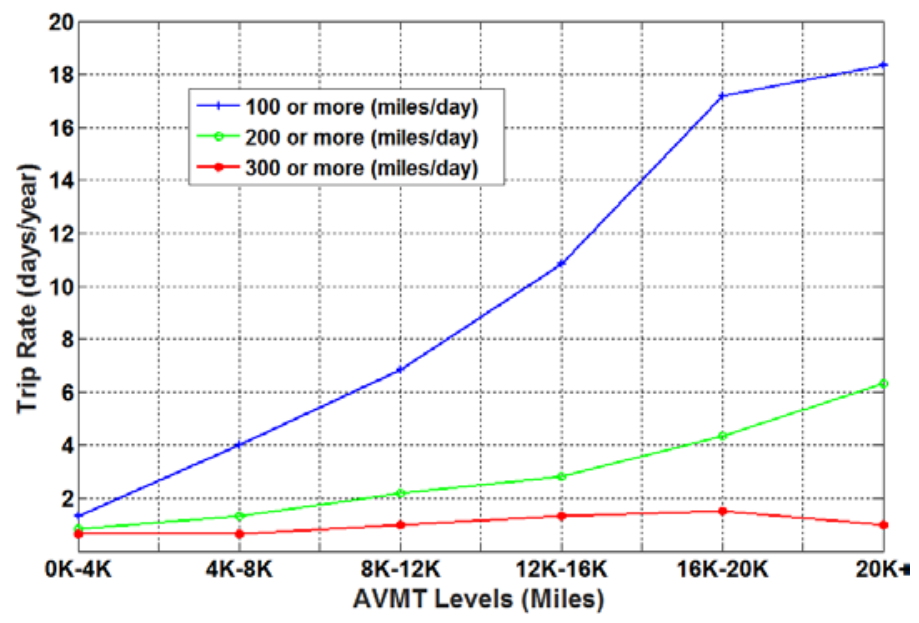

Figure D-3. Impact of annualized VMT (AVMT) on average long-distance travel frequency from SHRP2 NDS. 
As mentioned previously, a significant degree of heterogeneity exists in driving data sets such as SHRP2 NDS. Figure D-4 reflects this fact by displaying percentile curves for frequency of LDT days with at least 200 miles of driving versus annual VMT (note that percentile curves below 60 are not shown as $50 \%$ of the sample exhibited no LDT). Taking the $70^{\text {th }}$ percentile curve as an example, the data show that $70 \%$ of the SHRP2 NDS vehicles drove more than 200 miles on 3 or fewer days per year.

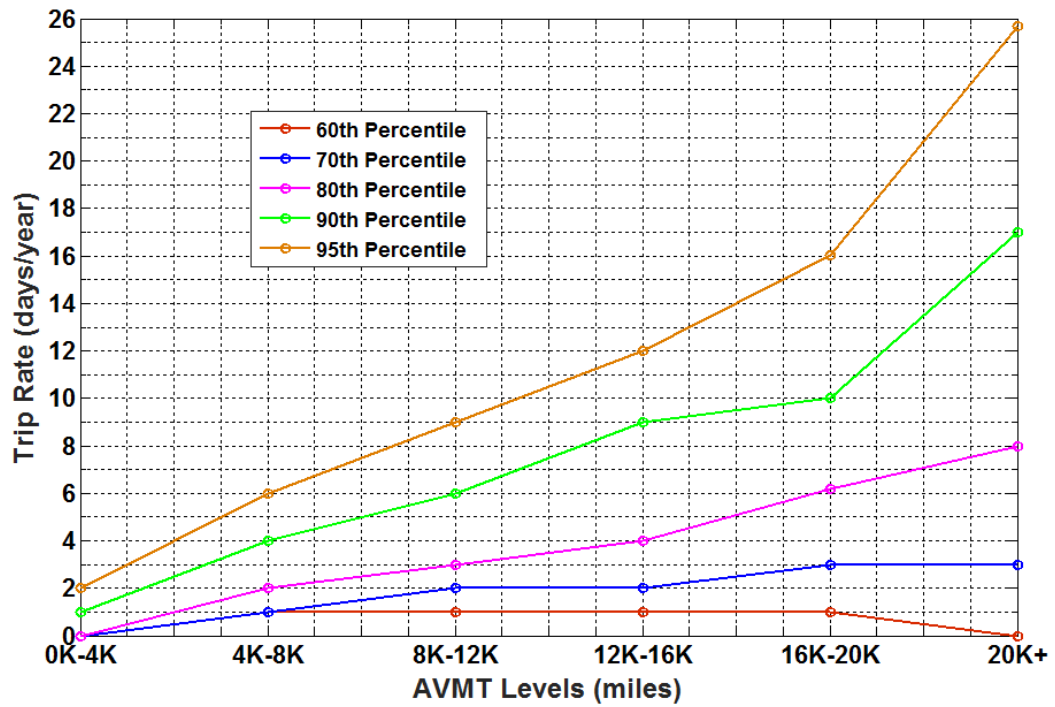

Figure D-4. Impact of annualized VMT (AVMT) on long-distance travel frequency from SHRP2 NDS (percentile bins, frequency of $200+$ mile days).

Evidence from the SHRP2 NDS data set suggests that a large segment of drivers routinely use their existing conventional vehicles for long-distance travel (e.g., 50\% of SHRP2 NDS vehicles drove more than 100 miles one day per month on average) and would presumably require long-distance single-charge ranges and DCFC support along corridors to consider adopting a BEV as a fully capable replacement for their existing vehicle. And even the remaining class of drivers that never makes a LDT over the course of a year might exhibit similar adoption requirements based on their perceived need for long-distance driving. 


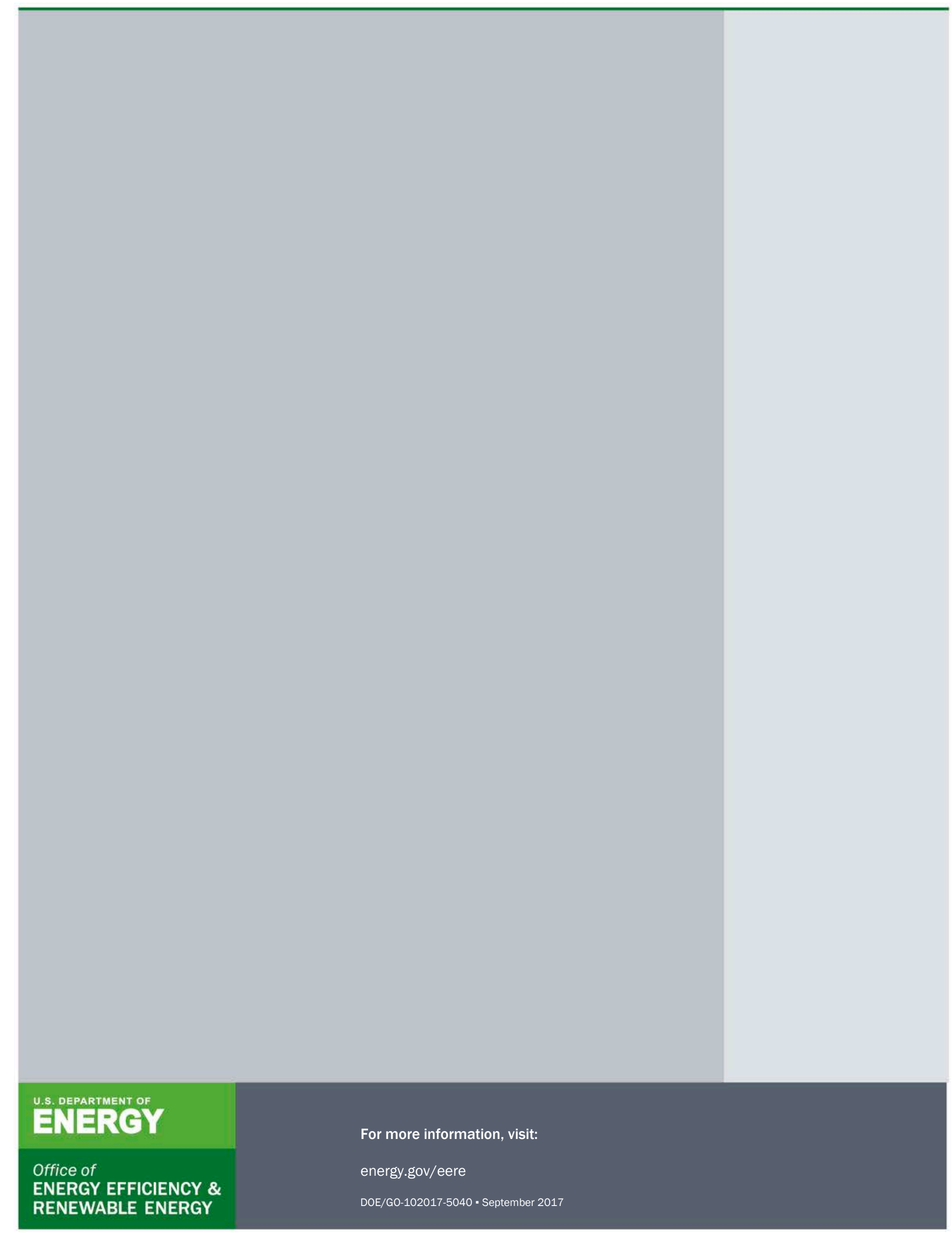

